\title{
A REVISION OF THE NEW WORLD CHRYSOMYINI (DIPTERA: CALLIPHORIDAE)
}

JAMES P. DEAR

\begin{abstract}
The 24 New World species of Chrysomyini are revised. Keys are given to genera and species with illustrations of characters of diagnostic and systematic importance. All taxa are fully described (except for the species of Chrysomya and Cochliomyia), and reference is made to their biology where is known. There are 20 endemic species (1 Chloroprocta, 3 Paralucilia, $6 \mathrm{He}-$ milucilia, 4 Cochliomyia, 6 Compsomyops), and 4 Chrysomya have been introduced from the Old World. Four new species are described: Paralucilia adesposta, P. xantogeneiates, Hermilucilia melusina, Compsomyops melloi. There are 2 new generic and 2 new specific synonymies. The types of previously described species have been examined wherever possible, and lectotypes designated where appropriate.
\end{abstract}

\section{INTRODUCTION}

The Calliphorid tribe Chrysomyini is represented in the New World by 20 endemic species and four introduced species: the endemic species are included in five genera (Chloroprocta, Paralucilia, Hemilucilia, Cochliomyia, Compsomyops) whilst the introduced species all belong to the Old World genus Chrysomya. Like their Old World relatives, the New World Chrysomyini are large, robust, metallic blowflies, but in their morphology they differ considerably from these and, furthermore, each genus has one or more unusual (autapomorphic) characters. ridae:

The following key will separate the New World subfamilies of Callipho-

1. Posterior spiracle with a long fringe of dense hairs which extend from the posterior margin along the lower margin to the anterior margin in a continuous fan. Anterior spiracle with a sinous division medially which opens above to form a circular funnellike opening. Often with a weakly developed subscutellum ...

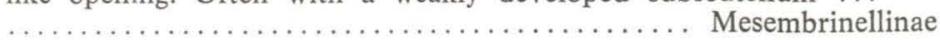

Posterior spiracle with an anterior and posterior lappet. Anterior spiracle without an opening above. Subscutellum undeveloped 2

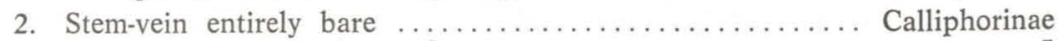

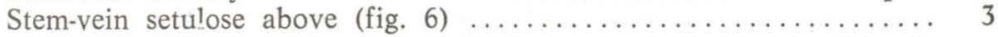

3. Stem-vein setulose below, but if bare then arista bare or with very short hairs on basal half or less ............... Toxotarsinae

Stem-vein bare below. Arista plumose to tip or on at least two-

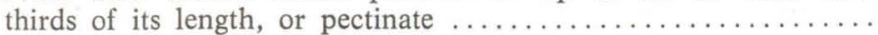

4. Arista pectinate. Vibrissal angle projecting beyond level of lunula. Genae glossy brown. Facial carina broad ............ Rhiniinae

Arista plumose. Vibrissal angle projecting at most as far as level of lunula. Genae usually bright yellow. Facial carina absent

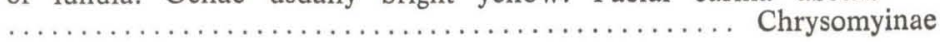

Formerly: Department of Entomology, British Museum (Natural History), Cromwell Road, London SW7 5BD, U.K. Present address: Devonport Cottages, Main Road, Stickney, Lincs PE22 8AY, U.K.

The author's manuscript has been prepared for publication and seen through press by A. C. Pont. Correspondence to: A. C. Pont, Department of Entomology, British Museum (Natural History), Cromwell Road, London, Sw7 5BD, U.K. 
The Calliphorid subfamily Chrysomyinae is found in all zoogeographical regions and is represented by two tribles, the Phormiini and the Chrysomyini. The Phormiini are a Holarctic group of the temperate to boreal life-zones; most species are carrion-feeders as larvae, but one genus (Protocalliphora) is a group of avian parasites. The Chrysomyini, on the other hand, are found in tropical and subtropical areas and, apart from two species which are obligatory wound parasites, the larvae are also saprophagous in habit. However, it is difficult to find clear-cut taxonomic characters which will separate the two tribes on a world basis, and the division can only be made by using a combination of characters together with distribution.

Zumpt (1956b: 11) used the shape of the lower calypter to distinguish the two tribes, but this breaks down when the New World Chrysomyini are considered as many have a "Phormia-like" lower calypter. Hall (1948: 96) used two characters to divide the New World species but I have not found either of them reliable for tribal definitions as a whole. I have found that the head-shape is characteristic for all the species of each tribe but that the differences are subtle and very difficult to define in words. Even illustrations do not always show these characteristics clearly. In the Chrysomyini the gena is usually broad; the genal dilation is close to the margin of the eye, square in shape but with a rounded margin; in the female the frons is often swollen; more often than not the whole head is yellow; the vibrissal angle, i.e. the angle formed by the genal margin and the facial ridge, is always angular. On the other hand the Phormiini have the genae narrow; genal dilation tongue-shaped and not reaching the eye-margin; female frons generally not swollen; head always black in ground-colour; and vibrissal angle rounded. Phormia regina (Meigen) is the only really non-conformist Phormiine, having some atypical characteristics and an overall appearance which is not immediately reminiscent of a Phormiine. It has a large basisternum, the hind coxa setulose posteriorly, and the male is holoptic. Without using additional characters it is difficult to separate regina from the less typical New World Chrysomyine genera Chloroprocta, Paralucilia and Hemilucilia, as the species of these three genera have the Phormia-type lower calypter. However, these three do have an angular vibrissal angle and most have an entirely yellow head.

To summarise, the species of Chrysomyini can be distinguished from all Phormiini by the following combination of characters:

Vibrissal angle angular. Genae broad; genal dilation square, with a rounded margin, and almost reaching the eye-margin. Third antennal segment at least 3 times as long as second. Arista long-plumose to the tip. Head often entirely yellow in ground-colour. Basisternum broad and triangular. Hind coxa setulose along posterior margin. Thoracic spiracles enlarged, the posterior one almost twice as long as deep. Lower calypter large, inner margin adjacent to scutellum, outer margin right-angled, and dorsal surface covered with short setulae to the margin; if diverging from the scutellar margin, rounded and bare on the dorsal surface, then parafacials bare.

The many complex taxonomic and nomenclatural problems of the New World Chrysomyini are dealt with below under the individual genera and species.

\section{SOURCES OF MATERIAL}

The present revision is based on almost 2,500 specimens from numerous sources. Virtually all relevant type-material has been studied, and lectotypes have been designated where necessary. In the lists of material examined the collector is only cited for the rare or new species.

Abbreviations for museums and institutions where material is located are:

AMNH - American Museum of Natural History, New York.

BMNH - British Museum (Natural History), London.

CAS - California Academy of Sciences, San Francisco.

FMNH - Field Museum of Natural History, Chicago. 
IOC - Instituto Oswaldo Cruz, Rio de Janeiro.

MNHNP - Muséum National d'Histoire Naturelle, Paris.

MNHNS - Museo Nacional de Historia Natural, Santiago.

MNHU - Museum für Naturkunde der Humboldt-Universität, Berlin.

MNRJ - Museu Nacional, Rio de Janeiro.

MZST - Museo ed Istituto di Zoologia Sistematica della Università, Torino.

MZUSP - Museu de Zoologia da Universidade de São Paulo.

NHMV - Naturhistorisches Museum, Vienna.

NRS - Naturhistoriska Riksmuseet, Stockholm.

SEM - Snow Entomological Museum, Kansas.

SMNL - Staatliches Museum für Naturkunde, Ludwigsburg.

UIC - University of Illinois, Chicago.

USNM - U.S. National Museum, Washington D.C.

UZMC - Zoologisk Museum, Copenhagen.

\section{TERMINOLOGY AND ABBREVIATIONS}

The terminology used in this paper follows that used in the recent Manual of Nearctic Diptera (McAlpine et al., 1981).

The following abbreviations are used, mainly for setae, in the keys and descriptions:

Head: $v t i$, inner vertical setae; vte, outer vertical setae.

Thorax: $a c r$, acrostichal setae; $d c$, dorsocentral setae; pprn, post-pronotal setae; $i a$, intra-alar setae; pra, prealar seta (anterior postsutural sa); sa, supraalar setae; pa, postalar setae; kpst, katepisternal setae; prst, presutural; post, postsutural.

Legs: $a d$, anterodorsal; $a v$, anteroventral; $p d$, posterodorsal; $p v$, posteroventral; $v$, ventral; $a$, anterior; $p$, posterior.

Abdomen: $\mathrm{T}$, tergite; St, sternite.

\section{KEY TO THE GENERA OF NEW WORLD CHRYSOMYINI}

1. Greater ampulla covered with long bristly-hairs. Thorax without distinct vittae on the mesonotum. Lower calypter haired to the margin with short hairs, and the outer edge angular (fig 1). [Species introduced from the Old World] ...............

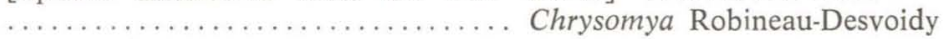

Greater ampulla only pilose. Thorax often with distinct mesonotal vittae. Lower calypter bare or with long hairs basally and the

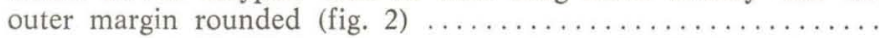

2. Parafacial with fine black or pale hairs (care should be taken as these are very inconspicuous in some specimens). Presutural $d c$ and $i a$ setae absent ............................. 5

Parafacial absolutely bare. Presutural $d c$ and $i a$ setae present ... 3

3. Posterior margin of hind coxa haired on outer edge only (fig. 4). Ventral surface of costa setulose to junction with $R_{1}$ (fig. 5). Femora brown. Anterior presutural sa seta absent. Acr setae $0+1$. Cross-vein dm-cu very sinuous (fig. 3). Lower calypter bare and the posterior margin diverging from the thorax (fig. 9)

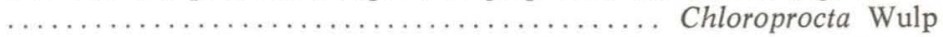

Posterior margin of hind coxa haired along its whole length. Ventral surface of costa setulose to junction with subcosta, rarely to $R_{1}$ but then femora bright yellow. Anterior presutural $s a$ seta present (rarely absent). $A c r$ setae $0+2$. Cross-vein dm-cu less sinuous. Lower calypter bare or setulose .........

4. Lower calypter with long hairs basally and along inner margin (fig. 2). Katepisternal setae $2+1$. Posterior spiracle brown. 
Femora brown to black ....... Paralucilia Brauer \& Bergenstamm Lower calypter bare. Katepisternal setae $1+1$. Posterior spiracle usually yellow, but if brown then femora bright yellow ...... $\ldots \ldots \ldots \ldots \ldots \ldots \ldots \ldots \ldots \ldots \ldots$ Hemilucilia Brauer

5. Palpi short and filiform, not reaching the vibrissal angle. Bend of $\mathrm{M}$ closer to the wing-margin than to cross-vein dm-cu ........ $\ldots \ldots \ldots \ldots \ldots \ldots \ldots \ldots \ldots \ldots \ldots \ldots \ldots \ldots$ Cochliomyia Coquillett

Palpi normal, clubbed and reaching beyond the vibrissal angle. Bend of $\mathrm{M}$ closer to cross-vein dm-cu than to the wing-margin Compsomyiops Townsend

\section{Genus Chrysomya Robineau-Desvoidy}

Chrysomya Robineau-Desvoidy, 1830: 444.

Type-species: Chrysomya regalis Robineau-Desvoidy, 1830, by designation of Coquillett (1910: 523).

\section{Diagnosis}

Chrysomya can be distinguished from all other New World Chrysomyinae by the bristly greater ampulla, together with the shape and setulosity of the lower calypter (fig. 1).

\section{Discussion}

Chrysomya is a tropical and subtropical Old World genus of some 30 species. Adults are often abundant filth-flies; larvae may develop in organic detritus, excrement, carrion, or even in living animal tissue as facultative or obligatory parasites. A summary of their medical and veterinary importance may be found in Zumpt (1965) and Greenberg (1971, 1973).

Four species are now well-established in Central and South Anerica, and it appears that the present wave of introductions began about a decade ago. The earliest record is of a larva, probably of albiceps, found in Puerto Rico in 1974; chloropyga was found in southern Brazil in 1975, and shortly afterwards albiceps and megacephala were found in Brazil (Gagné, 1981). In 1976, chloropyga first appeared in Argentina (Mariluis, 1980b), and in 1978 rufifacies was found in Costa Rica. Summaries of the spread and present distribution of these four species are given by Mariluis (1980b), Gagné (1981), Laurence (1981), Prado \& Guimarães (1982), and Baumgartner \& Greenberg (1983).

There are satisfactory keys, descriptions and illustrations of these and other related species in the standard monographs of Old World blowflies (Zumpt, 1956a, 1965; Senior-White, Aubertin \& Smart, 1940). A brief key is given here to facilitate recognition of the species now known to occur in South America, but fresh captures should always be checked in the Old World keys as further species may well be introduced into the Americas.

\section{KEY TO INTRODUCED NEW WORLD SPECIES OF CHRYSOMYA}

1. Anterior spiracle dark, blackish-brown. [Oriental, Australasian, Pacific, Malagasy, introduced W and S Africa.] Puerto Rico, Peru, Brazil, Argentina ................. megacephala (Fabricius)

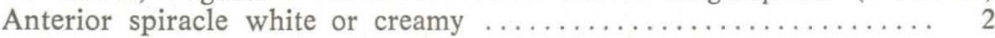

2. $\delta$ : frons at narrowest point less than diameter of anterior ocellus; genitalia as in Zumpt, 1956a: fig. 111. O : frons with 2 pairs of small outcurved orbital setae; tergite 5 not incised dorsally. [Afrotropical, including Malagasy.] Colombia, Peru, Bolivia, Brazil, Paraguay, Argentina............... chloropyga (Wiedemann)

(incl. putoria (Wiedemann))

$\delta$ : frons at narrowest point twice diameter of anterior ocellus; genitalia as in Zumpt, 1956a: figs. 112-113. o : frons without orbital setae; tergite 5 incised dorsally $\ldots \ldots \ldots \ldots \ldots \ldots \ldots$ 
3. Proepisternal seta present. [Oriental, Australia.] Mexico, Guatemala, Costa Rica ....................... rufifacies (Macquart)

Proepisternal seta absent. [Afrotropical, North Africa to NW India.]

Puerto Rico, Brazil, Paraguay, Argentina .. albiceps (Wiedemann)

\section{Genus Chloroprocta Wulp}

Chloroprocta Wulp, 1896: 296.

Callitrogopsis Townsend, 1935: 70. Syn. $n$.

Type-species of Chloroprocta: Chloroprocta semiviridis Wulp, 1896 [ = Chrysomya idioidea Robineau-Desvoidy, 1830], by monotypy. Type-species of Callitrogopsis: Callitrogopsis costalis Townsend, $1935[=$ Chrysomya idioidea Robineau-Desvoidy, 1830], by original designation.

\section{Diagnosis}

Chloroprocta can be distinguished from all other New World Chrysomyini by the bare parafacial (fig. 7) and lower calypter (fig. 9). Hind coxa setulose only on the extreme lateral posterior margin (fig. 4), and anterior presutural sa seta absent.

\section{Description}

Male holoptic, female dichoptic. Parafacial bare. $q$ frontal vitta bare (fig. 8). Genal groove with short black setulae. Vibrissae placed just above fronto-clypeal suture. Thorax and abdomen metallic blue to green. Thoracic vitta indistinct. Presutural $d c$ and ia setae present. Anterior presutural sa seta absent. Acr $0+1$. Lower calypter narrow, bare above and diverging from the scutellum. Hind coxa with a few fine hairs on the lateral posterior margin.

\section{Discussion}

Chloroprocta is a monotypic New World genus. It has a Central American and northern Neotropical distribution, occuring as far north as Texas and as far south as Paraguay. Previous authors have considered this genus to include two species and have used colour characteres to separate them, which have proved to be totally unsatisfactory. Shannon (1926: 126) and Hall (1948: 97) each keyed two species of Chloroprocta and appear to have based their initial recognition of these "species" on their geographical range, though this is not actually stated. They both used colour characteres in their keys, though with the qualifying phrases "more or less" and "usually". Shannon actually stated that the colour was variable but he still used this character in his key. He also mentioned the enlargement of the anterior eye-facets as an additional character for separating males. Males which I have examined always have the anterior facets enlarged to a certain extent, but in some males this is certainly more pronounced. I consider this to be infraespecific variation, and it is not unknown elsewhere in the Calliphoridae, for example in the Afrotropical Hemigymnochaeta Corti. An examination of the types of all the names referred to Chloroprocta by Shannon and Hall has shown them to be conspecific, and I therefore consider Chlorprocta to include only one species for which the oldest available name is idioidea (Robineau-Desvoidy).

\section{Chloroprocta idioidea (Robineau-Desvoidy)}

Musca violacea Fabricius, 1805: 288. [Preocc. Musca violacea Scopoli, 1763.] Chrysomya idioidea Robineau-Desvoidy, 1830: 445.

Lucilia fuscanipennis Macquart, 1851: 223 (250). Syn. $n$.

Musca purpurea Walker, 1853: 337.

Chloroprocta semiviridis Wulp, 1896: 296. Syn. $n$.

Strongyloneura flavifacies Engel, 1931: 138. Syn. $n$.

Callitrogopsis costalis Townsend, 1935: 71. Syn. $n$. 
Types

Holotype $q$ of Musca violacea Fabricius, 'America meridionali', in UZMC. Holotype $q$ of Chrysomya idioidea Robineau-Desvoidy, Brazil, in MNHNP. Lectotype $\hat{o}$ of Lucilia fuscanipennis Macquart, Brazil, in MNHNP; see designation below. Holotype $\hat{o}$ of Musca purpurea Walker, South America, in BMNH. Lectotype $q$ of Chloroprocta semiviridis Wulp, N. Yucatan, in BMNH; by fixation of Townsend (1937: 123). Holotype $\hat{\sigma}$ of Strongyloneura flavifacies Engel, Bolivia, in SMNL. Lectotype $\hat{\sigma}$ of Callitrogopsis costalis Towsend, Brazil, in USNM; by fixation of Townsend (1937: 123). [All types examined].

Note on the type of Musça violacea

This name has previously been erroneously applied to a species in the Muscidae, and past misidentifications have been fully discussed by Michelsen (1979: 191). The holotype agrees with the original description and is in good condition, with only the tip of the abdomen and the right mid tarsus missing.

Note on the type of Chrysomya idioidea

The holotype is in excellent condition, being only a little dirty and dusty, and with all parts intact. It is labelled 'Guaratuba ouest. mars. 1820'; 'idioidea' [Macquart's hand]; 'TYPE'; '204'; and 'Chrysomya idioidea R.D.' [Robineau-Desvoidy's hand].

\section{Lectotype designation for Lucilia fuscanipennis}

Macquart described this species from both sexes from Bahia, Brazil. In the Macquart collection in MNHNP I found under this name three males and one female, each with a small green disc with '4.44' on the reverse. One male is additionally labelled 'Lucilia fuscanipennis $\hat{o}$ o Macq. n.s.p.' and 'TYPE'. The accession number 4.44 refers to a collection made by Verreaux at Bahia. These four specimens are undoubtedly syntypes and all agree with the original description. Although a little dirty and dusty all are in excellent condition and I have labelled and designate herewith the male with the Macquart determination label as lectotype and the other two males and the female as paralectotypes. All specimens agree with the interpretation of Chloroprocta idioidea given here.

\section{Note on the lectotype of Chloroprocta semiviridis}

Wulp described this species from a male and female specimen from material collected by Gaumer in northern Yucatan. In the BMNH I found under this name a male and female labelled 'N. Yucatan, Gaumer', 'B.C. Dipt. II. Chloroprocta semiviridis v.d. W.'. They are in good condition, though rather teneral, dusty and greasy. The tips of the wings in the male are slightly damaged. Both specimens agree with the interpretation of Chloroprocta idioidea given here.

Townsend (1937: 123) mentioned the female as the "holotype" of this species and under the International Code of Zoological Nomenclature this is a lectotype fixation. I have labelled the female as lectotype and male as paralectotype, by fixation of Townsend.

Note on the types of Strongyloneura flavifacies

Engel described this species from four males and three females from Nord-Chiquitos, Bolivia, from material collected during the German Chaco Expedition. From SMNL, where the expedition material is deposited, I received for study three males and two females with type data. All these specimens have Engel's determination label 'Strongyloneura flavifacies' and are in good condition. In addition, a male has a red type label and a second male has been dissected and has the genitalia mounted separately. This name has generally been applied to a species of Hemilucilia, which is newly described below. This misidentification is fully discussed under the genus Hemilucilia below (p. 124). 


\section{Note on the lectotype of Callitrogopsis costalis}

Townsend described this species from four males and three females from Tapera and two males from Urucurytuba. Subsequently, in Volume V of his Manual of Myiology (1937), he stated that the "holotype" was a male from Tapera in the USNM. From the USNM I received a male and female specimen found under this name. The male is labelled 'Callitrogopsis costalis TT $\hat{o}$ ', by Townsend, 'Pernambuco, Tapera, 8.iv.1929', and on a red label 'Type Ht $\hat{o}$ '. I think that this is undoubtedly the specimen referred to as holotype by Townsend (1937). Under the International Code of Zoological Nomenclature this specimen should be regarded as the lectotype of costalis by fixation of Townsend, and I have labelled it as such. The female also bears the type

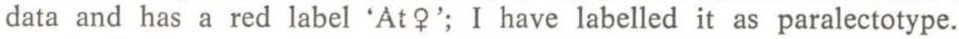

In further material borrowed from the USNM I found four specimens labelled 'Pt' on red labels similar to the one on the lectotype of this species. These specimens were part of an exchange between the USNM and the La Molina Museum, Lima (Gagné, in litt.). There are two males from Urucurytuba, and a male and a female from Tapera. I have labelled all four as paralectotypes. Only two males and a female from the syntypic series are unaccounted for; these are probably in Lima but I have not seen them.

The six specimens I have examined are in good condition and agree with the interpretation of Chloroprocta idioidea (Desvoidy) given here.

\section{Discussion.}

Among the specimens which I have examined, I have found that those from the southern part of the range (Brazil, Paraguay) are generally darker, having brown calypters and posterior spiracle, darker wings and a metallic blackish-blue body colour which obscures the thoracic vittae. Specimens from the nortinern Antilles and the southern states of the U.S.A. are paler, having brownish-orange legs, yellow to white calypters and a metallic green body colour which does not obscure the thoracic vittae. However, the majority of specimens from these northern areas have been teneral and therefore pale, with even the posterior spiracles cream-coloured. A few fully hardened specimens from Cuba and the Bahamas have the posterior spiracle dark brown like Brazilian specimens, but like the southern U.S.A. specimens have orange legs and in the female pure white calypters. The collection of so many teneral specimens, mainly from bait traps, suggests that this species is capable of sustained flight before becoming completely hardened. I have therefore included teneral coloring in the description below. Males of both pale and dark specimens from localities throughout the range of this species have been dissected and I have found the aedeagus, surstyli and cerci to be identical in all cases. This is supported by Mello (1965) in his paper on the variation of this species (as costalis) in Brazil: his illustrations only show minute variation in details of the genitalia, which are probably no more than artefacts resulting from slide-mounting prior to drawing. Males of this species always have the anterior eye-facets enlarged, but this is much more striking in certain specimens. Enlargement of the anterior eye-facets is very common in the Chrysomyinae but does not usually vary within species. However, this form of infraspecific variability is known elsewhere in the Calliphoridae, occurring in the species of the Afrotropical genus Hemigymnochaeta Corti. I believe that Chloroprocta consists of a single widespread species, idioidea, which exhibits some colour variation which is dependent upon geographical distribution.

\section{Description}

Head (figs. 7-8). Male holoptic; female dichoptic, frons equal to 0.26 of the head-width and slightly expanded medially. Ground-colour black on occiput, otherwise yellow. Eyes bare, the upper anterior facets of male slightly or greatly enlarged. Frontal vitta almost absent in male, reddishbrown, bare and with dense golden-brown to greyish-yellow dust in female. Fronto-orbital plates densely golden-brown to greyish-yellow dusted and with 
numerous small, fine, black setulae. Parafacial golden-brown dusted and bare. Face pale yellow dusted. Genal groove densely dusted golden yellow and with small, stout, black setulae on lower part. Genal dilation indistinctly margined. Genae golden-brown with a shifting glossy patch medially, anterior part with short black setulae and posteriorly with golden hairs. Upper occiput undested, lower occiput silvery-yellow dusted. Male with 7-8 weak frontals and a pair of $v t i$, ocellar setae weak and proclinate. Female with 9-10 frontals, 2 weak proclinate and 1 reclinate orbitals, a pair of $v t i$ and vte setae and two pairs of outcurved ocellars, the posterior pair weaker. Vibrissae strong, crossed and placed above fronto-clypeal suture. Subvibrissal and genal setae weak except for a single stronger subvibrissal below vibrissal. Facial ridge with fine black setulae on at least $2 / 3$ of its length. Antenna yellow, anteriorly darkened in some males. Arista yellow and long-plumose to tip, the rays black. Palpi long, yellow and dilated apically. Prementum glossy brown.

Thorax. Ground-colour dark brown with metallic blackish-blue to green reflections; in teneral specimens, ground-colour yellowish-brown with only weak metallic reflections. Mesonotum evenly grey dusted, which appears dense when viewed at an angle from behind; also with three longitudinal darker vittae which reach the scutellum but which are not so obvious in darker specimens. Acr $0+1$, rarely a second smaller postsutural one; $d c 2+4$, anterior post ones weaker; 3 pprn, ia 2+2, 1 pra, sa $1+2,2 \mathrm{pa}$. Basisternum of prosternum densely haired with mostly pale hairs. Proepisternum with pale hairs. Spiracles large, anterior one creamy, posterior one brown, both creamy in teneral specimens. Pleura with thin shifting grey dusting and fine black ground-setulae. Greater ampulla triangular and bare. Kpst $1+1$. Anatergite bare. Scutellum dusted as the mesonotum and with a pair of apical, lateral, basal and discal setae.

Wings. Whole of costal region darkened, and dark-coloured specimens with rest of wing lightly infuscated to varying degrees; in teneral specimens only the costa faintly infuscated. Tegula and basicosta brown; veins brown; all these yellowish-brown in teneral specimens. $R_{1}$ ending in costa a little beyond level of the cross-vein $\mathrm{r}-\mathrm{m}$. Stem-vein setulose dorsally (fig. 6). Subcostal sclerite setulose. Cross-vein dm-cu very sinuate (fig. 3). Costa haired ventrally to $R_{1}$ (fig. 5). Calypters brown to yellow in males and yellow to white in females, diverging from the scutellum and bare on disc (fig. 9).

Legs. Dark brown in southern specimens to yellow in northern females and teneral specimens. Fore tibia with 3-4 short, well spaced ad setae and 1 p v seta. Mid femur with a single, strong, median $a$ seta. Mid tibia with $1 a d, 1 p d, 2 p$ and $1 v$ seta. Hind tibia with 2-5 short $a d$ setae, $1 p d$ and 2 av setae. Hind coxa with fine hairs on the extreme outer posterior margin.

Abdomen. Ground-colour dark brown with metallic blue-green reflections and darker hind margins to $\mathrm{T} 1+2$ and $\mathrm{T} 3 ; \mathrm{T} 1+2$ often paler ventrally; $\mathrm{T} 1+2$ and $\mathrm{T} 3$ yellowish-brown in teneral specimens. When viewed at an angle from behind all tergites with a grey dusting which is denser on $\mathrm{T} 3$ and is interrupted medially by a thin black vitta. General setulosity black, longer and sparser on $\mathrm{T} 5 . \mathrm{T} 3, \mathrm{~T} 4$ and $\mathrm{T} 5$ with rows of weak marginal setae. St pale brown with black setulae and longer marginal setulae.

Genitalia. Male terminalia as in figs. 10-11.

Measurements. Length of body, 6.0-8.0 mm. Length of wing, 5.5-7.5 mm.

Distribution. Texas, Bahamas, Cuba, Mexico, Nicaragua, El Salvador, Panama, Colombia, Peru, Venezuela, Trinidad, Guyana, Brazil, Paraguay. Material examined.

TEXAS: Menard, Aug., 1930, 2 ㅇ, BMNH, $3 \hat{\delta}, 7$, USNM; Edinburg,

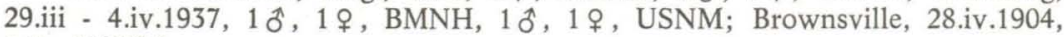
1 ㅇ․ USNM.

BAHAMAS: New Providence, v.1952, $1 \delta^{\star}$, USNM.

CUBA: Baraguá, 12.ii.1925, 1 , BMNH, 1 , USNM. 
MEXICO: Colima, $1 \hat{\delta}$, USNM; N. Yucatan, $2 \hat{\delta}, 1 \%$, BMNH; Chichen Itzá, vi.1929, 2 ô, USNM, 1 ô, BMNH; Tamasofa, 4.xii.1909, 1 \%, USNM.

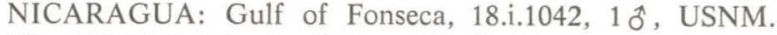

EL SALVADOR: La Union, 15.viii.1907, $1 \hat{\jmath}$, USNM.

PANAMA: Sabanas, $1 \delta^{\star}$, USNM; El Comemo, i.1940, $1 \delta^{\star}$, USNM; Canal Zone, Tabernilla, vii.1967, 1 \% , USNM; Arraijan, 7.x.1952, 1 ô, USNM; Pacora, 2.v.1945, $2 \hat{o}, 2$, USNM.

COLOMBIA: Isle of Pines; 29.vi.1960, 1 , USNM; Sevilla, 18.xii.1926, 10 , USNM.

PERU: Iquitos, iii-iv.1931, 2 , USNM.

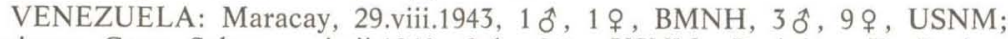
Akuriman Gran Sabana, xi-xii.1940, 20, 2q, USNM; Barinitas E. Barina, xii.1942, 1 ô, USNM.

TRINIDAD: xi.1931, 1 \%, USNM.

GUYANA: Essequibo R., Moraballi Creek, 7.ix.1929, 1 , 2.x.1929, 1 , BMNH; Georgetown, 1912, 9\%, BMNH; Mazaruni, low forest, 24.ix.1937, $7 \hat{\jmath}, 11$ ㅇ, BMNH, 16.ix.1937, $1 \hat{\jmath}, 1$ \&, BMNH, 18.ix.1937, $1 \hat{\jmath}, \mathrm{BMNH}$; New River, 750', 7-7.v.1938, $1 \hat{\delta}, 1 \hat{q}, \mathrm{BMNH}, 26$. iii.1938, $1 \hat{\jmath}, \mathrm{BMNH}$; Bartica, 23.vii, 2 ㅇ, USNM; Kaieteur, 3.viii.1911, 1 ๙ิ, 2 ㅇ, USNM.

BRAZIL: Mato Grosso, Maracaju, 1937, $1 \hat{\jmath}, 1$ 오 BMNH, $10 \hat{\delta}, 13 ㅇ$, USNM; same locality, ii.1937, $1 \hat{\jmath}, 1 \%$, BMNH, $3 \hat{\jmath}, 6 \%$, USNM; same locality, iii.1937, $3 \delta^{\star}, 5$ \% , USNM; Mato Grosso, 12 ${ }^{\circ} 50^{\prime} \mathrm{S}, 51^{\circ} 47^{\prime} \mathrm{W}, 14 . \mathrm{iii} .1968$, $4 \hat{\jmath}, 6 \uparrow$, BMNH, 28.ii.1968, $1 \hat{\jmath}, \mathrm{BMNH}$; Urururituba, R. Tapajós, 5.iv,

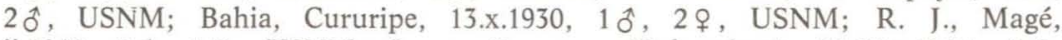

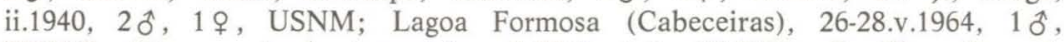
BMNH; Córrego Azul, Araçatuba, ii.1946, $1 \hat{0}$, BMNH; Castilho, Paraná, 1.xii.1964, 2 \%, BMNH; Estancia Sergipe, xii.1929, $1 \hat{\jmath}, \mathrm{BMNH}, 1 \hat{\jmath}$, USNM.

PARAGUAY: Villarica, 14.iv.1939, 1 , , USNM.

\section{Genus Paralucilia Brauer \& Bergenstamm}

Paralucilia Brauer \& Bergenstamm, 1891: 391 [87].

Type-species: Calliphora fulvipes Macquart, 1843, sensu Blanchard collection not Macquart [misidentification, = Somomya fulvinota Bigot, 1877], by monotypy.

\section{Diagnosis}

Paralucilia can be distinguished from all other New World Chrysomyini by the bare parafacial. Presutural sa, presutural $i a$ and presutural $d c$ setae present. Lower calypter with long hairs basally and along inner margin, the outer edge rounded and inner margin following $(\hat{\delta})$ or moderately diverging from ( $q$ ) the line of the scutellum (figs. 2, 12). Acr setae $0+2$. Posterior margin of the hind coxa haired on its whole length.

\section{Description}

Metallic green or blue flies with distinct or indistinct thoracic vittae and tergites with black hind margins. Male head holoptic, female dichoptic. Parafacial bare. Female frontal vitta haired. Vibrissae placed just above the fronto-clypeal suture. Facial ridges not strongly converging below. Arista longplumose to tip. Presutural $s a$, $i a$ and $d c$ setae present. $A c r 0+2$, anterior one weaker. Kpst setae $2+1$. Posterior spiracle brown. Ventral surface of costa setulose to subcostal break. Bend of $M$ right-angled. Stem-vein setulose dorsally. Subcostal sclerite setulose. Lower calypter with long hairs on dorsal surface, outer margin rounded, inner margin not ( $\hat{o})$ or moderately ( +9 ) diverging from the line of the scutellum. Male aedeagus with a short curving paraphallus and a long extended hypophallus. Female ovipositor of the usual calliphorid-type, telescopic. 


\section{Discussion}

A careful investigation into the taxonomy and nomenclature of the New World Chrysomyini has exposed a number of intricate problems. One of these concerns the two genera Paralucilia and Myiolucilia. Hall (1948) attempted to stabilise the situation in this group of flies, and his nomenclature was followed in the New World Diptera catalogues by Hall (1965) and James (1970). Unfortunately, Hall misinterpreted the statements of earlier authors and as a result the generic concepts Paralucilia and Myiolucilia have to be reversed.

Brauer \& Bergenstamm (1891: 391) erected the genus Paralucilia to accommodate a species misidentified by Blanchard and Schiner as Calliphora fulvipes Macquart. They did not however propose a new name for the misidentified species, but cited it simply as "Musca (Calliph.) fulvipes (Blanch. S.)." In a subsequent paper, Brauer (1895: 599) explained in detail what was the intended meaning of the name Paralucilia. He thought that confusion might arise as the specimens identified as fulvipes by Blanchard were a $\hat{o}$ and $q$, on a single pin, which belonged to two different species although, at firts sight, it might be thought they were a pair taken in copula. Brauer carefully explained that the name Paralucilia applied to the specimen with the Lucilia-type face, with the facial ridges almost parallel and the vibrissae placed at the fronto-clypeal suture. From NHMV I received for study the pair of specimens mentioned by Brauer, both on a single pin. The male has the facial ridges strongly constricted below and the vibrissae placed well above the fronto-clypeal suture. The female agrees with the characters of Paralucilia given by Brauer and intended by Brauer and Bergenstamm, having parallel facial ridges and the vibrissae at the fronto-clypeal suture. Townsend (1916: 11) saw this pair, and, recognising Brauer and Bergenstamm's intentions, realised the necessity for proposing a new name for the misidentified fulvipes. $\mathrm{He}$ correctly made the female the holotype of his new species Paralucilia braueri (now $=$ fulvinota Bigot) and gave the type-species of Paralucilia as braueri Townsend (fulvipes misident.). The male of the pair is actually conspecific with the lectotype of Calliphora fulvipes Macquart, and this must be the source of the original mistake made by Blanchard and Schiner who probably thought that the pair had been taken in copula.

Curran (1934: 407) continued the correct usage of the generic name and correctly included the species desvoidyi Hough. However, Hall (1948) unaccountably reversed the interpretation of these two New World Chrysomyine names: he incorrectly applied the name Paralucilia to species with constricted facial ridges, and erected a new genus, Myiolucilia, to accomodate those species with parallel facial ridges. Unfortunately, this error has been followed in the Nearctic (Hall, 1965) and the Neotropical (James, 1970) Diptera catalogues.

A further complication arises when it is found that Hall designated Musca lyrcea Walker as the type-species of Myiolucilia, without personally examining the holotype: he relied on curators in the European museums to identify Chrysomyine types in their care, using provisional copies of his keys (see Hall, 1948: 39). The holotype male of Musca lyrcea is in fact a specimen with converging facial ridges. As the main character for distinguishing these two Chrysomyine divisions, Hall used the presence or absence of parafacial hairs, the parafacials being haired in the species with converging facial ridges and bare in those with them parallel. In both sexes of those species with converging facial ridges the parafacial area is very short and does not extend to the lower margin of the eye as it does in most Calyptrates. The hairing is very difficult to detect, being pale, short and fine in most specimens, and unless special reference is made to the difficulties of its detection it can easily be overlooked. The holotype of $M$. lyrcea does not actually agree with Hall's diagnosis of Myiolucilia, and so this is a case of a misidentified typespecies. Under Article 70 of the International Code of Zoological Nomenclature this must be referred to the Commission, and an application should be made to fix true lyrcea (not lyrcea of Hall) as the type-species of Myiolucilia. 
In this paper I have taken what I consider to be the least confusing step for nomenclatural stability. I propose to accept that the type-species of Myiolucilia is the true lyrcea (as defined by Walker's holotype), and not lyrcea as misidentified by Hall (1948). The species with haired parafacial and constricted facial ridges are now referred to Myiolucilia, which becomes a junior synonym of Compsomyops Townsend, and the species with bare parafacials and paraliel facial ridges are Paralucilia.

KEY TO SPECIES OF PARALUCILIA BRAUER \& BERGENSTAMM

1. Mesonotum glossy metallic purple to blue-green; viewed obliquely from behind, prescutum densely silvery-brown dusted and without distinct vittae; postsutural region with indistinct lateral vittae. Male parafacials and fronto-orbital plates dark in ground-colour but without shining black reflections. Postgenal setae (beard) and head dusting silvery-yellow to cream; some females with the dusting more yellowish but then the dusting at vertex brownish and contrasting with that on the fronto-orbital plates. Anterior spiracle usually brownish, yellow in some females. Upper calypter bare ........................ fulvinota (Bigot)

Mesnotum metallic purple, blue or green but not glossy; viewed obliquely from behind with three distinct vittae which reach the scutellum, the dusting between them silvery-grey. Male parafacials pale or dark with glossy reflections around frontal setae. Postgenal setae (beard) and head dusting golden-yellow to pale yellow; dusting at vertex not contrasting in colour with that on the fronto-orbital plates. Anterior spiracle white or yellow. Upper calypter with or without hairs on dorsal surface

2. Postgenal setae (beard) bright orange-yellow. Anterior spiracle orange-yellow. Hind tibia with 1 pd seta. Anterior parts of calypters dark. $\delta$ : fronto-orbital plates with shining black reflections around frontal setae, and setulae outside frontal row black. $\$$ : dorsal surface of upper calypter with fine hairs xanthogeneiates $\mathrm{sp} . \mathrm{n}$.

Postgenal setae (beard) pale yellow to orange. Anterior spiracle white and enlarged. Hind tibia with $2 p d$ setae. Anterior parts of calypters white. $\hat{\delta}$ : fronto-orbital plates without black reflections, and with pale hairs outside the frontal row. $q$ : upper calypter bare ............................

\section{Paralucilia fulvinota (Bigot)}

Somomya fulvinota Bigot, 1877: 251.

Chrysomyia desvoidyi Hough, 1900: 208.

Paralucilia braueri Townsend, 1916: 11.

Types

Holotype $q$ of Somomya fulvinota Bigot, Mexico, in BMNH. Lectotype $\hat{o}$ of Chrysomyia desvoidyi Hough, Chapada, Brazil, in $\mathrm{AMNH}$; see designation below. Holotype $\&$ of Paralucilia braueri Townsend, Chile, in NHMV. [All types examined.].

Note on the holotype of Somomya fulvinota

A specimen in the BMNH collection labelled "ex Bigot coll." and with a recent label "Somomya fulvinota Big., Type" is accompanied by a Bigot drawer label "S. Fulvinota $\$$, G. Lucilia R.D., Mexic Bigot" and agrees with the original description. It is in good condition, rather dusty and with the right mid and hind legs missing. I have labelled it as holotype.

Lectotype designation for Chrysomyia desvoidyi

Hough described this species from four males and two females from Chapada, Brazil. From AMNH I received for study a single male found under 
this name. It is in excellent condition with all parts present and labelled "Chapada" "Type", "Am. Mus. Nat. Hist. Dept. Invert. Zool. No. 20307" and in Hough's handwriting "Chrysomya desvoidyi nov. sp.". From the SEM I received for study two males labelled "Chapada", "Co type", "CO-TYPE. Chrysomyia desvoidyi Hough". Both specimens are in good condition although one ras the dorsum cracked and is rather dusty. Additionally from the FMNH I received a male and female from "Chapada" and labelled "Univ. of Chicago. G. N. Hough Diptera Colln". The female is in exceilent condition and has a label "These are not types! They are in AMNH. D. G. H. [all]"; the rale is in good condition but with the right wing missing, and has a label "Chrysoriyia desvoidyi Hough Types?" I consider all five specimens to be yntypes and have labelled and designate herewith the AMNH male as lectotype and the other 4 specimens as paralectotypes. All five agree with the interpretation of Paralucilia fulvinota given here. I have been unable to locate the last female syntype, but should it eventually be found it should be conconsidered as a paralectotype.

\section{Note on the holotype of Paralucilia braueri}

As explained by Brauer (1895: 599) and Townsend (1916: 11), the holotype of this species is a female on the same pin as a male of a different species. I received this pair of specimens for study from the NHMV and have labelled the female as holotype. It has the right fore and mid legs missing but is otherwise in good condition, and it agrees with the interpretation of Paralucilia fulvinota given here.

\section{Discussion}

Hall (1948: 112) correctly assigned this species to the group of Chrysomyines with bare parafacials, and listed desvoidyi and braueri as synonyms. However, whilst his description fits fulvinota, his figures of the genitalia (1948: plate 16, fig. A) do not correspond to this species. The genitalia illustrated are in fact those of the new species, adespota, described below and illustrated in the present paper by figs. 24-25. His figures of lyrcea (1948: plate 16 , figs. B, C, and D) are in fact those of fulvinota as defined in the present paper.

\section{Description}

Head (figs. 13-14). Male holoptic; female dichoptic, frons equal to 0.31 of the head-width and slightly expanded medially. Ground-colour black except genae and face which are orange-brown. Eyes bare, anterior facets in male slightly enlarged. Frontal vitta of male absent above, otherwise reddish-brown and bare; in female, reddish-brown and constricted anteriorly, and black above, brownish-dusted above, silvery-yellow anteriorly and with very short fine pale hairs. Fronto-orbital plates densely dusted, so as to obscure the ground-colour, silvery-yellow anteriorly, brownish above; female with numerous short fine, pale and dark hairs, male with a few pale ones. Parafacials silvery-yellow dusted and bare. Face thinly silvery dusted. Genal groove thinly silvery dusted and with numerous pale hairs. Genal dilation not angular (fig. 13). Genae thinly silvery dusted and with dark hairs anteriorly, densely silvery-yellow dusted and with long pale yellow to white hairs posteriorly. Occiput thinly dusted above and densely dusted below, entirely pale haired. Male with 7-8 weak frontals and a pair of crossed vti, female with 9-11 frontals, 2 weak proclinate and 1 reclinate orbitals, a pair of $v t i$ and vte setae. Male with a pair of close-set ocellar setae, female with three outcurved pairs, the anterior pair strong. Post-ocular region with a row of fine pale hairs. Vibrissae strong and crossed, inserted slightly above the frontoclypeal suture. Subvibrissal and genal setae blak and weak. Facial ridges parallel for most of their length, only slightly convergent below and setulose on $2 / 3$ of their length. Antenna orange, the third segment darkened anteriorly. Arista yellow with dark rays, long-plumose to tip. Palpi long, orange and dilated apically. Prementum glossy brown. 
Thorax. Ground-colour black with metallic blue and purple reflections, some females with dark green reflections. Mesonotum in posterior view with the presutural area densely greyish-brown dusted and the lateral margin of the postsutural region thinly dusted. Viewed from various angles with two faint, lateral, dark vittae, which do not reach the scutellum, and with lateral rectangular dark patches presuturally. $\mathrm{Acr} 0+2$ (anterior one weaker), $d c$ $3+4-5$ (the anterior post ones weaker), 4 pprn in a row, ia $2+2,2$ pra (one weak), sa $2+2,2 \mathrm{pa}$. Basisternum of prosternum densely pale haired. Proepisternum with pale hairs. Anterior spiracle pale brown to brownishyellow, posterior spiracle dark brown with dark marginal setulae. Pleura mostly glossy, only the base of the katepisternum silvery-yellow dusted. The ground-setulae usually mostly black, paler in some females. Greater ampulla triangular and bare. Kpst $2+1$. Anatergite bare. Scutellum with a pair of apical, lateral and basal setae, one or two pairs of weaker basals, and a pair of strong and two pairs of weaker discals; one of the weaker pairs near the apex, placed close together and rather erect.

Wings. Clear, darkened only at base. Tegula and basicosta dark brown. Veins brown. $R_{1}$ ending in the costa well beyond the level of cross-vein $r-m$. Stem-vein setulose dorsally. Subcostal sclerite setulose. Bend of M right-angled. Costa haired ventrally to subcostal break. Calypters brown, with brown hairs on margins and dorsally on the lower one; anterior part of upper calypter paler, almost white in some females and in this case with white marginal hairs anteriorly.

Legs. Femora dark brown, tibiae and tarsi pale brown. Fore tibia with a row of short $a d$ setae and $1 p v$ seta. Mid tibia with $1 a d, 1 p d, 2 p$ and $1 v$ seta. Hind tibia with $1 a d, 1 p d$ and $2 a v$ setae. Hind coxa haired on whole length of posterior margin.

Abdomen. Ground-colour black with metallic blue, dark green and purple reflections, and dark hind margins to the tergites. Viewed from various angles with a dense, even, silvery dusting on $\mathrm{T} 1+2$, to $\mathrm{T} 4$. $\mathrm{T} 5$ with a pair of silvery lateral patches. T 3 and T 4 with a dark median line when viewed extremely low from behind. General setulosity longer and sparser on $\mathrm{T} 5$. $\mathrm{T} 3$ to $\mathrm{T} 5$ with rows of weak marginal setae. Ventral surface of $\mathrm{T} 1+2$ and St 1 to St 3 with pale hairs. Sternites otherwise with black setulae which are longer marginally.

Genitalia. Male terminalia as in figs. 20-21. Female ovipositor as in figs. 15-16.

Measurements. Length of body, $7.0-10.0 \mathrm{~mm}$. Length of wing, $6.0-8.0$ $\mathrm{mm}$.

Distribution. Mexico, Costa Rica, Colombia, Ecuador, Peru, Bolivia, Venezuela, Guyana, Brazil, Chile.

Material examined

MEXICO: Cordoba, 21.iii.1908, 10ิ, BMNH, 10 , USNM.

COSTA RICA: La Suiza, 1923, 1 \%, USNM.

COLOMBIA: Meta District, 1932, $1 \hat{\sigma}, \mathrm{BMNH}, 6 \hat{\delta}, 2 \rho$, USNM; Putamayo R., $6 \hat{\jmath}, 4 \uparrow$, BMNH, $44 \hat{\jmath}, 19 \%$, USNM; Bogota, $2 \hat{\jmath}, 3$ ㅇ, BMNH, $10 \hat{\jmath}, 14$ 으, USNM; Pasto, $2 \hat{\jmath}, 2$ ㅇ, USNM; $4 \mathrm{mls}$ W Guaduas, Cundinamarca, 1200 m, 15.iii.1955, $1 \hat{\delta}$, CAS; Villavicencio, Quatquia R., xii. 1914,

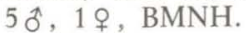
$\mathrm{BMNH}$.

BOLIVIA: no locality, 3 \% , BMNH; Mapiri, 14.iii.1903, $700 \mathrm{~m}, 1$ ô,

ECUADOR: Cachabé to Paramba, ii.1897, 1 कै, and iv. 1897, 1 ô, BMNH; Nisa, iv. 1938, 1 ô, USNM.

PERU: Previsto, $750 \mathrm{~m}, 6 . v i .1965,1 \%, 600 \mathrm{~m}, 4 . v i .1965,1 \hat{\text { o }}$, BMNH; Boqueron Abad, 500 m, 12.v.1964, 1 ô, BMNH; Meshagua, 4.x.1902, Urubamba R., $1 \hat{\jmath}$, BMNH; Chanchamayo, Dp. Junin, 25.vii.1948, $2 \hat{\jmath}, \mathrm{BMNH}$; same locality, 19.vii.1948, 1 \%, BMNH.

VENEZUELA: Quebrada Secca, $2 \hat{0}$, USNM.

GUYANA: Rockstone, 9.vii.1911, 1 \&, USNM; Kaieteur, 6.viii, 1911, 1 , USNM. 
BRAZIL: Rio de Janeiro, x.1938, $3 \hat{\jmath}, 3 \hat{\uparrow}$, BMNH, $8 \hat{\jmath}, 18 \%$, USNM; Para, 1920, 3 o , BMNH; Espirito Santo, 22.iv.1898, $1 \hat{\delta}$, USNM; Tem. Amazonas, Mt. Marahuaca, N slopes, Benstez Camp, 1-25.v.1950, 1 ô, USNM; Mangaratiba, R.J., viii.1938-ii.1939, 1 \%, USNM.

Paralucilia xanthogeneiates, sp. n.

\section{Description}

Similar to fulvinota but differing in the following characters:

Head. Female frons equal to 0.30 of the head-width. Female frontal vitta with short black hairs. Fronto-orbital plates thinly dusted, the ground-colour showing through, with shining black reflections around the bases of the frontal setae, and small black setulae which are numerous in the female and in a single row in the male. Parafacials, genae and lower occiput golden dusted. Genal groove with a few dark hairs. Postgenal setae dark orange-red. Male with 10-12 frontals, upper ones weak. Female with 10-12 frontals, and 1 pair of strong outcurved ocellars. Facial ridges setulose on their whole length. Arista brown. Prementum glossy black.

Thorax. Viewed from behind mesonotum with three distinct dark vittae which reach the scutellum. Postsutural region silvery-grey dusted between vittae. Basisternum mostly dark haired. Anterior spiracle yellow, sometimes brownish above. Pleura black-haired.

Wings. Wing-base and costa dark in some specimens. Tegula and basicota black. Calypters brown, yellow anteriorly in some specimens; basal dorsal hairs of lower calypter and anterior marginal hairs orange-brown; female upper calypter with dark dorsal hairs.

Legs. Femora black, tibiae and tarsi dark brown.

Abdomen. T 4 thinly silvery-grey dusted and without a dark median vitta. T 5 thinly silvery-grey dusted and with weak lateral silvery spots. Sternites in some specimens totally dark haired.

Genitalia. Male terminalia as in figs. 22-23. Female ovipositor similar to fulvinota, but St 6 and T 6 more bristly and differently shaped (figs. 17-18); grooves of St 7 sparser and wider.

Measurements. Length of body, 7.0 - $10.0 \mathrm{~mm} \mid$ Length of wing, 6.5 $8.0 \mathrm{~mm}$.

Distribution. Bolivia, Brazil, Paraguay, Argentina.

Material examined

Holotype $\hat{o}$, ARGENTINA: Horco Molle, c $12 \mathrm{~km} \mathrm{~W}$ of Tucuman, 700 m., Malaise trap, 18-21.iii.1974, C. R. Vardy, in British Museum (Natural History), London.

\section{Paratypes:}

BOLIVIA: no further data, 1 , $\mathrm{BMNH}$,

BRAZIL: Nova Teutonia, 2711'B, 52॰23’L, 25.v.1939, 1 ô, 1 ㅇ, 17.v.1939, 1 ㅇ, 23.v.1939, 1 ô, 6.vi.1939, $1 \hat{\delta}, 14 . v i .1939,1 \hat{\jmath}$, F. Plaumann, BMNH, iv.1973, $2 \hat{0}$, FMNH; Jundiahy, 8.ix.1898, 10ิ, BMNH; São Paulo, Cantareira, i.1945, M. P. Barreto, 2 , BMNH; Cássia dos Coqueiros, Mun. Cajuru, SP, x.1954, M. P. Barreto, 1 \%, BMNH; Arceburgo, M. G., xii.1946, M. P. Barreto, 1 ô, BMNH; Rio Grande do Sul, Pelotas, 23.iv.1967, V. Becker, $3 \hat{o}$, 1 \%, BMNH; R. G. do Sul, Pelotas, 3.xi.1956, C. Biezanko, 2 q, BMNH; same locality, 9.xi.1956, 1 ㅇ. vi.1957, 1 ô, 13.viii.1957, 1क, 2.xi.1957, 1 ô. 26.ix.1958,

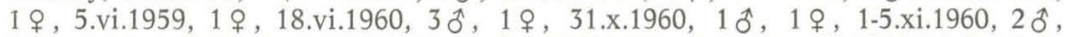

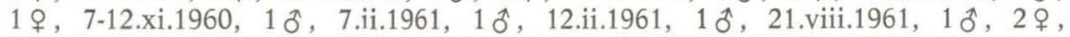

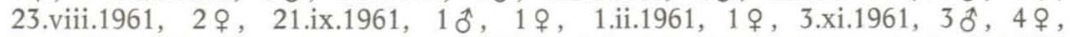
7.xi.1961, 2 ᄋ, 25.xi.1961, 2 + , 1.xii.1961, 1 ô, 1 ᄋ , 26.xii.1961, 1 ô, 5.viii.1963,

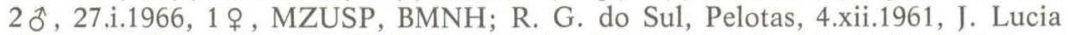
Mantovani-Biezanko, 2 \% , BMNH; same locality, 1964, $1 \hat{\jmath}, 1 \%$, USNM; Cajuru, S. P., xii.1944, M. P. Barretto, 1 \%, MZUSP; M. Grosso, Maracaju, Shannon \& Lane, 1 \%, USNM; same locality, Julho, 1937, 2 \%, USNM; Rio de Janeiro, 
D. F., xii.1937, 1 , , USNM; same locality, viii. 1938, 1 , USNM; Itaquaquecetuba, São Paulo, 9.i, C. H. T. Townsend, $1 \hat{0}$, USNM; same locality, 3.v., 1 ․ USNM; S. Paulo, Cantareira, J. Lane, $1 \hat{0}$, USNM; S. Paulo, Juquiá, 1-9.x.1935, J. Lane, 1 ô, USNM.

PARAGUAY: Sa. Trinidad, 3.ix.1935, Townsend Genotype collection, 1 오, USNM.

ARGENTINA: Haute Parana, Teju Cuare, Pr. San Ignacio, 1911, E. R. Wagner, $1 \delta$, USNM.

No data: "Somomya viridula", ex Bigot coll., 1 \% BMNH.

\section{Paralucilia adespota, sp. n.}

\section{Discussion}

This species is referred to as Myiolucilia lyrcea Walker by Hall (1948: 113) and its genitalia are illustrated by him under the name fulvinota (1948: plate 16, fig. A).

\section{Description}

Similar to fulvinota but differing in the following characters:

Head. Female frons 0.34 of the head-width. Ground-colour yellow except for upper half of occiput. Anterior facets of male eyes greatly enlarged. Frontal vitta of female reddish-brown on anterior two-thirds and thinly pale golden dusted. Fronto-orbital plates densely pale golden dusted in male, less densely above in female but without any noticeable difference in colour. Parafacials, genal groove and genae pale golden dusted. Postgenal setae golden or pale orange. Occiput with orange hairs. Male with 9-10 weak frontals. Facial ridges setulose on their whole length.

Thorax. Metallic colour paler and greenish. Mesonotum with three distinct dark vittae which reach the scutellum. Dusting silvery-grey. Ia $2+1$. Anterior spiracle enlarged and white. Katepisternal hairs mostly yellow. Scutellum often with a single basal marginal seta only.

Wings. Upper calypter mostly white with white marginal hairs; base of lower calypter white, with white dorsal hairs and outer marginal hairs white.

Legs. Hind tibia with 2 pd setae.

Abdomen. Tergites finely \& evenly dusted, lateral spots not very distinct.

Genitalia. Male terminalia as in figs $24-25$. Female ovipositor very similar to fulvinota but St 6 (fig 19) of different shape.

Measurements. Length of body, $7.0-10.0 \mathrm{~mm}$. Length of wing, 6.0 $7.5 \mathrm{~mm}$.

Distribution. Costa Rica, Panama, Colombia, Peru, Venezuela, Guyana, Surinam, Brazil.

\section{Material examined}

Holotype ô, COLOMBIA: Condota, 10.v.1912, H. G. J. Spurrell, in British Museum (Natural History), London.

\section{Paratypes:}

COSTA RICA: San Carlos, Schild \& Burgdorf, 1 ㅇ, USNM.

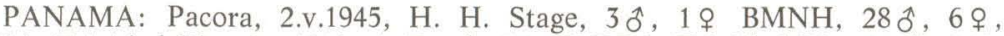
USNM; Trinidad Riv., 9.v.1911, A. Busck, 3 \% , USNM; Trinidad Rio, 23.iii.1912, A. Busck, 1 q , USNM; Porto Bello, 9.v.1911, A. Busck, 1 우, USNM.

COLOMBIA: Villavicencio, Quatquia R., xii.1914, $1 \hat{\jmath}, \mathrm{BMNH}$.

PERU: Boca-de-Napo, Upper Amazon, 24.iv-12.v.1913, J. J. Mounsey, 7 , BMNH; Loreto, $20 \mathrm{~km}$ from Ucayali, R. Calleria, Colonia Calleria, 5-10.x.1961, B. Malkin, $1 \%, \mathrm{BMNH}, 5 \%, \mathrm{FMNH}$; Loreto, Estiron, Rio Ampiyacu, 13.xi9.xii.1961, B. Malkin, 1\%, FMNH.

VENEZUELA: Valera, $1 \hat{o}$, USNM. 
GUYANA: 1908, K. S. Wise, $2 \hat{\jmath}, 2$,, $\mathrm{BMNH}$; Essequibo R., Moraballi Creek, 2.x.1929, $1 \hat{\delta}$, BMNH; Bartica District, 26.iv.1924, W. Beebe, $1 \delta$, AMNH, $2 \hat{o}, 3$, , USNM; Kartabo, W. Beebe, $1 \hat{\jmath}$, USNM.

SURINAM: Moengo, 4.iv.1946, Geijskes, $1 \%$, USNM.

BRAZIL: Para, 5.i.1896, E. E. Austen, 1 †, BMNH; bôca do Cuminá-Miri Oriximiná, PA., 19-26.i.1968, 1 , , MZUSP.

\section{Genus Hemilucilia Brauer}

Mya Rondani, 1850: 175. [Preocc. Mya Linnaeus, 1758.]

Hemilucilia Brauer, 1895: 598.

Type-species of Mya: Mya semidiaphana Rondani, 1850, by designation of Pont (1983: 108). Type-species of Hemilucilia: Musca segmentaria Fabricius, 1805 , by original designation.

Note: An Application has been made to the International Comission on Zoological Nomenclature discussing the names Mya, Somomya and Hemilucilia (Pont, 1983).

\section{Diagnosis}

Hemilucilia can be distinguished from all other New World Chrysomyini by the bare parafacials and lower calypter, the presence of presutural $d c$ setae, and palpi of normal length.

\section{Description}

Male head holoptic or subholoptic (fig. 26), female dichoptic. Parafacial bare. Female frontal vitta inconspicuously haired, and parallel sided; frontoorbital plates with proclinate orbital setae. Vibrissae inserted at or slightly above the fronto-clypeal suture. Thoracic setulae distinct. Thorax and abdomen metallic blue or green, both yellow anteriorly in most species. Anterior presutural sa seta (outer posthumeral) present. Lower calypter bare, the inner margin diverging from the scutellar margin. Costa setulose ventrally to subcosta or to $R_{1}$. Male aedeagus with a short, slightly curved or almost straight paraphallus and a long extended hypophallus. Female ovipositor normal, telescopic, of the usual calliphorid type.

\section{Discussion}

This endemic Central and South American genus can easily be distinguished from other genera of the tribe by the characters given above. In addition all species have a distinct and characteristic, almost Lucilia-like, headshape (fig. 26). Species of Hemilucilia, unlike the majority of the New World Chrysomyini, do not have distinct longitudinal thoracic vittae, though they are very faintly visible in some of the species. The female frons is narrow and parallel-sided, unlike the expanded frons found in Compsomyiops species. This genus is certainly more closely related to Chloroprocta and Paralucilia than to Compsomyiops and Cochliomyia. It is confined to Central and South America, and references to its occurrence in the Nearctic region (e.g. Cushing \& Hall, 1937: 196) are erroneous and refer to Chloroprocta idioidea (RobineauDesvoidy). However, Walker's type of femorata (= segmentaria Fab.) was described from Mexico and Hall (1948) also recorded flavifacies (Engel) [= semidiaphana Rondani] and segmentaria (Fabricius) from Mexico. The genus contains six species, one of which is described as new in the present paper, and the species can be recognised quite easily in both sexes using the key below, only the male of townsendi being unknown.

Brauer (1895) erected this genus for the Fabrician species Musca segmentaria, but it was not until 1925 that further species were described. Séguy (1925: 440) gave a key to males of three species, describing one as new (benoisti) and including idioidea (Robineau-Desvoidy) as well as segmentaria in the genus. $H$. idioidea is now assigned to the genus Chloroprocta. Shannon (1926: 125) gave a key to four species, describing parva and townsendi as new. Examination of his types has shown that parva is synonymous with benoisti, whilst townsendi is a good species though still only known from 
the female sex. Shannon also included segmentaria and fuscanipennis (Macquart) in his key, the latter now being recognised as a synonym of Chloroprocta idioidea. Engel (1931) described a species flavifacies as a member of the subfamily Rhiniinae, and this name has subsequently been placed in Hemilucilia and applied to the most common and widespread species by all authors (e.g. Hall, 1948, Mello, 1972). However, examination of the types of flavifacies has shown them to be specimens of Chloroprocta idioidea. How this misidentification took place is not clear, but it appears to have originated in Hall (1948: 106). Engel (1931: 140) also referred to a second Rhiniine but did not describe it, and this single female was probably another Hemilucilia species. Hall (1948: 104) keyed and correctly recognised two Central American species, flavifacies [= semidiaphana Rondani] and segmentaria, and he correctly transferred fuscanipennis Macquart to Chloroprocta. Nunes de Mello (1959) gave a resumé of the genus, redescribing and illustrating in detail the three species benoisti, flavifacies [ = semidiaphana] and segmentaria. Unfortunately he did not have any material of townsendi. Mello (1972) described two new species, souzalopesi and hermanlenti, and gave a key to the five known species together with excellent figures of both male and female characters. He was also unable to see specimens of townsendi. Through examination of material identified as hermanlenti by Guimarães and identical specimens from other sources, I have concluded that this species is no more than a dark form of the comon semidiaphana and I have placed it as a synonym of that species. In a short note, Mariluis (1979) has resurrected a new name proposed by Rondani for Wiedemann's interpretation of segmentaria. This is discussed further under segmentaria below. Mariluis also described a subspecies occidentalis of segmentaria which I consider to be no more than a colour variety. In a second paper, Mariluis (1980a) has given a key to the fcur species segmentaria, nubipennis, souzalopesi and benoisti, including his $\mathrm{s}$. p. occidentalis, and has described a new subspecies of segmentaria, paciiencis. The characters used in the key are not reliable, and the nomenclature of the common species is incorrect.

\section{KEY TO SPECIES OF HEMILUCILIA BRAUER}

1. Ventral surface of costa setulose to subcostal break. Males without any reclinate frontal setae. Females with weak proclinate orbital setae, the tip of the anterior one not reaching level of the

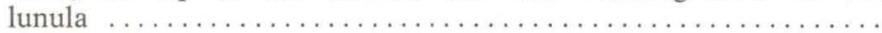

Ventral surface of costa setulose to junction with $R_{1}$ or beyond. Males with the upper frontal setae reclinate. Females with strong orbital setae, the tip of the anterior one reaching beyond level of the lunula

2. Wing-bases and calypters black to dark brown, opaque. Thorax and abdomen entirely dark in ground-colour, prosternum and sternites pale brown. Ventral surface of stem-vein without long fine hairs. Dorsal surface of upper calypter bare. Large metallic bluepurple species .................... melusina sp. nov.

Wing-bases hyaline, and calypters at most slightly brownish, transparent. Prosternum usually yellow, ventral surface of $\mathrm{T} 1+2$ and St 1 and St 2 always yellow. Ventral surface of stem-vein with or without long hairs. Dorsal surface of upper calypter usually with long hairs. Metallic blue-green species $\ldots \ldots \ldots$.

3. Posterior spiracle black or dark brown. Anterior part of thorax metallic coloured. Ventral surface of stem-vein bare. Dorsal surface of upper calypter haired in both sexes semidiaphana (Rondani)

Posterior spiracle yellow to creamy. Anterior part of thorax orangeyeliow, and anepisternum usually yellow. Ventral surface of stem-

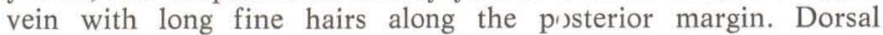
surface of upper calypter bare in ma.e, with long hairs in female ........................ segmentaria (Fabricius) 


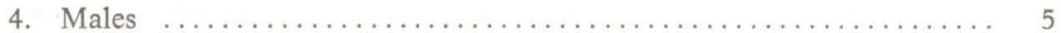

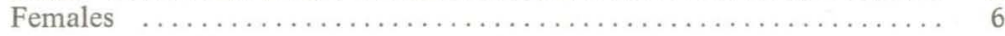

5. Mid tibia with a row of strong, stout, but short $p v$ spines. Frons at narrowest point equal to, or less than, the width of ocellar

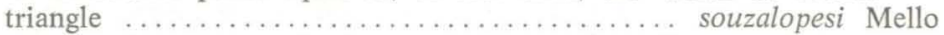

Mid tibia without a row of spines on the $p v$ surface. Frons at narrowest point distinctly broader than the width of ocellar triangle

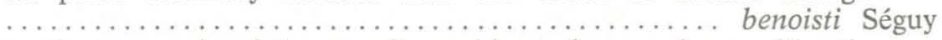

[The unknown male of townsendi would run here and may, like the 오 오 (all from Peru), have the postpronotal lobes extensively yellow; in the two species in this couplet these lobes are mostly metallic.]

6. Proepisternum and postpronotal lobes extensively or entirely yellow

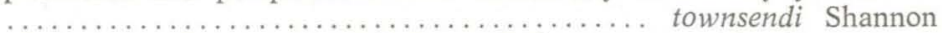

Proepisternum and postpronatal lobes metallic green or blue ..... 7

7. Frons shining black on more than half its length. Arista with $14-15$ rays above $\ldots \ldots \ldots \ldots \ldots \ldots \ldots \ldots \ldots \ldots \ldots \ldots \ldots \ldots$ benoisti Séguy

Frons shining black only at vertex. Arista with $26-30$ rays above

\section{Hemilucilia benoisti Séguy}

Hemilucilia benoisti Séguy, 1925: 440.

Hemilucilia parva Shannon, 1926: 125.

Types

Holotype $\hat{o}$ of Hemilucilia benoisti Séguy, French Guiana, in MNHNP. Holotype $\hat{\sigma}$ of Hemilucilia parva Shannon, 'Amazon', in BMNH. [Types examined.]

\section{Description}

Head. Male subholoptic, frons at narrowest point greater than width of the ocellar triangle; female dichoptic. Ground-colour yellow, except for the vertex and upper third to half of the occiput and upper half of frons in female which are black. Eyes bare. Frontal vitta reddish-brown above, yellowish on lower half in male, upper half black in female. Frontoorbital plates densely golden dusted and with fine pale yellow hairs. Parafacials, genae, face and lower half of occiput densely pale yellow dusted. Genal grooves, genae and postgenae with pale yellow hairs; anterior part of genae with a small patch of black hairs. Upper occiput thinly grey dusted. Frons with 9 frontals, 1 pair of reclinate orbitals and 1 pair of $v t i$ setae; female also with a pair of vte setae. Ocellars weak and divergent, stronger in female. Vibrissae strong and crossed, inserted just above the frontoclypeal suture. Facial ridges with fine hairs along their whole length, those on the lower third dark. Antenna orange-yellow, 3rd segment six times as long as 2nd. Arista long-plumose to tip and longer than the antennal length, with up to 10 rays above. Palpi yellow, slightly dilated apically. Prementum pale brown.

Thorax. Ground-colour brown with metallic green reflections, Lower anterior part of postpronotal lobes and basisternum yellowish-brown. Mesonotum thinly silvery-grey dusted with very faint dark vittae, a thin median one and a pair of broader laterals; these are only visible when the mesonotum is viewed at a low angle from behind. Acr $0+2, d c 2-3+4,3$ pprn, $2 p h, 2-3+2 i a, 1$ pra, $2+2 s a, 2 p a$. Basisternum of prosternum densely pale haired. Proepisternum with pale hairs. Pleura glossy metallic, only the katepisternum silvery-grey dusted; all pleura yellow-haired. Kpst $1+1$. Anatergite bare. Spiracles pale yellow to white. Scutellum with a pair of apical basal and discal setae, lateral and second basal pair very weak.

Wings. Costa darkened from junction with $R_{1}$ to tip. Veins yellow basally, otherwise brown. Tegula and basicosta yellow. Vein $R_{1}$ ending in 
costa at level of cross-vein r-m. Bend of $M$ to cross-vein dm-cu equal to 1.5 times the distance between the bend and the wing-margin. Bend of $M$ rounded and obtuse. Calypters creamy with yellowish margins and pale yellow marginal hairs; lower calypter longer than broad. Ventral surface of stem-vein bare. Subcostal sclerite setulose. Ventral surface of costa setulose to just beyond the junction with $\mathrm{R}_{1}$.

Legs. Variable in colour, from yellow with brown joints to entirely brown on mid and hind femora and tibiae. Mid and hind coxae brown, with thin grey dusting. Fore tibia with three weak ad setae, and no pd setae in male. Mid tibia with $1 \mathrm{ad}, 1 \mathrm{pd}$ and additionally in female $2 p$ setae and $1 \mathrm{v}$. Hind tibia with $3 a d, 1 a v$, and 1-2 pd setae. Hind coxa with a row of pale hairs along the posterior margin.

Abdomen. Ground-colour of $\mathrm{T} 1+2$ and $\mathrm{T} 3$ yellow, other tergites brown with metallic green and blue reflections. $\mathrm{T} 3$ with a broad median vitta which broadens posteriorly to join a brown hind-marginal band. St $1-4$ yellow; St 5 brown with weak metallic reflections. T 4 and $\mathrm{T} 5$ with a row of marginal setae, and a black hind-marginal band. St $2-4$ with a pair of black apical setae, otherwise the ground-setulae yellow.

Genitalia. Male terminalia as in figs. 27-28.

Measurements. Length of body, $6.0-6.5 \mathrm{~mm}$. Length of wing, $5.5 \mathrm{~mm}$.

Distribution. Costa Rica, Venezuela, Guyana, French Guiana, Brazil.

Material examined:

COSTA RICA: San Mateo, Higuito, P. Schild, $1 \hat{\delta}$, USNM; Turrialba, 31.v.1951, O. L. Cartwright, 10 , USNM.

VENEZUELA: Quebrada Seca, 1 \%, USNM. USNM.

GUYANA: Bartica Distr., 26-30.iii.1924, C. H. Curran, $1 \hat{0}, \mathrm{BMNH}, 1 \hat{\delta}$,

BRAZIL: São Paulo, i.1936, J. Lane, 1 ô, USNM.

\section{Hemilucilia segmentaria (Fabricius)}

Musca segmentaria Fabricius, 1805: 292.

Chrysomya hyacinthina Robineau-Desvoidy, 1830: 450. Syn. n.

Lucilia nubipennis Rondani, 1848: 77.

Calliphora femorata Walker, 1861: 310.

Hemilucilia nubipennis ssp. occidentalis Mariluis, 1979: 86. Syn. $n$.

Types

Holotype $q$ of Musca segmentaria Fabricius, 'America meridionali', in UZMC [examined]. Holotype $q$ of Chrysomya hyacinthina Robineau-Desvoidy, 'Amérique méridionale', coll. Serville, now lost or destroyed, not in MNHNP. Holotype + of Lucilia nubipennis Rondani, 'America meridionali', in UZMC [examined]. Holotype $q$ of Calliphora femorata Walker, Mexico, in BMNH [examined.] Holotype $\hat{\delta}$ of Hemilucilia nubipennis ssp. occidentalis Mariluis, Ecuador, in Mariluis collection, San Miguel, Argentina [not examined].

\section{Note on the type of Musca segmentaria}

From UZMC I received for study the single female under this name. It is in excellent condition and agrees with Fabricius' description except for the antennal colour, a discrepancy which was also noted by Wiedemann (1830: 401) when he studied the type. It has a recent 'TYPE' label and a hand-written label " $M$. segmentaria ex. Am: mer: Schmidt' which is the data given by Fabricius. It agrees with the most recent interpretation of the species (Mello, 1972) and with that given here.

\section{Note on the type of Chrysomya hyacinthina}

Robineau-Desvoidy described this species from specimens of unstated number and sex from "Amérique méridionale", in the collection of Serville. This 
collection is thought no longer to exist, and I found no material in MNHNP. The description is a very good one and undoubtedly refers to segmentaria. The name has previously been assigned to the synonymy of macellaria Fabricius (James, 1970: 6).

\section{Note on Lucilia nubipennis}

Wiedemann (1830: 401) studied Fabricius' original specimen of segmentaria (the holotype) and noted a mistake in Fabricius' description: the antenna is actually yellow, and not black as reported by Fabricius. Rondani (1848: 77) misunderstood Wiedemann and thought that he had a species distinct from Fabricius' segmentaria. This could not have been the case, as Wiedemann was actually describing the Fabrician holotype! Rondani gave a new name, Lucilia nubipennis, to segmentaria sensu Wiedemann, but Wiedemann's interpretation of segmentaria was in fact the correct one: the mistake was not by Wiedemann, but by Fabricius when he described the antenna as black. The holotype of nubipennis is the specimen of segmentaria which Wiedemann studied, which is the holotype of segmentaria. I have therefore labelled the holotype of segmentaria also as the holotype of nubipennis.

\section{Note on the type of Calliphora femorata}

Walker described this species from a single female from Mexico. The specimen is in the BMNH. It is rather rubbed and dirty, and has the right fore leg and hind leg and several tarsal segments missing; the abdomen has been glued back to the body at some time. It is labelled ' 68.4 ', 'Mex' and has Walker's determination "femorata W.". It agrees with the interpretation of Hemilucilia segmentaria given here.

\section{Description}

Head. Male holoptic; female dichoptic, frons equal to 0.25 of the headwidth. Ground-colour yellowish-orange. except for the upper half of the occiput and the vertex which are black. Frontal vitta matt orange. Frontoorbital plates golden-yellow dusted below, more brownish-yellow above, and with numerous fine pale hairs; very narrow in female, hardly wider than a frontal bristle socket. Parafacials, genae, face and genal grooves pale yellow dusted. Upper occiput shining, lower occiput greyish-yeliow dusted. Genal groove, genae, postgenae and occiput with pale yellow hairs; anterior part of genae with black hairs. Frons with 9-10 frontals in male, the upper ones weak, and 13-14 in female. Male with a pair of vti and a weak pair of proclinate ocellar setae; female with 1 pair each of reclinate orbitals, $v t i$ and $\nu t e$, and two pairs of outcurved ocellars. Vibrissae strong, crossed, and inserted at the fronto-clypeal margin. Facial ridges with hairs along their whole length, those just above the vibrissa black. Antenna bright orange, 3rd segment five times as long as 2 nd. Arista long-plumose, yellow, the tip and the rays black, with up to 36 rays above. Palpi yellow and slightly dilated apically. Prementum glossy brown.

Thorax. Ground-colour yellow to pale brown with metallic green and blue reflections. Mesonotum thinly and evenly silvery-grey dusted; when viewed at an extreme angle from behind, with a median and a pair of lateral dark vittae faintly defined. Acr $0+2, d c 2+4,3$ pprn, $2-3+2 i a$, 1 pra, $1+2$ sa, $2 \mathrm{pa}$. Anterior part extensively yellow, including the proepisternum and basisternum; anepisternum extensively or entirely yellow, or pale brown; katepisternum irregularly silvery-grey dusted. Basisternum and proepisternum with pale hairs. Anepisternum with some dark hairs, otherwise pleura pale haired. Kpst $1+1$. Anatergite bare. Spiracles pale yellow. Scutellum with a pair of apical and basal setae, and a weaker discal and lateral pair.

Wings. Costa darkened from base to subcosta and from $R_{1}$ to tip, and with a brownish suffusion around all veins. Basal veins yellowish, otherwise veins brown. Tegula and basicosta yellow. Vein $\mathrm{R}_{1}$ ending in costa a little beyond the level of cross-vein $r-m$. Distance between the bend of $M$ and cross-vein dm-cu equal to twice the distance between dm-cu and the wing- 
margin. Bend of $\mathrm{M}$ almost right-angled. Calypters pale creamy-brown, transparent, with yellow marginal hairs; upper calypter with long fine hairs in female, bare in male; lower calypter a little longer than broad. Ventral surface of stem-vein with a row of long fine pale hairs posteriorly. Subcostal sclerite setulose. Ventral surface of costa setulose as far as the subcostal break.

Legs. Yellow, including coxae; hind tibia and all tarsi darker in some specimens. Fore tibia with a row of weak, widely-spaced ad setae, and $1 p v$ seta. Mid tibia with $1 a d, 1 p d, 2 p$ and $1 v$ seta. Hind tibia with weak rows of $a d$ and $p d$ setae, and $2 a v$ setae; female with 2 or 3 stronger setae in the rows. Hind coxa with a row of pale hairs on the posterior margin.

Abdomen. Ground-colour of $\mathrm{T} 1+2$ yellow, otherwise abdomen brown with metallic green-blue reflections; $\mathrm{T} 3$ yellow anteriorly in some specimens; St brown, faintly metallic. Ground-setulae yellow anteriorly and ventrally on $\mathrm{T} 1+2$, otherwise black. St 1 and St 2 with yellow hairs, black on other sternites. T 3, 4 and 5 with a row of weak marginal setae. Seen from an extreme angle from behind, T 3 to 5 thinly silvery dusted, T 3 with a median dark vitta and a dark hind-margin.

Genitalia. Male terminalia as in figs. 29-30.

Measurements. Length of body, $7.5-10.0 \mathrm{~mm}$. Length of wing, 7.0 $9.0 \mathrm{~mm}$.

Distribution. Mexico, El Salvador, Costa Rica, Panama, Colombia, Ecuador, Bolivia, Peru, Trinidad, Guyana, Brazil, Paraguay, Argentina.

Material examined.

EL SALVADOR: San Salvador, 20.xii.1953, 1 , USNM.

COSTA RICA: Higuito, San Mateo, 1 ô, BMNH.

PANAMA: Porto Bello, 18.iv.1912, $1 \%$, USNM; Barro Colorado Is, 18.vii.1923, 3 o , USNM; same locality, 31.v.1939, 1 \% , BMNH; Pacora River, 14.v.1953, 2 , USNM; Pacora, 2.iv.1945, $3 \%$, BMNH, $13 \%$, USNM.

COLOMBIA: Gorgona Is, 2.59 N, $78.20 \mathrm{~W}$, vii.1924, 2 \%, BMNH.

ECUADOR: Nisa, iv.1938, $1 \%$, USNM.

BOLIVIA: Huachi Beni, ix.1921, 1 , , USNM.

PERU: Previsto, 700 m, 28.v.1965, 1 ㅇ, BMNH.

TRINIDAD: Port of Spain, v.1897, 3 \% BMNH; Caroni Swamp, 20.iv.1965, 1 ô, 1 ㅇ, USNM.

GUYANA: Essequibo R., Moraballi Creek, 19.viii.1929, 1 \& , 27.viii.1929, 1ㅇ, 1.x.1929, 1ㅇ, BMNH; New River Head, 1500 - 25000', 1-27.iv.1938, 1 ㅇ, BMNH; Bartica District, 25.iv.1924, 1 ㅇ, BMNH, 3 으, USNM.

BRAZIL: Rio de Janeiro, 27.viii.1950, 1 ô, 1 \% , BMNH; Nova Teutonia,

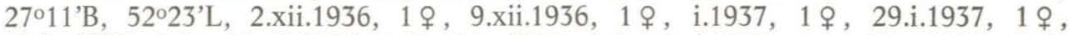

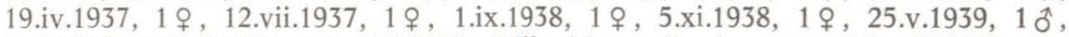
5.vi.1939, 1 oิ , i.1971, 1 ㅇ, BMNH; Villa Nova, R. Amazon, 1 오 BMNH; R. Amazon, 2 , BMNH; Bclém, iv.1969, 2 \% , BMNH; Corumbá, ii.1946, 1 \% , BMNH; Rio de Janeiro, viii.1938, 2 ô, 1 우 , ix.1938, 3 우, x.1938, 3 q , BMNH,

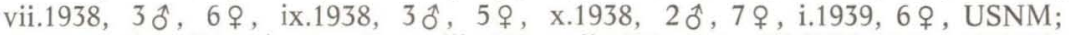
Mangaratiba, Rio de Janeiro, viii.1938 - ii.1939, 1 , BMNH, 2 \%, USNM; D.F., Rio de Janeiro, xii.1937, $1 \hat{\jmath}$, viii.1938, $1 \hat{\jmath}$, ix.1938, $1 \hat{0}, 1$ 우, BMNH; x.1937, $2 \hat{\sigma}, 1+$, xii-1937, 1 , , xi. $3 \hat{\jmath}$, vii.1938, $1 \hat{\sigma}, 2$, , viii.1938, $1 \hat{\sigma}, 1 \%$, ix.1938, $1 \hat{\jmath}$, USNM; Mato Grosso, Maracaju, iii-vii.1937, $2 \hat{o}, 13 \hat{q}$, USNM, 3 ㅇ, BMNH; Magé, ii.1940, 1 \& , BMNH, 3 q , USNM; same locality, iii.1940, 2 o , USNM; Manguinhos, ii.1940, 1ô, USNM; São Paulo, Juquiá, x.1935, 1 \&, USNM; Tinguá, Est. Rio, vi.1940, 1 \&, USNM; Santos, 30.v.1894, 1 ô, USNM; Espírito Santo, 1 \% , USNM.

PARAGUAY: Sa. Trinidad, viii.1913, 1 ô, BMNH; iv.1914, 2 q, vii.1914, $1 \hat{\jmath}$, USNM; Villarica, iii.1938, $1 \hat{o}, 1$, USNM: Sapucay, 23.v.1902, 1 , USNM.

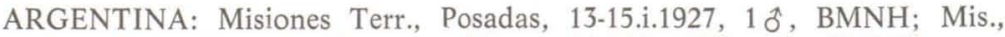
Iguazu Nat. Park, Hosteria Hoppe, c 140 m, 10-11.iv.1974, 1 , BMNH. 


\section{Hemilucilia semidiaphana (Rondani)}

Mya semidiaphana Rondani, 1850: 177.

Hemilucilia hermanlenti Mello, 1972: 548. Syn. n.

Hemilucilia segmentaria ssp. pacifiencis Mariluis, 1980a: 85. Syn.n.

Hemilucilia fuscanipennis, authors, nec Macquart [misidentifications].

Hemilucilia flavifacies, authors, nec Engel [misidentifications].

Types

Holotype $\hat{\delta}$ of Mya semidiaphana Rondani, São Sebastião Is., in MZST [examined]. Holotype $\hat{o}$ of Hemilucilia hermanlenti Mello, Brazil, IOC [not examined]. Holotype $\hat{\delta}$ of Hemilucilia segmentaria ssp. pacifiencis Mariluis, Ecuador, in Mariluis collection, San Miguel, Argentina [not examined].

Note on the holotype of Mya semidiaphana

Rondani described this species from an unstated number of males from São Sebastião Island. I received for study a single male specimen found under this name in MZST. The specimen is rather damaged and the abdomen is in pieces and pinned in a paper envelope with the specimen. It has a large rectangular white label "Mya Rndn, Lucilia alior, semidiaphana Rndn., Ins. S. Sebastiani". It agrees with the original description and is undoubtedly the holotype, and so I have labelled it accordingly.

Discussion

There has been much confusion as to the correct name for this species, as previous authors have not examined all the relevant type material. The name semidiaphana Rondani has generally been placed as a synonym of segmentaria (e.g. James, 1970), but examination of the type has shown that it is the species described below and is the earliest available name for this species. Earlier authors (e.g. Séguy, 1925) called this species fuscanipennis Macquart, but this name is actually a synonym of Chloroprocta idioidea (Ronibeau-Desvoidy). Recent authors (James, 1970; Mello, 1972) have called this species $H$. flavifacies Engel, but examination of the syntypes of this species has shown that they are also Chloroprocta idioidea. The situation has been further confused by Mariluis (1979, 1980a), who has reversed the interpretation of the two common species, segmentaria and nubipennis [= semidiaphana]. $\mathrm{He}$ has also described a subspecies of each, based on colour differences. I do not consider that these characters are of subspecific value and I have therefore placed these names in synonymy. Mello (1972) described a new species hermanlenti which he distinguished from flavifacies [= semidiaphana] using colour characters and a very slight difference in the male frons: head-width ratio. I have not found these characters to be of any diagnostic value and I have placed hermanlenti in synonymy with semidiaphana.

\section{Description}

Head (fig. 26). Male holoptic; female dichoptic, frons equal to $0.27-0.29$ of the head-width. Ground-colour yellow, except the upper occiput and vertex which are black. Eyes bare. Frontal vitta mostly obscured in male, orange-brown below; female with upper half black, lower half orange, and with thin yellowish-brown dusting. Fronto-orbital plates densely golden dusted and with numerous small pale hairs; upper fifth and vertex glossy black. Parafacials, genal grooves, face and genae densely golden dusted; middle section of genae with a glossy patch. Parafacials bare; genae with golden hairs except for those on the glossy patch, which are usually dark. Upper occiput yellowish-grey dusted except medially, where it is glossy, and with yellow hairs. Male with 8-9 frontals, 1 pair of crossed $v t i$ and 1 pair of proclinate ocellar setae. Female with 9-10 frontals, two pairs of proclinate orbitals, the upper one weaker, 1 reclinate orbital, 1 vti and 1 vte setae and a pair of strong outcurved ocellar setae. Vibrissae strong, crossed and inserted at the fronto-clypeal suture. Facial ridges with fine hairs along their whole length, pale in females, often darkened in males. Antenna orange, 3rd seg- 
ment 6 to 6.5 times as long as 2nd and darkened anteriorly in males. Arista long-plumose to tip, yellow, with dark rays. Palpi yellow, and slightly dilated apically. Prementum glossy black.

Thorax. Ground-colour brown with metallic green and purple reflections. Mesonotum, viewed at an angle from behind, with even silvery-brown dusting and without distinct vittae. Acr $0+2, d c 2+4,3$ pprn, 3+2 ia, 1 pra, $1+2 s a, 2 \mathrm{pa}$. Pleura, except for the proepisternum, without distinct dusting; general setulosity variable, usually entirely yellow, but some specimens almost wholly black haired. Kpst $1+1$. Anatergite bare. Anterior spiracle enlarged, creamy-white to yeliowish, posterior spiracle brown. Scutellum with a pair of apical, lateral, basal and discal setae and a second weaker pair of basals.

Wings. Apical part from just beyond $R_{1}$ brown, intensely so along the costa. Base pale brown below subcostal break. Veins pale brown. Tegula black, basicosta yellow. Vein $R_{1}$ ending in the costa beyond the level of cross-vein $r-m$. Distance between the bend of $M$ and the wing-margin equal to half the distance between cross-vein dm-cu and the bend of $\mathrm{M}$. Bend of $\mathrm{M}$ rounded and obtuse. Calypters creamy, with pale yellow marginal hairs; inner margin of lower caypter diverging from the scutellar axis. Ventral surface of stem-vein bare. Subcostal sclerite setulose. Ventral surface of costa setulose to subcostal break.

Legs. Colour variable, usually orange-yellow, but the mid and hind legs brownish in some specimens. Apical fore tarsomeres brown. Fore tibia with a row of short weak ad setae and $1 p v$ seta. Mid tibia with $1 a d, 1 p d, 2 p$ and $1 v$ setae. Hind tibia with 3 weak ad setae, $2 p d, 2 a v$ setae. Hind coxa haired along its whole length.

Abdomen. Ground-colour brown. T $1+2$ usually wholly yellow, but some specimens entirely darkened; otherwise tergites with blue, green and purple metallic reflections. T 3 and $\mathrm{T} 4$ with thin silvery-grey dusting laterally which is only visible when viewed at a low angle from behind, and with a thin dark median vitta. $\mathrm{T} 3$ with a complete row of weak marginal setae; T 4 and T 5 with a row of marginal setae. Ground-setulae on T 5 longer and sparser. Ground-setulae on ventral surface of all tergites denser in male. St 1 to St 3 usually yellow with yellow hairs. St 4 yellow haired in some specimens.

Genitalia. Male terminalia as in figs. 31-32.

Measurements. Length of body, 5.0-8.0 mm. Length of wing, 4.5-7.5 mm.

Distribution. Generally distributed from Mexico to Argentina, West Indies to Peru.

Material examined.

GUATEMALA: no further data, $1 \delta^{\star}$, USNM.

COSTA RICA: Higuito, San Mateo, 3ㅇ, USNM; La Suiza, 1923, 2 , BMNH, 2 으, USNM; La Suiza de Turrialba, 2 으, USNM; no further data, 8 o, USNM; Cache, $1 \hat{\jmath}$, BMNH; Puntarenas Prov., Osa Peninsula, $3.5 \mathrm{mi}$. S. of Rincón, 11-12.iii.1969, 1오, CAS.

PANAMA: Canal Zone, Barro Colorado I., 11.i.1929, $1 \hat{\delta}, \mathrm{BMNH}$,

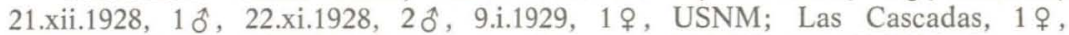
BMNH, $1 \hat{o}, 1$, USNM; Pacora, 2.v.1945, 1 ,, BMNH, 2 , USNM; Pacora, 8.vii.1953, 1 \% , USNM; Porto Bello, 25.ii.1911, 1 으. USNM; Cerro Campana, 3000', v.1954, 2 ô, BMNH; Canal Zone, Barro Colorado I., 24.vii.1963, $4 \hat{\delta}$, BMNH, 14 ơ, CAS; Gambona, vi.1944, 1 ㅇ CAS.

COLOMBIA: Upper Putamayo R., $3 q$, USNM; Bogota, $1 \hat{\jmath}, 1+$, USNM; Meta Dist., 1932, $1 \%$, USNM; Pasto, $1 \%$, USNM.

ECUADOR: $1 \mathrm{mi}$. W. Santo Domingo de los Colorados, Pichincha, 23.ii.1955, $1 \hat{o}$, CAS.

PERU: Previsto, 1965 2.vi, 800 m., 1 ㅇ, 850 m., 1 \& , 6.vi., 750 m., 1 ô, 2 , 15.vi., 700 m., 1 ㅇ, 800 m., $1 \hat{\jmath}$, 28.vi., 700 m., $2 \hat{0}, 2$ 우, BMNH; Boca de Napo, 24.iv-12.v.1913, 1 을 BMNH; Pebas, 26.v-15.vii.1913, 1 으, BMNH; Junin Prov., San Ramon, $1.000 \mathrm{~m}$, 7.vii.1980, UIC; $16 \mathrm{~km}$. W. San Ramon, 1.433 m., 23.vi.1980, $30^{\star}, 3$, UIC. 
BOLIVIA: no locality, $1 \hat{\delta}, 1 \%$, BMNH.

VENEZUELA: Aragua, Rancho Grande, Parque Nacional Henry Pittier, 4.iii.1967, $1.110 \mathrm{~m}, 1$ 우 $\mathrm{BMNH}, 2$ ㅇ, CAS.

TRINIDAD: Port of Spain, v.1897, 1 ㅇ, BMNH; Arima Valley, 500', 12.iii.1964, $1 \hat{\delta}$, BMNH, $3 \hat{o}$, CAS; same locality, 500-1.000', 10.iii.1964, 10 , CAS.

TOBAGO: $\mathrm{x} .1937,1$ ๙ิ, BMNH.

GUYANA: Essequibo R., Moraballi Creek, 2-7.viii.1929, 4 \% , BMNH; New River Head, 1,500-2,500', 1-27.iv.1938, 2 ㅇ, BMNH; Bartica Distr. 30.iii.1924, 1 \% , USNM.

BRAZIL: Chapada, $2 \hat{o}, 1 \%$, SEM; R. Amazon, $1 \%$, BMNH; São Paulo, Estação Biológica de Boracéia, 27.ii.1967, 1우 CAS; São Paulo, Embu, 15.ii.1946, 1 ồ, MZUSP; Pará, 1920, 3 오, BMNH; Nova Teutonia, 270 11’B 52。 23’L, 2.xi.1936, 2 ô, 19.ii.1937, 1ㅇ, 15.iii.1937, 1ㅇ, 7.vii.1937, 1 ô, 10.vii.1937, 1 ô, 7.ix.1938, 1 ㅇ, 20.ix.1938, 1 ㅇ, 25.v.1939, 3 우, BMNH; Belém,

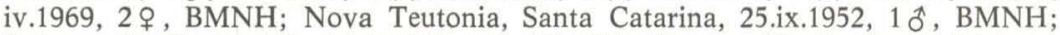
Pelotas, R. G. do Sul, 5. vi.1959, 1 ô, BMNH; Caraça, M. G., Santa Bárbara,

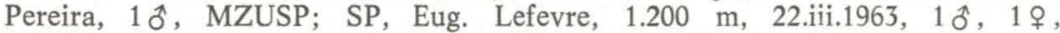
MZUSP; Lagoa Formosa, Cabeceira, GO, 26-28.x.1964, 1 \% , MZUSP; Itaguaçu, E. S., x.1970, 1 ô, MZUSP; São Paulo, Juquiá, x.1939, 1 q, USNM; Espírito Santo, 20.ii.1904, $1 \%$, USNM; same locality, 22.iv.1898, $1 \%$, USNM; Rio de

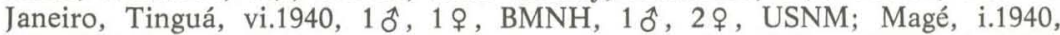
1 ô, ii.1940, 1 우, iii.1940, 1 o , USNM; Rio de Janeiro, D.F., x.1937 - ix.1938, $3 \hat{0}, 4$ ․ BMNH, $7 \hat{\jmath}, 8$, USNM; sabe locality, iv.1938, Teresópolis, $1 \hat{\delta}$, USNM; Mato Grosso, v.1937, Maracaju, $1 \%$, BMNH, 2 ㅇ, USNM; Rio de Janeiro, ix-x.1938, $10 \hat{\delta}, 30 \%, B M N H, 44 \hat{\jmath}, 155 \%$, USNM; Mangaratiba, R. J., viii.1938 - ii.1939, 5 \% USNM.

PARAGUAY: Sa. Trinidad, 5.v.1914, 1 ô, iv.1914, 1 오, USNM.

\section{Hemilucilia souzalopesi Mello}

Hemilucilia souzalopesi Mello, 1972: 551.

Type

Holotype $\hat{o}$ of Hemilucilia souzalopesi Mello, Brazil, in IOC [not examined].

\section{Description}

Head. Male subholoptic, frons at narrowest point equal to three times width of the anterior ocellus; female dichoptic, frons equal to 0.23 of the head-width. Ground-colour yellow, except for the vertex and upper occiput which are dark brown. Eyes bare. Frontal vitta orange-yellow, reddish in upper third. Fronto-orbital plates golden-yellow dusted, glossy near the ocellar triangle; with fine pale hairs, female with some dark ones on upper half. Parafacials, face, genal grooves and genae densely yellow dusted. Parafacials bare. Genae with a median glossy patch which has a few dark hairs, otherwise yellow-haired. Genal groove with a few fine pale hairs. Upper occiput thinly yellowish-grey dusted and with pale setulae. Male with 11 frontals, a stronger reclinate upper one, a pair of $v t i$ and a weak pair of proclinate ocellars. Female with 8-9 frontals, 2 pairs of proclinate orbitals, the tip of the anterior one reaching the antennal base, 1 reclinate orbital, 1 vti, 1 vte and a strong outcurved pair of ocellars. Vibrissae strong and crossed, inserted just above the fronto-clypeal suture. Facial ridges with short hairs along their whole length. Antenna orange-yellow, 3rd segment 4 times as long as 2 nd in male, $41 / 2$ times in female. Arista long-plumose, longer than the antennal length, with black rays and with up to 32 rays above. Palpi yellow and slightly dilated apically. Prementum glossy brown.

Thorax. Ground-colour brown, with metallic green and coppery reflections; lower anterior part of postpronotal lobes and prosternum orange-yellow. Mesonotum thinly silvery-grey dusted, with 1 median and 2 lateral indistinct 
dark vittae which are only visible when viewed at an extreme angle from behind. Acr $0+2$, but wit 3 pairs of stronger setulae amongst the groundsetulae anteriorly, $d c 3+4,3 \mathrm{pprn}, 3 \mathrm{~h}, 3+2$ ia, 1 pra, $1+2$ sa, 2 pa. Basisternum densely pale-haired. Proepisternum white dusted and with pale hairs. Pleura glossy metallic, only the katepisternum with silvery-grey dusting. Pleura yellow haired, upper part of anepisternum with a few dark hairs. Kpst 1+1. Anatergite bare. Spiracles creamy-white. Scutellum with a pair of apical, basal and discal setae, and a weaker lateral and second basal pair.

Wings. Cost darkened beyond $R_{1}$ to tip, cross-veins slightly infuscated. Veins brown, paler basally. Vein $\mathrm{R}_{1}$ ending in costa at level of cross-vein $\mathrm{r}-\mathrm{m}$. Distance between cross-vein dm-cu and bend of $\mathrm{M}$ equal to 1.75 times the distance between bend of $M$ and the wing-margin. Bend of $M$ sharp, almost right-angled. Ventral surface of stem-vein bare. Subcostal sclerite setulose. Ventral surface of costa setulose to beyond $R_{1}$. Calypters creamy, with pale yellow marginal hairs; lower calypter longer than broad.

Legs. Yellow; tibia and apical tarsomere of each leg darker, tip of hind femur also darkened; mid coxa brownish-yellow. Fore tibia with a row of weak $a d$ setae, and in female with $1 p v$ seta. Mid tibia with $1 a d, 1 p d$, and row of short $p v$ spines in male; female with $1 a d, 1 p d, 2 p$ and $1 v$ seta. Hind tibia with $3 a d, 2 p d$, and $2 a v$ setae. Hind coxa haired along its posterior margin.

Abdomen. Ground-colour of $\mathrm{T} 1+2$ yellow and $\mathrm{T} 3$ of male extensively yellow, otherwise brown with metallic green and coppery reflections. Male $\mathrm{T} 3$ with a broad median metallic vitta which broadens posteriorly. T 3 - T 5 with a black marginal band. $\mathrm{T} 3$ with a row of weak marginal setae, $\mathrm{T} 4$ and $\mathrm{T} 5$ with a row of stronger marginal setae. St pale brown to yellow, with yellow ground-setulae and black apical setae.

Genitalia. Male terminalia as in figs. 33-34.

Measurements. Length of body, $7.0 \mathrm{~mm}-8.5 \mathrm{~mm}$. Length of wing, 6.5 $7.5 \mathrm{~mm}$.

Distribution. Brazil.

Material examined.

BRAZIL: Nova Teutonia, 27 11'B, 52॰ 23'L, 19.ii.1937, $2 \hat{0}$, BMNH; same locality, 25.v.1939, 1 으, BMNH; Est. Biol. Boracéia Salesópolis, S.P., ii.1972, 2 ô, MZUSP; Bahia, Pirajá, 10.x.1929, 2 ô, USMN; Teresópolis, Rio de Janeiro, iv.1938, 2 ㅇ, USNM.

\section{Hemilucilia townsendi Shannon}

Hemilucilia townsendi Shannon, 1926: 125.

Type mined].

Holotype + of Hemilucilia townsendi Shannon, Peru, in USNM [exaNote on the holotype of Hemilucilia townsendi

Shannon described this species from a single female specimen collected by Townsend at Yahuarmayo, Peru, 11.ii.1910. Dr Gagné was unable to locate this specimen in the USNM collections. However, in accession material loaned to me for study from the USNM I found a single female specimen with type-locality data, labelled by Shannon "Hemilucilia townsendia" [sic]. It is worth noting that this lapsus for townsendi also occurs in Shannon's key. I consider this specimen to be the holotype of $H$. townsendi and I have labelled it accordingly.

\section{Description}

Female only. Very similar to souzalopesi but differing in the following characters. 
Head. Frons equal to 0.25 of the head-width. Fronto-orbital plates with numerous golden hairs. Hairs on facial ridges entirely yellow. 3rd antennal segment 4.6 times as long as 2 nd.

Thorax. Postpronotal lobes yellow.

Legs. Coxae yellow.

Abdomen. T 3 extensively yellow laterally.

Measurements. Length of body, $7.0-8.5 \mathrm{~mm}$. Length of wing, 6.0 $7.5 \mathrm{~mm}$.

Distribution. Peru.

Material examined.

PERU: Previsto, $800 \mathrm{~m}$, 2.vi.1965, J. Schunke, 1 오 BMNH, same locality, 700 m., 28.vi.1965, 1 \% , BMNH.

Hemilucilia melusina, sp. nov.

\section{Description}

Head. Male holoptic; female dichoptic, frons equal to 0.29 of the headwidth. Ground-colour orange-yellow except for upper frons, vertex and upper occiput which are black. Fronto-orbital plates golden-yellow dusted anteriorly, thinly brownish dusted on the upper half and with numerous small black setulae. Frontal vitta matt orange and with numerous small fine pale or dark setulae. Parafacials, genae, genal grooves, and face densely yellow dusted. Upper occiput shining, central part grey dusted. Genal groove with a few pale hairs. Genae densely yellow haired, with some black hairs anteriorly. Male with 7 frontals and a pair of $v t i$ setae. Female with 11-12 frontals, 2 proclinate and 1 reclinate orbitals, $1 v t i$ and 1 vte setae, and a pair of strong outcurved ocellar setae. Vibrissae strong and crossed, inserted just above the fronto-clypeal suture. Facial ridges with fine pale hairs along their whole length. 3rd antennal segment bright orange, basal two orange-yellow, 3rd segment five times as long as 2nd. Arista long-plumose, yellow, with black rays that are as long as the antennal length. Palpi yellow, and slightly dilated apically. Prementum glossy dark brown.

Thorax. Ground-colour black with metallic, purple and blue reflections. Mesonotum thinly grey dusted when viewed at an angle from behind, without distinct vittae. Basisternum and proepisternum dark with pale hairs, pleura otherwise dark-haired. Katepisternum grey dusted basally. Kpst $1+1$. Anatergite bare. Spiracles orange-yellow, posterior one browner in male. Scutellum with a pair of apical, basal and discal setae, and a pair of weaker second basal, discal and lateral setae.

Wings. Basal half of wing infuscated, all veins smoky-brown. Tegula and basicosta dark brown to black. Vein $R_{1}$ ending in costa beyond level of cross-vein r-m. Distance between cross-vein dm-cu and the bend of $\mathrm{M}$ equal to twice the distance between the bend and the wing-margin. Bend of $M$ almost right-angled. Calypters brown with brown marginal hairs; lower one as broad as long. Stem-vein with a few short dark hairs ventrally on the posterior margin. Subcostal sclerite setulose. Ventral surface of costa setulose as far as the subcostal break.

Legs. Brown, fore coxae and all basal tarsomeres paler in female. Fore tibia with a row of weak $a d$ setae and $1 p v$ seta. Mid tibia with $1 a d, 1 p d$, $2 p$ and $1 v$ seta. Hind tibia with a row of weak ad setae (1 or 2 stronger in the row) and $p d$ setae, and 2 av setae. Hind coxa with a row of dark hairs along the posterior margin.

Abdomen. Ground-colour black with metallic blue and purple reflections, without distinct dusting. Ground-setulae black. T 3 and T 4 with a row of weak marginal setae. Ground-setulae on $\mathrm{T} 5$ longer and sparser, marginal setae not distinct.

Genitalia. Male terminalia as in figs. 35-36.

Measurements. Length of body, 10.0 - $11.0 \mathrm{~mm}$. Length of wing, 9.0 $10.0 \mathrm{~mm}$. 
Distribution. Colombia, Peru.

Material examined.

Holotype ô, PERU: Junin Prov., 16 km W San Ramon, fish bait, 1.433 m, asynanthropic, 23.vi.1980, M. Szyska, in University of Illinois at Chicago Circle, Chicago.

Paratypes, 3 . .

PERU: same locality as holotype, 21.vi.1980, $1 \%$, in UIC.

COLOMBIA: Bogota, B. Guevara, 1 , USNM; Villavicencio, Quatquia R., xii.1914, Welcome Bureau of Scientific Research, 1 , BMNH.

\section{Genus Cochliomyia Townsend *}

Callitroga Brauer, 1883: 74. [See discussion below].

Cochliomyia Townsend, 1915: 646.

Type-species of Callitroga: Musca macellaria Fabricius, 1775, by original designation.

\section{Diagnosis}

Cochliomyia can be distinguished from all other New World Chrysomyini by the short filiform palpi.

\section{Description}

Male holoptic or subholoptic, female dichoptic. Female frontal vitta setulose. Genal groove with pale hairs. Vibrissae inserted well above the frontoclypeal suture. Thorax and abdomen metallic blue or green, thoracic vittae distinct. Presutural $d c$ and $a c r$ setae absent or inconspicuous, but $d c$ distinguishable in some species. Anterior presutural sa seta absent or inconspicuous. Acr $0+2$, the anterior one weaker. Lower calypter haired basally, outer margin lobed, inner margin adjacent to scutellum. Costa setulose ventrally to subcostal break. Male aedeagus with long extended paraphallus and short complex hypophallus. Female ovipositor of the usual calliphorid-type, telescopic.

\section{Discussion}

The nomenclatural history of this genus and of its species is extremely confused, and one of the purposes of this revision is to stabilise the situation for future work. It is especially important in this case because of the medical, veterinay and economic importance of the species.

The name Callitroga was originally a manuscript name given by Schiner to specimens in his collection but never published. Brauer (1883: 74) published the name in his treatise on larval habitats, with reference to the species Calliphora anthropophaga Lesbini, Weyenbergh \& Conil. He stated that $C$. anthropophaga was the same as Compsomyia macellaria and Lucilia hominivorax, and that this species (under any of these three names) was referred to Lucilia by Osten Sacken, Callitroga by Schiner and Musca by earlier authors. The name Callitroga was therefore first published in synonymy and up until 1964 the correct course was to treat it as invalid under Article 11d of the International Code of Zoological Nomenclature. However, an emendment from 1964 validates any name published in synonymy before 1961 if it has been treated as an available name and cited with its original date and author. Callitroga fulfils these conditions, as Hall (1948: 120) used this name for his screwworm species. Strictly speaking, therefore, Callitroga should now be used as the name for the genus at present referred to as Cochliomyia. However, all recent publications refer to the genus as Cochliomyia, including several major catalogues and bibliographies, and as the species are of such importance it is clearly preferable that the name Cochliomyia should continue in use. An application has recently been made to the International Comission

* This section was left unfinished by the author. It has been completed by A. C. Pont together with Dr. R. J. Gagné, whose generous co-operation and advice is here gratefully acknowledged. Adequate descriptions of the species are given by Hall (1948: $120 \mathrm{ff}$.). 
on Zoological Nomenclature to suppress the name Callitroga (Melville, in press).

Cochliomyia is an endemic New World genus containing four distinct species. Two of these are confined to the West Indies and adjacent parts of the mainland; one is a widespread species, ranging from Argentina to southern Canada, but especially abundant in the tropical regions; and the fourth is the New World screwworm fly, ranging from Argentina to, presently, central Mexico where it is being further restricted by an eradication programme. All four species possess two morphological characters unique in the Calliphoridae: the palpi are short and filiform, and the male aedeagus (figs. 37-44) has an extremely elongate paraphallus and a complex distiphallus. These features appear de novo in Cochliomyia, as there is no suggestion of such developments in other Chrysomyine genera of the Old or New World. However, apart from the strongly vittate thorax, which is often found in New World Calyptrate Diptera, the general appearance is that of other Chrysomyini and the species could certainly not be placed elsewhere in the family. Striking individual morphological adaptations, with the retention of the basic recognisable Chrysomyine form, are not unusual in this tribe: Chrysomya albiceps (Wiedemann) has peculiar genitalia and a very unusual predatory larva, $C$. polymita Villeneuve (Africa) has an incised membraneous fifth tergite in the female, and C. villeneuvei Patton (Oriental) and Chrysopyrellia Séguy (Madagascar) have femoral and abdominal modifications.

The taxonomy of the species has been very confused, mainly because of misidentifications of, and mis-applications of names to, the important screwworm species, $C$. hominivorax. As this species is an obligatory wound parasite it is not often encountered in the field or in collections, which is generally true of all mammal parasites. It is also difficult to rear, without special techniques, species that infest wounds in living tissue, and the secondary infestation by saprophagous species often gives rise to the incorrect identification of the true offender. Reviews of the various misidentifications are given below under individual species.

\section{KEY TO SPECIES OF COCHLIOMYA TOWNSEND}

1. Upper anterior part of genae with a few or numerous short black setulae. 5th tergite coppery, contrasting in colour with the preceding tergites. Thoracic vittae extending on to scutellum ....

Genae with entirely yellow setulae. 5th tergite concolourous with the preceding tergites. Thoracic vittae not extending to the scutellum

2. 5th tergite evenly dusted. Parafacials yellow dusted. Occiput with pale hairs only. Male with a pair of proclinate orbital setae at the level of anterior ocellus .............. minima Shannon

5 th tergite with a pair of median dorsal silvery dusted spots. Parafacials silvery dusted. Occiput with a few or numerous short dark setulae above. Male without orbital setae .. aldrichi Del Ponte

3. Fronto-orbital plates with black setulae. Postgenal setae (beard) golden yellow. Fifth tergite without lateral dusted spots. Female basicosta dark brown .............. hominivorax (Coquerel)

Fronto-orbital plates with pale hairs. Postgenal setae (beard) pale yellow, not golden yellow. Fifth tergite with a pair of distinct lateral silvery-dusted spots. Female basicosta yellow .......... macellaria Fabricius

\section{Cochliomyia minima Shannon}

Cochliomyia minima Shannon, 1926: 124.

Type

Holotype $\hat{o}^{\hat{A}}$ of Cochliomyia minima Shannon, West Indies, S. Domingo Island (Dominican Republic), in USNM. [Examined.] 


\section{Description}

See Hall (1948: 148). Male terminalia as in figs. 37-38.

Distribution

Florida, Jamaica, Cuba, Dominican Republic, Puerto Rico, Virgin Islands. Material examined

FLORIDA: Stock I., Monroe Co., 1954, 1 으, USNM; Key West, 6.ii.1969, 1 \% , USNM.

JAMAICA: Hope Kingston, 16.iii.1960, 3ㅇ, USNM; Spanish Town, vii.1911, 1 \% , BMNH.

DOMINICAN REPUBLIC: San Francisco Mts, 5.ix, ơ holotype, $q$ allotype, $1 \hat{o}$ paratype, USNM.

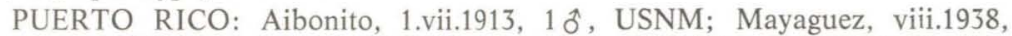
$1 \hat{\sigma}, 2$ ㅇ, USNM, and 1-31.viii.1953, $1 \hat{\sigma}, 2$, , USNM, and 1-31.viii.1953, $1 \hat{0}, 1 \%$, BMNH; Carolina, reared from maggots in dog, $2 \hat{\sigma}$, USNM.

VIRGIN ISLANDS: St. Thomas, 30.xi.1953, 1 , USNM.

Bionomics

Adults have been collected on human faeces, meat and fruit in Cuba (Gregor, 1975), and were also implicated in a case of primary myiasis of a dog in Puerto Rico.

\section{Cochliomyia aldrichi Del Ponte}

Cochliomyia aldrichi Del Ponte, 1938: 274.

Cochliomyia laniaria, authors, nec Wiedemann [misidentifications].

Type

Lectotype $\hat{\delta}$ of Cochliomyia aldrichi Del Ponte, Florida, Key West, in USNM; see designation below.

Lectotype designation for Cochliomyia aldrichi

Del Ponte proposed aldrichi as a "new name" for material misidentified by Aldrich (1925: 18) as laniaria (Wiedemann). C. aldrichi should correctly be regarded as a new species rather than a replacement name, and the material listed by Aldrich as laniaria is therefore the syntypic series of aldrichi Del Ponte. I received for study from the USNM $20^{\hat{\sigma}}$ and $2 \%$ from Aldrich's series: $2 \hat{\sigma}$ and $1 \%$ labelled "Key West, Fla. Jan. 31/69", and $1 \%$ simply labelled "Fla." In addition, there are $4 \delta$ and $5 q$ in the BMNH, labelled "San Salvador, Bah., 1923?, P. Bartsch Coll.", which are also part of the series studied by Aldrich. I consider all these specimens to be syntypes and herewith designate a $\delta$ from the USNM as lectotype and the other specimens as paralectotypes. All of them belong to aldrichi as defined here.

Description

See Hall (1948: 123). Male terminalia as in figs. 39-40.

Distribution

Florida, Bermuda, Bahamas, Cuba, Puerto Rico, San Salvador, Virgin Islands, Cayman Islands.

Material examined

BAHAMAS: New Providence, v.1952, 5 $\%$, USNM; Nassau, 14.xii.1912, $10 \hat{0}, 2$ ㅇ, USNM.

CUBA: Pinar d. Rio, 9-24.ix.1913, 1 ઠิ , USNM; Guantanamo, 4-8.x.1913,

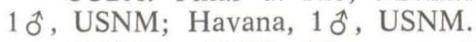

PUERTO RICO: Mayaguez, 1-31.viii.1958, 1 ㅇ, USNM, and 6.i.1932, 1 운, USNM; Mona I., 21-26.ii.1914, 1 \%, USNM, 22.xi.1955, $3 \hat{0}, 2$, USNM, 20.x.1955, 1 , USNM, 1.iv.1940, 1 , USNM. 
SAN SALVADOR: Bah, 1923, $4 \hat{0}, 5 \%, \mathrm{BMNH}, 11 \hat{0}, 28 \%$, USNM.

VIRGIN ISLANDS: St Thomas, 25.xi.1925, $1 \hat{\delta}$, USNM.

CAYMAN ISLANDS: Little Cayman, Crawl Bay, 14.vii.1975, 10 , BMNH; Cayman Brac, $\mathrm{N}$ coast of Stakes Bay, 22.v.1938, 1 ô, BMNH.

\section{Bionomics}

Adults of this species have been collected on fresh horse manure and carrion, especially dead fish and mollusca.

\section{Cochliomyia hominivorax (Coquerel)}

Lucilia hominivorax Coquerel, 1858: 173.

Compsomyia homicida, erroneous subsequent spelling.

Calliphora infesta Philippi, 1861: 513.

Calliphora anthropophaga Lesbini, Weyenbergh \& Conil, 1878: 71.

Somomyia fulvobarbata Bigot, 1888: 598.

Cochliomyia americana Cushing \& Patton, 1933: 539.

\section{Types}

Holotype $\boldsymbol{o}^{\lambda}$ of Lucilia hominivorax Coquerel, Cayenne, in BMNH [examined]. Holotype $\hat{\sigma}$ of Somomyia fulvobarbata Bigot, Uruguay, in BMNH [examined.] Lectotype $\hat{o}$ of Cochliomyia americana Cushing \& Patton, Menard, Texas, in USNM; see designation below. Types of Calliphora infesta Phillippi and Calliphora anthropophaga Lesbini, Weyenbergh \& Conil, lost and probably destroyed.

Note on the holotype of Lucilia hominivorax and the name homicida

Coquerel described the species hominivorax from a single male reared from a case of myiasis of the frontal sinuses of a man in Cayenne. In the BMNH I found a single male from Cayenne, above a Bigot drawer label. There is a puparium attached to the specimen; it is labelled ' $\mathrm{S}$. America. Fr. Guiana, Cayenne", "ex Coll Bigot BM 1930 - 221", "Brauer WIEN CVIII (No 217)". The drawer label reads "S. homicida 10, 2 o , Lucilia id Typ. Cayenne, Coquerel". On this label the " 1 " and " $2 \%$ " are obvious later additions, being in a different hand, probably Verrall's. I believe this male to be the type of hominivorax and that Bigot altered the name from hominivorax to homicida when arranging it in his collection.

Furthermore, I found 2 females in the main series of hominivorax in the $\mathrm{BMNH}$ collection, with data identical to that of the male. These specimens are not types, but were seen by Brauer when he studied the Bigot collection whilst it was in Verrall's possession. Unfortunately Brauer (1899: 525) published the species name as it appears on the Bigot drawer label, i.e. as homicida. In the present paper, homicida is treated as an erroneous subsequent spelling.

\section{Note on the holotype of Somomyia fulvobarbata}

Bigot described this species from a single male from Montevideo. This specimen is in the BMNH above a Bigot drawer label " $\mathrm{C}$. Fulvobarbata $\hat{o}$, Somomyia, Montevideo. J. Bigot". It has no data labels; it has been removed from its pin and gummed to a celluloid point, and is rather damaged and damp as a result. The terminalia have been removed and are mounted dry on a card point.

\section{Lectotype designation for Cochliomyia americana}

Cushing \& Patton described this species from 150 males and 95 females reared from wounds in cattle at Menard, Texas. Not all these syntypes have been located, but 58 are in BMNH, from Patton's collection, and $3 \hat{\sigma}$ and $4 \%$ are in USMN. A male in USNM originally labelled as "type" has been labelled and is herewith designated as lectotype, and the remaining syntypes have been labelled as paralectotypes. 


\section{Description}

See Hall (1948: 125). Male terminalia as in figs. 41-42.

\section{Distribution}

Southern states of USA. Central America and northern areas of South America, with some records from further south.

\section{Material examined}

Specimens in BMNH and USNM are from: U.S.A. (Arizona, New Mexico, Texas, Florida, Georgia, Missouri, Iowa, Illinois, Indiana, Washington D.C.), Cuba, Jamaica, Dominican Republic, Puerto Rico, Virgin Is, St. Lucia, Mexico, Costa Rica, Panama, Colombia, Peru, Trinidad, Guyana, French Guiana, Brazil, Uruguay, Argentina (Bompland), Chile (Valparaiso and Limache).

\section{Bionomics}

This species is a irue obligatory wound parasite ("primary screwworm") and is a serious pest of cattle in the New World. For some time there was much confusion over the identification of this species, but its distinction from the commoner species, macellaria, in biology and morphology, was conclusively established by Cushing \& Patton (1933). An account of the biology, with illustrations of all stages, is given by Laake, Cushing \& Parish (1936).

Screwworm myiasis can be fatal, and because of the financial losses to the U.S. cattle industry an extensive eradication programme was instigated in 1973. Previous to this a number of campaigns using chemical control had been tried, but none was successful. The fly is now under control using a sterile male technique, in which millions of irradiated males are released into the affected areas. This method has held the screwworm more or less in check throughout the southern states of the USA, and the programme is being continued into Mexico to prevent reinvasion.

Further information on all aspects of control, biology, distribution and ecology can be found in the annotated bibliography of this species published by the USDA (Snow, Siebenaler \& Newell, 1981) and Guimarães et al. (1983).

\section{Cochliomyia macellaria (Fabricius)}

Musca macellaria Fabricius 1775: 776.

Musca taniaria Wiedemann 1830: 406, lapsus.

Musca laniaria Wiedemann 1830: 683, justified correction of taniaria.

Chrysomya viridula Robineau-Desvoidy, 1830: 445.

Chrysomya affinis Robineau-Desvoidy, 1830: 445.

Chrysomya tibialis Robineau-Desvoidy, 1830: 446.

Chrysomya lherminieri Robineau-Desvoidy, 1830: 446.

Chrysomya alia Robineau-Desvoidy, 1830: 447.

Chrysomya socia Robineau-Desvoidy, 1830: 447.

Chrysomya decora Robineau- Desvoidy, 1830: 448.

Chrysomya plaei Robineau-Desvoidy, 1830: 448.

Chrysomya lepida Robineau-Desvoidy, 1830: 448.

Calliphora violacea Macquart, 1843: 128(285).

Lucilia vittata Macquart, 1843: 141(298).

Lucilia durvillei Macquart, 1843: 142(299).

Musca certima Walker, 1849: 873.

Musca phauda Walker, 1849: 896.

Lucilia cyanicolor Rondani, 1850: 178, replacement name for Calliphora violacea Macquart.

Calliphora tristriata Verhuell, 1850: 273.

Calliphora tibialis Macquart, 1851: 215(242).

Lucilia rubrifrons Macquart, 1851: 223(250) 
Musca turbida Walker, 1853: 336.

Musca fasciata Walker, 1853: 337.

Lucilia picicrus Thomson, 1869: 543.

Lucilia curvipes Thomson, 1869: 544.

Lucilia porticola Thomson, 1869: 544.

Lucilia quadrisignata Thomson, 1869: 544.

Somomya flavigena Bigot, 1877: 249.

Somomya aztequina Bigot, 1877: 252.

Somomyia iridicolor Bigot, 1888: 599.

Chrysomya lynchi Lahille, 1915: 12.

Cochliomyia fontanai Garcia, 1952: 71.

Types

Holotype $q$ of Musca macellaria Fabricius, "America", in UZMC. Syntypes of Musca laniaria Wiedemann, Brazil, not found in MNHU. Holotype $q$ of Chrysomya viridula Robineau-Desvoidy, Brazil, in MNHNP. Holotype 9 of Chrysomya affinis Robineau-Desvoidy, Brazil, in MNHNP. Holotype $q$ ? of Chrysomya tibialis Robineau-Desvoidy, Jamaica, probably destroyed, not in MNHNP. Holotype $q$ of Chrysomya lherminieri Robineau-Desvoidy, Carolina, in MNHNP. Holotype $\hat{\sigma}$ of Chrysomya alia Robineau-Desvoidy, Brazil, in MNHNP. Holotype $q$ of Chrysomya socia Robineau-Desvoidy, Brazil, in MNHNP. Holotype $\delta^{\star}$ ? of Chrysomya decora Robineau-Desvoidy, 'Antilles', probably destroyed, not in MNHNP. Holotype $\hat{o}$ of Chrysomya plaei, 'Antilles', in MNHNP. Holotype $\hat{o}$ of Chrysomya lepida Robineau-Desvoidy, Brazil, in MNHNP. Holotype + of Calliphora violacea Macquart, 'Africa' [actually Chile], in MNHNP. Holotype $\subsetneq$ of Lucilia vittata Macquart, 'NouvelleHollande' [actually S. America] in MNHNP. Holotype $q$ of Lucilia durvillei Macquart, Peru, in MNHNP. Holotype $q$ of Musca certima Walker, Floride, BMNH. Holotype ô of Musca phauda, Galapagos Islands, in BMNH. Holotype $\hat{\sigma}$ of Calliphora tibialis Macquart, Brazil, in MNHNP. Holotype $q$ of Lucilia rubrifrons Macquart, Argentina, in MNHNP. Holotype $\delta / \% ?$ of Musca turbida Walker, probably destroyed, not in BMNH. Holotype $q$ of Musca fasciata Walker, Brazil, in BMNH. Lectotype $q$ of Lucilia picicrus Thomson, Panama, in NRS; see designation below. Holotype $q$ of Lucilia curvipes Thomson, 'Brazil' [Rio de Janeiro, see Persson, 1972] in NRS. Lectotype $q$ of Lucilia porticola Thomson, 'Callao' [Lima, Peru, see Persson, 1972], in NRS; see designation below. Lectotype $\hat{\sigma}$ of Lucilia quadrisignata Thomson, Galapagos Islands, in NRS; see designation below. Holotype $q$ of Somomya flavigena Bigot, Mexico, in BMNH. Lectotype of of Somomya aztequina Bigot, Mexico, in BMNH; see designation below. Lectotype $q$ of Somomyia iridicolor Bigot, Cuba, in $\mathrm{BMNH}$; see designation below. Holotype $\uparrow$ of Cochliomyia fontanai Garcia, Belgrano, Argentina, in Instituto de Entomologia Sanitaria, Buenos Aires [not examined]. Location of types of Calliphora tristriata Verhuell and Chrysomyia lynchi Lahille not known. [All types examined, except where stated.]

Note on the holotype of Musca macellaria

Fabricius described this species from specimens of unspecified sex and number from 'America'. From UZMC I received for study four specimens found under this name: $1 \%$ in very poor condition labelled "macellaria", $1 \hat{0}$ labelled "M-macellaria", and two unlabelled females. Dr. V. Michelsen (in litt.) informs me that the first female, in poor condition, is the only specimen from Fabricius' own collection (Kiel) and should be considered to be the holotype, as the original description does not say 'Mus'. Because of the similarity of the pin, the holotype clearly belongs to the same series as the other three specimens, but it should be inferred that Fabricius originally acquired one specimen for his own collection and that he based his description solely on that specimen. The other three specimens therefore have no type status, though Townsend (1937: 125) regarded them as types. 


\section{Note on the syntypes of Musca laniaria}

Wiedemann proposed this name for a variety of macellaria, which he found represented by several specimens from Brazil in Hoffmannsegg's collection where they were labelled as 'Musca taniaria' [sic, corrected by Wiedemann on p. 683 to laniaria]. From MNHU I received 1 of macellaria for study, which is the only specimen that Dr. Schumann could find from Hoffmannsegg's collection. It has two green labels, 'Bras.' and 'maxillaria. F.' [sic]. It is immature, but otherwise in quite good condition. If it is indeed one of the syntypes of laniaria, then the alleged differences between laniaria and macellaria are not at all obvious. It agrees with the interpretation of Cochliomyia macellaria given here.

\section{Note on the holotype of Musca viridula}

Robineau-Desvoidy described this srecies from material of unspecified sex and number from Brazil, collected by M. Auguste Saint-Hilaire. From MNHNP I received for study a single female found under this name, labelled 'Chrysomya viridula R.D.' by Robineau-Desvoidy himself and 'du midi de la Capit: de Goyaz'. I consider this specimen to be the holotype and have labelled it accordingly. It agrees with the interpretation of Cochliomyia macellaria given here.

\section{Note on the holotype of Chrysomya affinis}

Robineau-Desvoidy described this species from specimens of unspecified number and sex from Brazil, collected by M. Auguste Saint-Hilaire. From MNHNP I received for study a single female found under this name, labelled 'Chrysomya affinis R.D.' by Robineau-Desvoidy himself and 'Brésil. Delalande', '206' and by Macquart 'macellaria var'. I consider this specimen to be the holotype, although the collecting data are not as given by Robineau-Desvoidy, because Delalande and Saint-Hilaire were companions on collecting trips in $\mathrm{S}$. America. I have labelled the specimen as holotype, and it agrees with the interpretation of Cochliomyia macellaria given here.

\section{Note on the holotype of Chrysomya lherminieri}

Robineau-Desvoidy described this species from specimens of unspecified sex and number from Carolina, collected by Dr. Lherminier. From MNHNP I received for study a single male found under this name, labelled "Chrysomya Lherminieri. R.D." by Robineau-Desvoidy himself, '207', and 'Caroline. l'herminier'. I consider it to be the holotype and have labelled it accordingly. It agrees with the interpretation of Cochliomyia macellaria given here.

Note on the holotype of Chrysomya alia

Robineau-Desvoidy described this species from material of unspecified sex and number from Central Brazil, collected by M. Auguste Saint-Hilaire. From MNHNP I received for study a single male found under this name, labelled 'Chrysomya alia. R.D.' by Robiněau-Desvoidy himself, '208', 'du nord de la Capite. de St. Paul', and by Macquart 'macellaria, var.'. Although the locality is obviously not in Central Brazil, this specimen can hardly be anything but the holotype, and I have labelled it accordingly, concluding that RobineauDesvoidy must have made a slip when recording the locality. It agrees with the interpretation of Cochliomyia macellaria given here.

\section{Note on the holotype or Chrysomya socia}

Ronibeau-Desvoidy described this species from material of unspecified sex and number from Brazil, collected by M. Auguste Saint-Hilaire. From MNHNP I received for study a single female found under this name, labelled 'Chrysomya socia. R.D.' by Robineau-Desvoidy himself, '210', 'du nord de la Capite. de St. Paul', and by Macquart 'macellaria, var.'. I consider it to be the holotype and have labelled it accordingly. It agrees with the interpretation of Cochliomyia macellaria given here. 
Note on the holotype of Chrysomya plaei

Robineau-Desvoidy described this species from specimens of unspecified sex and number from the 'Antilles', collected by M. Plée. From MNHNP I received for study a single headless male found under this name. It is labelled 'Chrysomya plaei R.D.' by Robineau-Desvoidy himself, "Plée 1826', '211', and by Macquart 'macellaria var.'. I have labelled it as holotype, and it agrees with the interpretation of Cochliomyia macellaria given here.

Note on the holotype of Chrysomya lepida

Robineau-Desvoidy described this species from specimens of unspecified sex and number from Brazil, coliected by Auguste Saint-Hilaire. From MNHNP I received for study a single headless male found under this name, labelled 'Chrysomya lepida R.D.' by Robineau-Desvoidy himself and 'du Nord de la Capite de St. Paul', '212', and by Macquart 'macellaria, var.'. I have labelled it as holotype, and it agrees with the interpretation of Cochliomyia macellaria given here.

Note on the holotype of Calliphora violacea

Macquart described this species from an unspecified number of females from Africa. From MNHNP I received for study a single female found under this name. It agrees with the original description in all details except for the locality. I agree with Sabrosky (1953: 38) that the locality is an error, as Macquart mentions the thoracic white bands which do not occur in any Afrotropical species of 'Calliphora'. The description was obviously based on a specimen of New World origin, i.e. on the specimen now before me. It is labelled 'No. 48 Calliphora violacea' in Macquart's hand, a small green disc with '953.37', and by Séguy "Calliphora violacea. Paralucilia'. The accession number refers to a collection made by Gay in Chile. I have therefore labelled this rather dirty, dusty and shrunken female as the holotype. It agrees with the interpretation of Cochliomyia macellaria given here.

Note on the holotype of Lucilia vittata

Macquart described this species from an unspecified number of females from Nouvelle-Hollande [Australia], collected by M. Dumont-Durville. From MNHNP I received for study a single female found under this name. The locality is in error as the specimen is a New World Chrysomyine. It is labelled. 'nouv. holl. Durville', '953', 'No. 65 Lucilia vittata' in Macquart's hand, 'conica', and by Séguy 'Cochliomyia macellaria F.'. The specimen is in fair condition but has the abdomen, left mid and hind legs missing. I have labelled it as holotype. It agrees with the interpretation of Cochliomyia macellaria given here.

\section{Note on the holotype of Lucilia durvillei}

Macquart described this species from an unspecified number of females from Payta, Peru, collected by M. Dumont-Durville. From MNHNP I received for study a single $\$$ found under the name peruviana in the collection; it is labelled 'Payta de Perou, Durv.', 'Lucilia peruviana' by Macquart, and by Séguy 'Cochliomyia macellaria F.'. I agree with Sabrosky (1953: 37) in considering that this is the holotype of durvillei and that peruviana is a Macquart MS name. I have labelled it as holotype. It agrees with the interpretation of Cochliomyia macellaria given here.

Note on the holotype of Musca certima

The single $q$ in the $\mathrm{BMNH}$ is considered to be the holotype. It is in good condition, and is labelled as collected in Florida by Doubleday. It agrees with the interpretation of Cochliomyia macellaria given here.

Note on the holotype of Musca phauda

Walker described this species from a male specimen collected by Darwin in the Galapagos Islands. The holotype in the BMNH is in good condition, with all parts present; the terminalia have been removed (probably by Auber- 
tin) and mounted separately. It agrees with the interpretation of Cochliomyia macellaria given here.

\section{Note on the holotype of Calliphora tibialis}

Macquart described this species from an unspecified number of males from Rio de Janeiro, collected by M. d'Orbigny. From MNHNP I received for study two males and one female found under this name. One of the males is labelled '9501 34', '5', 'Calliphora tibialis ô Macq.n. sp.' by Macquart himself, and with a recent label 'Museum Paris, Rio de Janeiro. D'Orbigny 1834'. The other two specimens do not have the correct type data nor do they fit the description. I have labelled the first male as holotype. It agrees with the interpretation of Cochliomyia macellaria given here.

\section{Note on the holotype of Lucilia rubrifrons}

Macquart described this species from an unspecified number of females from Buenos Aires. From MNHNP İ received for study a single female found under this name. It is labelled ' 130 40', 'Lucilia rubrifrons o Macq. n. sp.' by Macquart. Although the accession number refers to material from Colombia, I believe that this female must be the holotype and I have labelled it accordingly. It agrees with the interpretation of Cochliomyia macellaria given here.

Note on the holotype of Musca fasciata

Walker described this species from Brazil, from Saunder's collection. A female in the BMNH labelled 'Brazil', 'Ex coll. Saunders 68.4', 'fasciata' in Walker's hand, 'identified as the type by E.E. Austen', is considered to be the holotype and has been labelled accordingly. It agrees with the interpretation of Cochliomyia macellaria given here.

\section{Lectotype designation for Lucilia picicrus}

Thomson described this species from an unspecified number of females from Panama. From NRS I received for study 3 females found under this name, all labelled 'Panama', 'Kinb' $[=$ Kinborg, the collector $]$. One of them is also labelled ' 82 ', 'Lucilia picicrus Th.' and 'Typus'. I consider these specimens to be syntypes, and they are all in good condition. I have labelled and designate herewith the specimen with the 'Typus' label as lectotype and the other two specimens as paralectotypes. All three specimens agree with the interpretation of Cochliomyia macellaria given here.

Note on the holotype of Lucilia curvipes

Thomson described this species from an unspecified number of females. From NRS I received for study a single female found under this name, labelled 'Rio Jan', 'Kinb', 'Typus'. I consider this specimen to be the holotype, and have labelled it accordingly. It agrees with the interpretation of Cochliomyia macellaria given here.

\section{Lectotype designation for Lucilia porticola}

Thomson described this species from an unspecified number of females from Callao, Peru. From NRS I received for study three females found under this name, all labelled 'Callao' and 'Kinb'. One is also labelled 'Lucilia porticola Th', 'Typus', '86'. They are in fair condition, with all parts present but the setulae rubbed. They are all undoubtedly syntypes. I have labelled and designate herewith the specimen labelled 'Typus' as lectotype and the other two specimens as paralectotypes. All three specimens agree with the interpretation of Cochliomyia macellaria given here.

\section{Lectotype designation for Lucilia quadrisignata}

Thomson described this species from an unspecified number of males from the Galapagos Islands. From NRS I received for study two males found under this name, labelled 'Ins Gallop' and 'Kinb'. One is also labelled 'Typus', '85'. 'Lucilia quadrisignata Th'. Both are in excellent condition and are undoubtedly syntypes. I have labelled and designate herewith the speci- 
men labelled 'Typus' as lectotype and the other specimen as paralectotype. Both specimens agree with the interpretation of Cochliomyia macellaria given here.

Note on the holotype of Somomya flavigena

Bigot described this species from an unspecified number of females from Mexico. Under this name in the BMNH collection I found a single female from Bigot's collection labelled 'genitalia on slide'. The accompanying Bigot drawer label reads 'S. flavigena of g. Chrysomyia R.D. Mexic. J. Bigot'. The specimen is in good condition, but has the left mid leg and the tip of the abdomen [on slide] missing. I have labelled it as holotype. It agrees with the interpretation of Cochliomyia macellaria given here.

\section{Lectotype designation for Somomya aztequina}

Bigot described this species from an unspecified number of both sexes from Mexico. Under this name in the MBNH I found four males and six females from Bigot's collection, labelled 'Brauer WIEN CVIII [우 (No 192) [ô] (193)' and with a Bigot drawer label 'S. aztequina o , g Chrysomyia R.D. Mexic., J. Bigot'. All the specimens are in fair condition. I have labelled and designate herewith the only male with all legs present as lectotype and the other nine as paralectotypes. All the specimens agree with the interpretation of Cochliomyia macellaria given here.

\section{Lectotype designation for Somomyia iridicolor}

Bigot described this species from two males from Cuba. In the Bigot collection in the BMNH I found two males labelled 'Australia ex coll Bigot', one with an additional label 'Lucilia iridicolor, J. Bigot, Austral.'. These two specimens are of New World origin, and I believe that they are Bigot's syntypes of iridicolor and that the locality 'Austral.' is a labelling error by Bigot. I have labelled and designate herewith the specimen with Bigot's determination label as lectotype and the second specimen as paralectotype. Both specimens agree with the interpretation of Cochliomyia macellaria given here.

Note on Cochliomyia fontanai

Garcia separated his species from macellaria chiefly on the basis of size and colour characters, which are quite variable in macellaria. He drew details of the male genitalia of fontanai and macellaria for comparative purposes, but differences between them are practically non-existent in his drawings and are meaningless in the context of the known variation in macellaria, particularly as his specimens were immature and not fully sclerotised (see Mariluis, 1982: 22).

\section{Description}

See Hall (1948: 138). Male terminalia as in figs. 43-44; see also Gagné \& Peterson (1982).

\section{Distribution}

Southern North America (Oregon to Quebec \& Maine), Central America and the Caribbean, southwards to Chile and Argentina.

\section{Material examined}

Specimens in BMNH and USNM are from:

Canada (Ontario), USA (California, Arizona, New Mexico, Texas, Kansas, Missouri, Arkansas, Louisiana, Tennessee, Mississippi, Alabama, North and South Carolina, Georgia, Florida, Wyoming, South Dakota, Nebraska, Minnesota, Iowa, Illinois, Michigan, Indiana, Ohio, Virginia, Maryland, Washington D.C., Pennsylvania, New Jersey, New York, Connecticut, Massachusetts, New Hampshire), Bermuda, Bahamas, Cuba, Cayman Is, Jamaica, Haiti, Dominican Republic, Puerto Rico, Virgin Is, St. Kitts, Antigua, Montserrat, Dominica, St. Vincent, Barbados, Grenada, Mexico, Belize, Guatemala, Honduras, Costa Rica, Panama, Colombia, Ecuador, Peru, Bolivia, Curacao, Venezuela, Trinidad, Tobago, Guyana, Brazil, Paraguay, Uruguay, Argentina ( $N$ of latitude $\left.35^{\circ} \mathrm{S}\right)$, Chile (Antofagasta and Iquique), Galapagos. 


\section{Genus Compsomyiops Townsend}

Compsomyiops Townsend, 1918: 153.

Myiolucilia Hall, 1948: 109. Syn. n.

Type-species of Compsomyiops: Calliphora fulvipes Macquart, 1843 [ = Chrysomya fulvicrura Robineau-Desvoidy, 1830], by original designation. Type-species of Myiolucilia: Musca lyrcea Walker, 1849 [ = Chrysomya fulvicrura Robineau-Desvoidy, 1830] by original designation.

\section{Diagnosis}

Compsomyiops can be distinguished from all other New World Chrysomyini by the haired parafacials, pubescent greater ampulla and normal-sized palpi.

\section{Description}

Male holoptic or subholoptic, female dichoptic. Parafacials setulose. Female frontal vitta setulose. Genal groove with dark or pale hairs. Vibrissae placed well above the fronto-clypeal suture. Thorax and abdomen metallic blue, purple or green. Thoracic vittae distinct. Presutural $d c$ and acr setae absent. Anterior presutural sa seta absent. Acr $0+1$ (sometimes a weaker second). Lower calypter with long hairs basally; outer margin rounded, inner margin not $(\hat{\sigma})$ or moderately $(q)$ diverging from the line of the scutellum. Costa setulose ventrally to subcostal break. Male aedeagus with a short curving paraphallus and a long extended hypophallus. Female ovipositor of the usual calliphorid-type, telescopic.

\section{Discussion}

Members of this endemic New World genus are easily distinguished from other genera of the tribe by the characters given above. In addition they have a characteristic head-shape, with an inflated frons in the female. The facial ridges are not parallel but curve inwards abruptly at the vibrissae, which are inserted well above the fronto-clypeal suture.

Like other authors working on this genus, I have encountered considerable difficulties in trying to discover useful characters for species definition, and have found it virtually impossible to separate the majority of females into meaningful species. However, I have been able to recognise, and to key with certainty, both sexes of two common species, namely fulvicrura (Robineau-Desvoidy) and callipes (Bigot). Furthermore, I have keyed and recognised three distinct species or groups of species of males, which can be sorted initially using the frontal width and then further divided using less convincing supplementary characters. However, there appears to be some supportive evidence for these divisions when geographical distribution is considered. Females not assigned to the two species fulvicrura and callipes have proved virtually impossible to group: although I have keyed them separately, the divisions are far from convincing.

Using combinations of characters I have been able to construct a key to three distinct groups, though this has only been possible after prolonged and repeated study of the material and is based mainly on a 'feeling' for the genus resulting from this study. Two of these 'species' almost certainly represent more than one species, but I have been unable to find satisfactory characters for a further division. The key given below is only tentative, and the names applied to 'species' should not be interpreted as definitive taxonomic statements except for the common North American callipes and the widespread South American fulvicrura.

The absence of unambiguous characters for species definition and the possibility of geographically defined species-groups suggest recent or active speciation in the genus. Production of a definitive taxonomic solution is always extremely difficult in such a situation. Mello (1968) mainly used colour characters to define his species in this genus (as Paralucilia), including the five that he described as new. I have found colour characters to be of little use, as altitude, geographical location and specimen size all influence 
colour. For instance, high altitude specimens of fulvicrura from Chile and Peru are smaller and always have dark legs, and such specimens were called nigripes by Mello (1968: 184). Mello has also carefully illustrated the male and female head and the male terminalia of each species: although minor differences can be detected in his terminalia drawings, I have been unable to see them in preparations I have made. These differences may not be constant and in any case are of limited or no value to field workers wishing to make an accurate and correct identification.

Hall (1948: 96, 150) correctly recognised two species of this genus (as Paralucillia), namely fulvipes Macquart $[=$ fulvicrura $]$ and wheeleri Hough $[=$ callipes $]$. His and subsequent authors' misinterpretation of the generic name Paralucilia was discussed above (page 124). Shannon (1926) also keyed two species (as Paralucilia), affinis Robineau-Desvoidy $[=$ fulvicrura $]$ and viridula Robineau-Desvoidy [his description suggests that his single specimen is a female of Paralucilia xanthogeneiates sp.n. described above]. Smart (1937) referred to a single species, affinis [= fulvicrura and other species].

\section{KEY TO SPECIES OF COMPSOMYIOPS TOWNSEND}

1. Genae glossy without tiny hairs anteriorly; the margins sharply delimited from the surrounding dusted membranes. Calypters white, only the inner margin of the lower one sometimes darkened. Upper calypter bare or with one or two pale hairs dorsally. $\mathrm{Pa}$ rafacial hairs shorter than those on the fronto-orbital plates, erect and pale. Head dusting silvery-grey. Tergites without lateral metallic patches. Basicosta yellow. Genal and postgenal hairs white ..................... fulvicrura (Robineau-Desvoidy)

Genae glossy, but with tiny hairs anteriorly along the margin; if entirely glossy then calypters infuscated. Upper calypter with fine dark hairs dorsally. Parafacial hairs as long as those on the fronto-orbital plates, proclinate and usually black. Head dusting silvery-yellow to golden. Tergites with or without lateral metallic patches. Basicosta brown or yellow. Genal and postgenal hairs

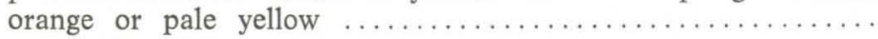

2. Junction of parafacial with fronto-orbital plate (at level of second antennal segment) with a dark shifting spot in male and a thin transverse dark line in female. Basicosta brown. Genae entirely glossy or with a few tiny hairs anteriorly. Kpst $2+1$ (rarely $1+1)$. Calypters infuscated. Male frons equal to width of anterior ocelius; anterior eye-facets slightly enlarged. Female frontal vitta at lunula twice as wide as a fronto-orbital plate; frontal vitta at widest point 3.5 times as wide as a frontoorbital plate at narrowest point. Tergites without metallic la-

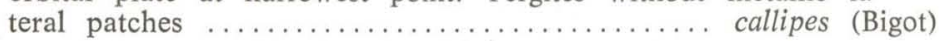

Fronto-orbital plate evenly dusted, without a distinct spot or line at level of second antennal segment. Basicosta usually pale. orange to yellow; but if brown the genae extensively dusted and kpst $1+1$. Colour of calypters variable. Frons and frontal vitta/

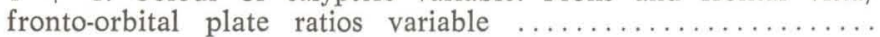

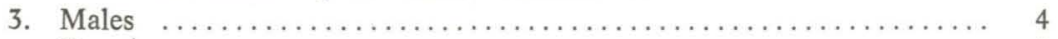

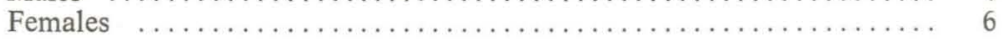

4. Eyes holoptic, the anterior facets greatly enlarged. [Costa Rica, Colombia, Peru, Venezuela $]. . . \ldots \ldots \ldots \ldots \ldots$ verena (Walker)

Eyes subholoptic, anterior facets not unusually large $\ldots \ldots \ldots \ldots 5$

5. Tergites $3-5$ with lateral metallic, coppery patches encroaching well on to the dorsal surface of tergites. Abdominal dusting densely silvery-grey and shifting. Calypters and postgenal setae (beard) pale, aimost white. Parafacial hairs mostly pale. [Ecuador, Peru, Bolivia, Chile $]$................... alvarengai (Mello) 
Lateral metallic patches on tergites $3-5$ confined to the margins and not encroaching on to the dorsal surface. Abdominal dusting white, not shifting, and only appearing dense in extreme posterior view. Lower calypter infuscated, but if pale then genal groove golden dusted. Postgenal setae (beard) pale or golden. Parafacial hairs dark. [Ecuador, Peru, Bolivia] .... boliviana (Mello)

6. Tergites without lateral metallic patches which contrast with the surrounding metallic colouring. [Mexico, Colombia] .. melloi sp.n.

Tergites with lateral metallic patches which contrast with surrounding metallic colouring

7. Frontal vitta at lunula narrower than a fronto-orbital plate at the same level. Calypters dark. Basicosta brownish in some specimens. Metallic abdominal patches confined to the lateral margins of tergites $3-5$; abdominal dusting thin and brownish. [Costa Rica, Colombia; Peru, Venezuela] ...... verena (Walker)

Frontal vitta at lunula equal to or wider than a fronto-orbital plate at the same level. Calypters variable in colour. Basicosta yellow. Abdominal metallic patches variable. [Ecuador, Peru, Bolivia, Chile

8. Lateral metallic spots extending on to dorsal surface of tergites $3-5$. Abdominal dusting dense, silvery and shifting. Postgenal setae (beard) and calypters pale [Ecuador, Peru, Bolivia, Chile]

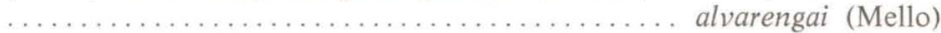

Lateral metallic spots confined to margins and ventral surfaces of tergites 3 - 5. Abdominal dusting white, only appearing dense in extreme posterior view. Postgenal setae (beard) and calypters variable in colour. [Ecuador, Peru, Bolivia] .... boliviana (Mello)

\section{Compsomyiops fulvicrura (Robineau-Desvoidy)}

Chrysomya fulvicrura Robineau-Desvoidy, 1830: 446.

Calliphora fulvipes Macquart, 1843: 229 (132).

Musca lyrcea Walker, 1849: 873.

Musca caruca Walker, 1849: 877.

Musca gamelia Walker, 1849: 878.

?Calliphora annulipes Philippi, 1861: 514.

Lucilia taeniaria Thomson, 1869: 544.

Paralucilia nigripes Mello, 1968: 184. Syn.n.

Types

Lectotype $\subsetneq$ of Chrysomya fulvicrura Robineau-Desvoidy, Montevideo, Uruguay, in MNHNP; see designation below. Lectotype $q$ of Calliphora fulvipes Macquart, Chile, in MNHNP; see designation below. Lectotype $\hat{\sigma}$ of Musca lyrcea Walker, Montevideo, Uruguay, in BMNH; see designation below. Holotype $q$ of Musca caruca Walker, Chile, in BMNH. Holotype $\hat{o}$ of Musca gamelia Walker, Montevideo, Uruguay, in BMNH. Syntypes of Calliphora annulipes Philippi, Santiago, Chile, not in MNHNS and probably destroyed. Lectotype $\delta$ of Lucilia taeniaria Thomson, Buenos Aires, Argentina, in NRS; see designation below. Holotype $\hat{\sigma}$ of Paralucilia nigripes Mello, Boulogne, Buenos Aires, Argentina, in IOC [topotypical ô paratype seen in MNRJ]. [All types examined except where stated.]

Lectotype designation for Chrysomya fulvicrura

Robineau-Desvoidy described this species from specimens of unspecified sex and number from Montevideo. From MNHNP I received for study the three females located under this name. Two of them are headless and were noted by Sabrosky (1953) as syntypes. I agree with this view, as both specimens have the type data 'Montevid 7bre 9bre 1820 ' on a small white 
disc. In addition, one is labelled by Robineau-Desvoidy 'Chrysomya fulvicrura R.D.' and has a printed tag '962'. This specimen is in poor condition, being dirty and dusty, and having the right fore leg, right mid leg below middle of tibia, left fore leg, and left hind leg missing. The second specimen has the additional labels 'fulvicrura' in Macquart's hand, a handwritten '217' and a printed ' 961 '. It has all legs present, but is dirty and dusty and has the left wing missing. I have labelled and designate herewith the specimen with the left wing missing and the Macquart determ:nation label as lectotype and the specimen labelled by Robineau-Desvoidy as paralectotype. Both specimens agree with the interpretation of Compsomyops fulvicrura given here. The third specimen is labelled 'Chrysomya fulvicrura (Lat.) R.D. Bresil' and is not considered to be a syntype.

\section{Lectotype designation for Calliphora fulvipes}

Macquart described this species from an unspecified number of males from the Paris Museum. However, the situation is not as clear as this statement suggests: his description is headed ' $\hat{\sigma}$ ' but he then refers to an illustration that is definitely of a female; moreover, he describes the frons as a dusted band with metallic reflections, and does not refer to it as linear as he does in other descriptions of males. On page 286 of the same work (1843) he mentions the same figure (plate 16, fig. 3) as being of rufipes, and does so again in the legend on page 443. The figure shows a fly with dusted vittae on the thorax and certainly refers to fulvipes and not rufipes. The situation becomes even more confused when reference is made to the types in MNHNP. In the Macquart collection I found two drawer labels for rufipes, in different parts of the collection. The first (Box 17, no. 687) had a single male specimen of an Austro-Oriental Calliphora species labelled 'Java' and by Macquart 'Calliphora rufipes'. This specimen agrees with the description of Calliphora rufipes Macquart and is undoubtedly the holotype. Under the second drawer label (Box 59, No. 1828) I found three specimens of obvious South American origin. One is a toxotarsine and has a black head, disagreeing with the orig nal description of fulvipes; it cannot be a syntype. The other two, both females, agree with Macquart's description of fulvipes, and have the locality data of that species. However, one of them is labelled by Macquart 'No 45 Calliphora rufipes', but neither can actually be rufipes because they differ from the description in many details and do not have the correct locality data. I believe that the errors made by Macquart in his references to figure 3 of plate 16 (1843) stem from the mislabelling of this specimen, and I consider that the two female specimens found under the second drawer label rufipes (No. 1828) are in fact syntypes of Calliphora fulvipes.

The f'rst of them is rather dirty, dusty, and rubbed; the right wing has been glued on; and the fore and mid legs are missing. It has a small green disc '670.37' [Chile, Gay]; 'No 45 Calliphora rufipes' [Macquart's hand]; 'Paralucilia violacea Macq. E. Séguy (det [crossed out]) 19'. The second specimen is very rubbed, with most setulae missing and the dusting rubbed off; the right mid leg is missing. It has a small green dise ' 15.43 ' [Chile, Gay]. I have labelled and designate herewith the specimen labelled ' 15.43 ' as lectotype and the other specimen as paralectotype. Both specimens agree with the interpretation of Compsomyiops fulvicrura given here.

\section{Lectotype designation for Musca lyrcea}

Walker described this species from an unspecified number of male specimens from Montevideo collected by Charles Darwin. In the BMNH I found two male specimens under this name, both with type data, labelled 'M. Video' and 'Monte Video, Uruguay, S. America, C. Darwin, 45.68'. One specimen is also labelled 'Identified as the type by E.E. Austen' and has a green Walker type label 'Musca lyrcea Walk. Type'. It is in fair condition but has the left wing-margin damaged; the left fore leg and the right fore tibia are missing. The other specimen is also labelled 'One of Walker's series so named E.A. W[aterhouse]'; it is very greasy and has the tarso- 
meres of the left mid leg and both hind legs missing. I have labelled and designate herewith the specimen with the Walker type label as lectotype and the other specimen as paralectotype. Both specimens agree with the in terpretation of Compsomyiops fulvicrura given here.

Note on the syntypes of Calliphora annulipes

According to a letter from Prof. Ariel Camousseight, no material of annulipes exists in the Philippi collection in MNHN, Santiago.

\section{Lectotype designation for Lucilia taeniaria}

Thomson described this species from an unspecified number of both sexes, without locality. From NRS I received for study a series of three males and two females under this name. They are all labelled 'Buen Ayr', 'Kinb' $[=$ Kinborg $]$, and are in good condition. One male is also labelled ' 83 ' and one female 'Typus', 'Lucilia taeniaria Th.' and ' 84 '. One male has a large hole in the mesonotum and the second has the left hind leg missing. The third male is smaller but intact, and I have labelled and herewith des:gnate this specimen as lectotype. The two damaged males and the two females I have labelled as paralectotypes. All five specimens agree with the interpretation of Compsomyiops fulvicrura given here.

\section{Discussion}

The name of this common South American species was finally settled by Sabrosky (1953: 38) after he had studied the type-material in the Paris Museum. Until then this species had been known as fulvipes Macquart (e.g. Lynch Arribálzaga, 1880: 71; Hall, 1948: 157). Mistakes in synonymy are numerous, but most importantly those given by James (1970) and Hall (1948) should be noted. In both works the Walker names lyrcea, caruca and gamelia have been incorrectly referred to the genus Myiolucilia (as intended by Hall). The complex nomenclatural problems in this genus have been discussed above under the genus Paralucilia.

\section{Description.}

Head. Male subholoptic, frons at narrowest point equal to 1.5 to 2 times the diameter of anterior ocellus. Female dichoptic, frons equal to $0.40-0.42$ of the head-width, and expanded medially. Ground-colour orange except for the fronto-orbital plates and upper half of occiput which are black. Eyes bare. Frontal vitta of male reduced to an orange-brown triangular area anteriorly, absent above; orange-red in female, constricted anteriorly, with thin silvery-grey dusting, and numerous fine black hairs. Fronto-orbital plates silvery-grey dusted anteriorly, sometimes with a yellowish tinge, undusted above, the black ground-colour showing through, and the wole length with fine black hairs. Parafacials silvery-grey dusted and with fine, short, pale hairs, sometimes with a few dark ones. Face thinly silvery dusted. Genal groove densely silvery-grey dusted and with a few pale hairs below. Genal dilation angular. Genae glossy and with long fine pale yellow to white hairs. Occiput thinly dusted above, densely grey dusted medially, glossy below. Male frontals very weak, with $4-5$ stronger ones; female with $9-10$ anteriorly, those above very weak. Both sexes with a pair of $v t i$, and female also with a pair of weak reclinate orbitals and 1 vte. Male ocellar setae proclinate and weak, female with a weak outcurved pair. Post-ocular region with a row of fine short hairs. Vibrissae strong and crossed, inserted well above the frontoclypeal suture. Facial ridges with small black setulae on $1 / 3$ to $1 / 2$ of their length, and strongly bowed. Antenna brown, the tip of the 2 nd segment orange. Arista brown, long-plumose to tip. Palpi pale orange, long, slightly darkened and dilated apically. Prementum glossy brown.

Thorax. Ground-colour black with metallic blue, purple and green reflections. Mesonotum in posterior view with three dark vittae, the median one reaching the scutellar margin, the lateral pair reaching the posterior $d c$ seta. The areas between these vittae densely silvery-grey dusted, the median and lateral dusted areas confluent posteriorly and continued on to the scutel- 
lum. Acr $0+2$ (anterior one weaker), $d c 0+1-2$, second one very weak or absent, 3 pprn ( 2 weak), $0+1$ ia (sometimes a weak second), 2 pra, $1+2 \mathrm{~s} a, 2 \mathrm{pa}$. Pleura with shifting silvery-grey dusting. Basisternum of prosternum grey dusted and with pale and dark hairs. Proepisternum grey dusted and with orange hairs. Pleural hairing dark except on the posterior half of the katepisternum, upper meron and lower anepimeron. Anterior spiracle creamy; posterior one fawn, with a fringe of black hairs. Greater ampulla triangular and with pale pubescence. Kpst $2+1$, the lower anterior one weaker. Anatergite bare. Scutellum with a pair of apical, lateral and basal marginal setae, and a weaker pair of discal setae which are slightly more widely separated than the apicals.

Wings. Clear, base slightly brownish or greyish. Veins pale brown to orange. Tegula black, basicosta orange. Level of crossvein r-m mid-way between the points where subcosta and $R_{1}$ reach the costa. Subcostal sclerite setulose. Bend of $M$ right-angular and equidistant between crossvein $\mathrm{dm}-\mathrm{cu}$ and the wing-margin. Costa haired ventrally as far as the subcosta. Calypters white to creamy, inner margin of lower one pale brown in some specimens. Marginal hairs white on lower calypter, sometimes brown on upper one; dorsal surface of upper one usually bare in male, rarely with one or two fine pale or dark hairs, female with numerous pale or dark hairs.

Legs. Colour variable, entirely dark brown in small specimens. Groundcolour usually orange. Fore femur darkened above, mid and hind femora darkened basally and on the apical third. Fore tibia and tarsi brown; mid and hind tibia and basal tarsomeres orange-brown; other tarsomeres brown. Fore tibia with $1 p v$ seta and a row of short widely-spaced ad setae. Mid tibia with $1 a d, 1 p d, 2 p$ and $1 v$ setae. Hind tibia with $2 a v$, a row of weak $a d$ and 2 weak $p d$ setae. Hind coxa haired along its entire posterior margin.

Abdomen. Ground-colour black with metallic green, purple and blue reflections; the hind margins of all tergites and dorsal surface of $\mathrm{T} 1+2$ black. T $1+2$ ventrally and all surfaces of other tergites densely silverydusted, the dusting shifting according to the angle of light and divided by a median black line on $\mathrm{T} 3$ to 5 . $\mathrm{T} 3$ with a weak row of marginal setae; $\mathrm{T} 4$ and $\mathrm{T} 5$ with a row of long fine marginal setae, and $\mathrm{T} 5$ with longer sparser ground-setulae. St black with metallic reflections and a grey dusting which shifts about a median line. 47-48.

Genitalia. Male terminalia as in figs. 45-46. Female ovipositor as in figs.

Measurements. Length of body, $5.5-9.0 \mathrm{~mm}$. Length of wing, 5.5 $8.0 \mathrm{~mm}$. Island.

Distribution. Bolivia, Guyana, Brazil, Uruguay, Argentina, Chile, Easter

Material examined

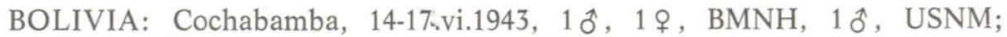
Cochabamba, Cliza, 17.vi.1943, $3 \hat{o}, 6$ \% , USNM.

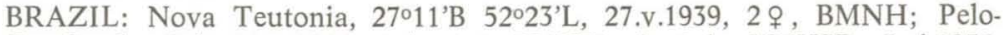
tas, R. G. do Sul, 20.x.1963, $10 \hat{0}, 1$ ㅇ BMNH, \& $1 \hat{0}$, MZUSP, 3.xi.1956, $1 \hat{o}, 1$ ㅇ, BMNH, 31.x.1959, 1 으, BMNH, 30.ix.1963, $1 \hat{\delta}$, MZUSP, 1964, $1 \%$, USNM.

URUGUAY: Colon, Monte Video, 8.v.1896, 2\%, 9.v.1896, 1 \%, BMNH; Montevideo, 27.x.1927, 1 ㅇ, BMNH; Montevideo, 17.x.1926, $1 \hat{\sigma}$, BMNH; Montevideo, Peñarol, 1904, 1 \& , BMNH; Montevideo, 1 \% , BMNH; Montevideo, 2-22.i.1927, 1 ๙ึ, BMNH

ARGENTINA: Buenos Aires, Boulogne, 23.xi.1957, 10 paratype of $n i$ gripes Mello, MNRJ; Mucar, xii.1965, 2 \% , BMNH, 9 \% MZUSP; Rio Teno,

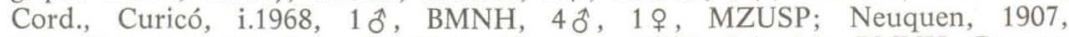
$6 \hat{0}, 61$ 오 BMNH; Prov. La Rioja, Patquia, x.1932, $3 \hat{o}, 1$ 우, BMNH; Buenos Aires, 21.x.1926, 20 , 2 ㅇ, BMNH; S.S. Prinzessin, Buenos Aires, South Dock, 9.vi.1920, 1 q, BMNH; 3.vi.1920, 1 \% , BMNH; ibidem, but Boca, 13.vi.1920, 
$1 \hat{\jmath}, 1$ q , BMNH; Bariloche, 28.xi - 1.xii.1926, Terr. Rio Negro, 2ô, BMNH; Bonifacio, 2 , BMNH; La Plata City, 28.v.1896, $1 \%$, BMNH; L. Nahuel Huapi, eastern end, 17.xi.1926, 10ิ, BMNH; El Jabahi, 29.xii.1930, $1 \hat{\delta}$.

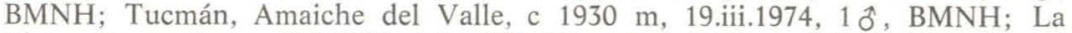
Plata, Punta Lara, 13.i.1970, 10, BMNH; 'Chubut Prov., 13 km N Puerto Madryn, 14.xii.1966, $120 \mathrm{~m}, 1 \hat{0}, 3$ ㅇ․ CAS; Chubat Prov., $3 \mathrm{~km} \mathrm{~N}$ Puerto Lobos, 14.xii.1966, 1 9 , CAS; Santa Cruz, $2 \mathrm{~km} \mathrm{~S}$ Caleta Olivia, 12.xii.1967, $1 \hat{0}$, CAS; Neuquen Prov., Mariano Moreno, 16.xii.1966, 750 m, 1ㅇ, CAS; Neuquen Prov., Rio Agrio nr. Bajada del Agrio, 16.xii.1966, 600 m, 1 ô, CAS; Buenos Aires, Bahia Blanca, 23.x.1926, 10ิ, BMNH; Catamarca, Kisliuk, 31.v.1927, 1 đิ , BMNH; Tucumán, Tafi del Valle, 2500 m, 6-8.i.1970, 1 \%, BMNH.

CHILE: Llanquihue prov., Osorno, 25.xii.1926, 1 \& , BMNH; Concepción, 26-28.xii.1926, 2 \% , BMNH; Los Andes, 1-2.i.1927, 1 ô, BMNH; Coquimbo, Hda. Las Burras, Illapel, 23.ii.1963, 20, 19 , BMNH; Las Trancas, Cord. Chelián, $980 \mathrm{~m}, 25.1 i .1963,1$ ô, BMNH; R.N., El Bolson, 18.ii.1961, 20 , BMNH; Chubut, Rio Turbia, 24.vi.1962, 1 ㅇ, BMNH; Coquimbo, 16.xi.1961, 1 ${ }_{0}$, MZUSP; Santiago, El Arbol, Aculeo, x.1969, $2 \hat{\delta}, 1$ ㅇ․ MZUSP; Faz. San Lorenzo de Queime E Concepción, i.1970, 10ิ, MZUSP; Las Mercedes, $10 \hat{~}$; no further data, 1 \% , MZUSP; Aisen Prov., $8 \mathrm{~km} \mathrm{~W}$ Chile Chico, $540 \mathrm{~m}$, 22.xi.1966, 1 \% , CAS; Nuble Prov., Las Trancas, road nr. Termas de Chillan, 1270 - $1350 \mathrm{~m}, 364^{\prime} \mathrm{S}, 71^{\circ} 31^{\prime} \mathrm{W}, 28 . \mathrm{i} .1967,1$ \% , CAS; Osorno Prov., PucaCallejones, 22.i.1967, 1 ô, CAS; Coquimbo Prov., Puerto Oscuro, 3126'S, 71037’W, 23.ix.1966, $1 \hat{\delta}$, CAS; Coquimbo Prov., Hacienda Illapel, Rio Illapel, $600-900$ m, 19.x.1966, $10^{\star}, 1 \%$, BMNH, $12 \delta^{\star}, 3 \%$, CAS; Coquimbo Prov., Fray Jorge Natn'l Pk., 15 k SW Pachingo, 100-200 m, 20.x.1966, $2 \hat{\text {, }}$ 1 , CAS; Curico Prov., Fundo la Montana Estero la Palma at Rio Teno, $6 \mathrm{~km}$ E Los Quenes, 4.i.1967, $30^{\star}$, CAS; Santiago Prov., $5 \mathrm{~km} \mathrm{E} \mathrm{Cuesta} \mathrm{de}$

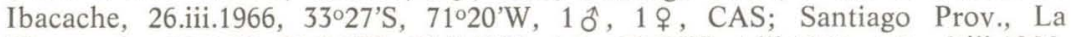
Rinconada, 3334'S, 71¹4'W, 20.ii.1966, 1 오, BMNH, 4.iii.1966, 1 오, 9.iii.1966, 1 ․ CAS; Santiago Prov., Quebrada de la Plata, La Rinconada, nr. Maipu, $33^{\circ} 30^{\prime} \mathrm{S}, 70^{\circ} 55^{\prime} \mathrm{W}$, various dates from $25 . \mathrm{i}$. to $18 . \mathrm{ix} .1966,8 \hat{\sigma}, 2 q, \mathrm{BMNH}$, 40 ô, 10 o , CAS.

CAS.

\section{Bionomics}

Larvae of this species are saprophagous and are generally found breeding in carcasses. However, like the next species, they may be able to develop in cases of wound myiasis, but not as primary invaders.

\section{Compsomyiops callipes (Bigot), comb. n.}

Somomya callipes Bigot, 1877: 249.

Somomya calopus Bertkau, 7879: 538 [unjustified emendation of callipes]. Chrysomyia wheeleri Hough, 1899: 284. Syn. n.

Types

Holotype $\hat{o}$ of Somomya callipes Bigot (and Somomya calopus Bertkau), Mexico, in BMNH. Lectotype $\hat{o}$ of Chrysomyia wheeleri Hough, Monterey, California, in USNM; see designation below. [All types examined.]

Note on the holotype of Somomya callipes

Bigot described this species from an unspecified number of males from Mexico. In the BMNH I found a single specimen under this name with a Bigot drawer label 'S. Calopus [altered by over-writing to 'Callipes']. $\hat{o}$, $g$. Lucilia, R.D., Mexic. J. Bigot.'. This specimen is evidently the holotype of callipes. It is in good condition but has the left mid leg missing and the wings tattered. Brauer (1899: 524, no. 197) saw this specimen and assigned it to Compsomyia Rondani [i.e. Chrysomya Robineau-Desvoidy], and it was confirmed as a Chrysomyine by Aubertin (1933: 428). 
Lectotype designation for Chrysomyia wheeleri

Hough described this species from $4 \hat{\delta}$ and $2 \%$ from California, from W.M. Wheeler's collection. I have seen a $\hat{\delta}$ syntype from USNM from Monterey, California, which I have labelled and designate herewith as lectotype. It agrees with the interpretation of callipes given here.

\section{Discussion}

This is the only Nearctic species of the genus Compsomyiops and has previously been referred to by most authors as Paralucilia wheeleri Hough. It can be distinguished from all other species of the genus by the dark shifting spot of dust on the fronto-orbital plates in the males and by a dark line in the same position in the female. Examination of types in this genus has shown Somomya callipes Bigot to belong to this species, for which it is the oldest name. The name callipes has generally been placed in synonymy with Paralucilia fulvicrura, but Mello (1968: 182) and Hall (1948: 153) referred to Aubertin \& Buxton's (1934: 246) interpretation of callipes as a synonym of wheeleri. How this misunderstanding arose is not clear as Aubertin \& Buxton clearly state that they examined the type of callipes and found it to be a synonym of fulvicrura. In the Neotropical Catalogue (James, 1970) callipes is placed as a synonym of lyrcea in the genus Myiolucilia (see above in the discussion of Paralucilia). In the Nearctic Catalogue (Hall, 1965) callipes is referred to as wheeleri.

Bertkau (1879) proposed a correction to the name callipes on linguistic grounds, correcting it to calopus. This emendation was subsequently accepted by Bigot (1880), but is not justified.

\section{Description}

This species is very similar to fulvicrura but differs in the following characters.

Head. Frons at narrowest point equal to width of anterior ocellus. Frontal vitta golden dusted above in female. Fronto-orbital dusting often with a yellowish tinge on two-thirds of its length. Parafacial hairs long, dark and proclinate. Lower part of fronto-orbital plates with a dark shifting spot at level of antennal base. Genae often dusted anteriorly, and golden haired. Facial ridges with short black setulae along whole length.

Thorax. Pleural hairs usually entirelly dark.

Wing. Darkened basally. Basicosta brown. Calypters brown, the lower one with a white margin; upper calypter with fine dark hairs dorsally.

Legs. Mid and hind femora often not darkened at tip.

Abdomen. Dorsal dust of tergites dense but not shifting.

Genitalia. Male terminalia as in figs. 49-50. Female ovipositor similar to fulvicrura (see figs. 47-48), but St 6 T-shaped and St 7 parallel-sided.

$9.0 \mathrm{~mm}$.

Measurements. Length of body, 6.5 - $11.0 \mathrm{~mm}$. Length of wing, 6.5 Mexico.

Distribution. Nearctic: Washington to Colorado and California, south to

Material examined

NEW MEXICO: R. Tularosa, 5200', $1 \hat{\delta}$, BMNH; White Mts, 8.xii, N. Fk. Ruidoso, abt 8200', 1 \% , BMNH.

ARIZONA: S. Catalina Mts., Sabino Basin, 13.x., 2 ㅇ, BMNH, no date, 1 ․ BMNH, 9.x, 1 ô, BMNH, 10.x, 1 \% , BMNH; Turkey Creek, $6 \mathrm{~m}$ W Portal, 18.v.1973, 1 ô, USNM; Pima Co., Tucson Mts., i - v.1964, 2 \% , BMNH.

CALIFORNIA: Sonora Co., Santa Rosa, 24. x.1965, 1ㅇ, 23.x.1965, 1 ô, BMNH; San Mateo Co., Jasper Ridge, Sandhill Range, 13.x.1952, 1 ô, BMNH; Cottonwood Carr, Riverside, 8.iii.1934, 1 ㅇ, BMNH; Berkeley, ii.1925, 1 ô, BMNH; Stan U., x.190?, 1 9 , BMNH; Alameda Co., Strawberry Canyon, 9.xii.1948, 1 ㅇ, BMNH; Contra Costa Co., Tilden Park, 13.v.1961, $2 \hat{o}$, BMNH.

MEXICO: Guerrero, Omilteme, 8000', July, $1 \hat{\jmath}$, BMNH; Sierra de las Aguas Escondidas, 7000', 1 \%, BMNH; Xucumanatlan, 7000', $1 \hat{0}, 1$ ㅇ․ BMNH; 
Ciudad, 8100', 5 ô, BMNH; Michoacan, Mt. Tanitaro, 7800', 1941, 1 ô, 1 오. BMNH.

\section{Bionomics}

Like fulvicrura this species is saprophagous and of little economic importance. The immature stages, life history and distribution were dealt with by Deonier \& Knipling (1940) and by Hall (1948).

\section{Compsomyiops verena (Walker), comb. n.}

Musca verena Walker, 1849: 874.

Paralucilia apolinari Mello, 1968: 185. Syn. $n$.

Holotype $q$ of Musca verena Walker, Venezuela in BMNH [examined]. Holotype $\hat{\delta}$ of Paralucilia apolinari Mello, Colombia, Bogotá, in IOC [topopypical $\hat{o}$ paratype seen, in MNRJ].

Note on the holotype of Musca verena

Walker described this species from an unspecified number of females from Venezuela, from Mr Dyson's collection. Under this name in the BMNH I found a single female with the type data and with a green Walker type label 'Musca verena Walk'. I consider this specimen to be the holotype. It is in good condition but has all the left legs missing.

\section{Discussion}

This name has generally been placed as a synonym of Paralucilia fulvicrura (e.g. Lynch Arribálzaga, 1880; Smart, 1937), but James (1970) synonymised it with Myiolucilia lyrcea. His reasons for this are explained under the genus Paralucilia above.

\section{Description}

This species is very similar to fulvicrura but differs in the following characters.

Head. Male holoptic for a distance equal to length of antennae, and eye-facets greatly enlarged anteriorly. Female dichoptic, frons equal to 0.42 of the head-width. Frontal vitta golden-brown dusted. Fronto-orbital plates wider than the frontal vitta, measured at the lunula, silvery-yellow dusted. Genae silvery dusted anteriorly. Facial ridges with short black setulae on their whole length.

Thorax. Some specimens with a weak third post $d c$ seta. Scutellum with two pairs of discal setae. Kpst $1+1$ (rarely a weaker anterior one below).

Wings. Base brown. Veins brown. Basicosta brown in some females. Calypters brown; dorsal surface of upper one with a few brown hairs in both sexes.

Leges. Fore tibia dark at base and tip, not dorsally.

Abdomen. Dusting brownish, thin and not conspicuous. Anterior ventral region of $\mathrm{T} 3-\mathrm{T} 5$ with coppery patches.

Genitalia. Male terminalia indistinguishable from those of fulvicrura (see figs. 45-46). Female ovipositor with st 6 broader, otherwise as in fulvicrura (see figs. 47-48).

Measurements. Length of body, $8.0-12.0 \mathrm{~mm}$. Length of wing, 7.0 $10.0 \mathrm{~mm}$.

Distribution. Costa Rica, Colombia, Peru and Venezuela.

Material examined

COSTA RICA: Irazu, 6 - 7000', 1 , BMNH.

COLOMBIA: Bogota, 24.ii.1934, $10^{\star}$, paratype of apolinari Mello, MNRJ; Bogota, $1 \delta^{\star}$, BMNH; El Industan, Meta del Intendencia Ocobo R., 1200', 1914, 1 \%, BMNH; Magdalena, Cerro San Lorenzo, 2100 m, 9.vii.1970, 3 q, BMNH; Villavicencio, Quatquia R., xi-xii.1914, 5\%, BMNH; Cundinamarca, ca $1400 \mathrm{~m}$, Monterredondo, ix.1959, 10․ CAS. 
PERU: Huadquina, 5000', 30.vii.1911, 1 \% BMNH; San Miguel, 6000', 1.ix.1911, 1 ㅇ, BMNH.

VENEZUELA: Montevilla, Caracas, ix.1976, J. Kugler, $1 \hat{\delta}, 1$ 오, MZUSP; Pico del Avila, Caracas, 2200 m, 18.xi.1968, 1 , BMNH; Avila Peak, Caracas, 25.ix.1960, 6904', 2 ㅇ, CAS.

Compsomyiops alvarengai (Mello), comb. n.

Paralucilia alvarengai Mello, 1968: 188.

Type

Holotype $\hat{\sigma}$ of Paralucilia alvarengai Mello, El Alto, La Paz, Bolivia, in IOC [topotypical ô paratype seen, in MNRJ].

Description

This species is very similar to fulvicrura but differs in the following characters.

Head. Female frons equal to $0.38-0.39$ of head-width, and frontal vitta equal to width of a fronto-orbital plate measured at lunula. Genal groove orange dusted. Genae orange dusted anteriorly. Facial ridges with small black setulae on their whole length.

Thorax. Two pprn setae. Proepisternum with white hairs. Kpst $1+1$. Scutellum with a weaker second pair of discal setae.

Wings. Male with a few dark hairs on dorsal surface of upper calypter.

Legs. Fore femur rarely darkened dorsally, usually with a large orange median ring.

Abdomen. All tergites with dense shifting silvery dusting. T $3-\mathrm{T}_{5}$ with a median black line, and with lateral metallic patches which contrast with the surrounding metallic colour and extend on to the dorsal surface and, more extensively, on to the ventral surface.

Genitalia. Male terminalia and female ovipositor indistinguishable from those of fulvicrura (see figs. 45-48).

Measurements. Legth of body, 6.5 -10.5 mm. Length of wing, $6.0-9.0 \mathrm{~mm}$.

Distribution. Ecuador, Peru, Bolivia, Chile.

Material examined

ECUADOR: Imbabura, Hazienda Piman bei Ibarra, 2200 m, 2 - 4.vi.1977, 1 , BMNH.

PERU: Lima, 3 , BMNH; Arequipa, Arequipa, 2,500 m, 30.vii 1.viii.1971, 2 ơ, 4 o , BMNH; Cuzco, Pisac, 3000 m, 15.viii.1971, 1 $\hat{0}$, BMNH; NW of Cuzco, Barrio Magisterial, $3500 \mathrm{~m}, 8 . v i i i .1971,1 \hat{0}, 2$,, BMNH; Apurimac, Cuzco-Abancay road, Apurimac crossing at Cuya, 1,900 m, 7.viii.1971, $4 \mathrm{O}, \mathrm{BMNH} ; 8 \mathrm{~km} \mathrm{~S}$ of Cuzco, $3500 \mathrm{~m}, 6 . \mathrm{viii} .1971,1 \delta^{\circ}, \mathrm{BMNH}$; Cuzco, Machu Pichu Museum, 1385 m, 11-14.viii.1971, 1 , BMNH.

BOLIVIA: El Alto, La Paz, 15.xii.1955, 1 ô paratype of alvarengai Mello, in MNRJ.

CHILE: Tarapacá Prov., 3 km E Zapahuire, 18²2'S, 69²7'W, 11,100', 29.ix.1966, 1 ô, CAS.

Compsomyiops boliviana (Mello), comb. n.

Paralucilia boliviana Mello, 1968: 190.

Paralucilia arequipensis Mello, 1968: 187. Syn. n.

Types

Holotype $\hat{\sigma}$ of Paralucilia boliviana Mello, Calacota, La Paz, Bolivia, in IOC. Holotype $\hat{o}$ of Paralucilia arequipensis Mello, Arequipa, Peru, in IOC. [Topotypical ơ paratypes seen, in MNRJ.]

Description

This species is very similar to fulvicrura but differs in the following characters. 
Head. Female frons equal to $0.40-0.42$ of head-width. Frontal orbital dusting distinctly yellowish. Fronto-orbital plates as wide ar, or wider than, frontal vitta measured at lunula. Genal groove and anterior genae golden to silvery-yellow dusted. Anterior genal hairs golden. Facial ridges with small black setulae on entire length. First antennal segment creamy-white.

Thorax. Sometimes only 2 pprn setae present. Anterior lower kpst seta often weak.

Wings. Calypters pale brown to buff. Male upper calypter bare, or, as in female, with numerous fine black hairs.

Legs. Fore femur not darkened above, mid and hind femora usually entirely orange.

Abdomen. All tergites densely silvery dusted, more thinly so in the largest specimens; T 3 \& 4 with a median dark line and small lateral metallic patches which contrast with the surrounding metallic colour.

Genitalia. Male terminalia and female ovipositor indistinguishable from those of fulvicrura (see figs. 45-48).

Measurements. Length of body, $6.0-9.5 \mathrm{~mm}$, or even $11 \mathrm{~mm}$. Length of wing, $5.0-8.5 \mathrm{~mm}$.

Distribution. Ecuador, Peru, Bolivia.

Material examined.

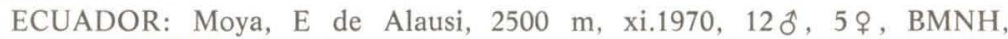
396 , 17 \% , MZUSP; Imbabura, Hazienda Piman bei Ibarra, $2200 \mathrm{~m}, 2$ 4.vi.1977, $1 \hat{\text { ô }, 3}$ o , BMNH; Colta, c 3000 - $3500 \mathrm{~m}$, bei Riobamba, vii.1905, 1 ㅇ, BMNH; Sta. Isabel, Girón, $1800-2300 \mathrm{~m}$, xii.1970, 1 우, MZUSP; Sto. Domingo, Quito, $2600 \mathrm{~m}$, xii.1970, 3 , BMNH, 3 으 MZUSP.

PERU: Arequipa, vii.1955, 1 ô paratype of arequipensis Mello, MNRJ; Huaral, Hda. San Jose, $63 \mathrm{~km}$ N of Lima, $180 \mathrm{~m}, 29 . \mathrm{viii} .1971,1$ \%, BMNH; Cuzco, Machu Picchu museum, 11 - 14.viii.1971, 1 , , BMNH; Arequipa, 2500 m, 30.viii - 1.viii.1971, 1 ô, 1 \&, BMNH.

BOLIVIA: Calacota, La Paz, $3200 \mathrm{~m}$, 9.xii.1956, $1 \hat{\sigma}$ paratype of boliviana Mello, MNRJ.

Compsomyiops melloi, sp. n.

Description

This species is very similar to fulvicrura but differs in the following characters ( 9 only).

Head. Frons equal to 0.40 of the head-width. Frontal vitta broader than a fronto-orbital plate measured at lunula. Parafacial hairs dark and proclinate. Genae silvery-yellow dusted anteriorly. Frontal vitta orange-brown dusted.

Wings. Calypters pale brown.

Genitalia. Ovipositor not examined.

Measurements. Length of body, $7.0-8.5 \mathrm{~mm}$. Length of wing, $6.5-8.0 \mathrm{~mm}$.

Distribution: Mexico, Colombia.

Material examined

Holotype 9 , MEXICO: Ciudad, 8100', Forrer, in British Museum (Natural History), London.

Paratypes 2 , COLOMBIA: Bogota, B. Guevara, 1 으, USNM; Bogota, 21.v.1942, W.H.W. Komp, 1 \% , USNM.

\section{ACKNOWLEDGEMENTS}

I am very grateful to the following colleagues who have lent me material for study from the collections in their care: Dr P.H. Arnaud (CAS), Dr. G.W. Byers (SEM), Prof. Ariel Camousseight (MNHNS), Dr R. Contreras-Lichtenberg (NHMV), Dr R.J. Gagné (USNM), Prof. B. Greenberg (UIC), Dr J.H. Guimarães (MZUSP), Dr B. Herting (SMNL), Dr L. Lyneborg (UZMC), L. 
Matile (MNHNP), Dr V. Michelsen (UZMC), Dr. P. Passerin d'Entrèves (MZST), P.I. Persson (NRS), Dr H. Schumann (MNHU), Dr H. de Souza Lopes (Rio de Janeiro, for IOC and MNRJ material), Dr L. Watrous (FMNH), and Dr P. Wygodz'nsky (AMNH).

(A.C. Pont also wishes to thank Dr R.J. Gagné (USNM) for his support and assistance with the task of completing the section of the MS on Cochliomyia, and Mrs Joan Cranston, for her careful typing of the entire MS.)

\section{REFERENCES}

Aldrich, J. M., 1925. New Diptera or two-winged flies in the United States National Museum. Proc. U. S. natn. Mus. 66 (18): 36 pp., 1 f'g.

Aubertin, D., 1933. Revision of the genus Lucilia R.-D. (Diptera, Calliphoridae). J. Linn. Soc. (Zool.) 38: 389-436, 30 figs.

Aubertin, D. \& Buxton, P. A., 1934. Cochliomyia and myiasis in tropical America. Ann. trop. Med. Parasit. 28: 245-254, pl. 4.

Baumgartner, D. L. \& Greenberg, B., in press. The genus Chrysomya R.-D. (Diptera, Calliphoridae) in the New World. J. med. Ent., Honolulu.

Bertkau, P., 1879. Diptera. Ber. wiss. Leist. Geb. Ent. 1877-1878: 518-542.

Bigot, J.-M.-F., 1877. Diptères nouveaux ou peu connus. $8^{\mathrm{e}}$ partie. X. Genre SOMOMYA (Rondani) Calliphora, Melinda, Mufetia, Lucilia, Chrysomyia (alias MICROCHRYSA Rond.) Robineau-Desvoidy. (Suite.) XI. Notes et mélanges diptérologiques. Annls Soc. ent. Fr. (5) 7: 243-262.

Bigot, J.-M.-F., 1880. [Note in Séance of 10 March 1880.] Annls Soc. ent. Fr. (5) 10: xl.

Bigot, J.-M.-F., 1888. Diptères nouveaux ou peu connus. MUSCIDI (J.B.). Bull. Soc. zool. Fr. 12 [1887]: 581-617.

Brauer, F., 1883. Die Zweiflügler des Kaiserlichen Museums zu Wien. III. Systematische Studien auf Grundlage der Dipteren-Larven nebst einer Zusammenstellung von Beispielen aus der Literatur über dieselben und Beschreibung neuer Formen. Denkschr. Akad. Wiss., Wien 47: 1-100, pls. $1-5$.

Brauer, F., 1895. Bemerkungen zu einigen neuen Gattungen der Muscarien und Deutung einiger Original-Exemplare. Sber. Akad. Wiss. Wien 104 (Abt.1): 582-604, 1 pl.

Brauer, F., 1899. Beiträge zur Kenntnis der Muscaria schizometopa. I. Bemerkungen zu den Originalexemplaren der von Bigot, Macquart und Robineau-Desvoidy beschriebenen Muscaria schizometopa aus der Sammlung des Herrn G. H. Verrall. Dritte Folge. Sber. Akad. Wiss. Wien 108 (Abt. 1): 495-529.

Brauer, F. \& Bergenstamm, J. E. von, 1891. Die Zweiflügler des Kaiserlichen Museums zu Wien. V. Vorarbeiten zu einer Monographie der Muscaria schizometopa (exclusive Anthomyidae). Pars II. Denkschr. Akad. Wiss., Wien 58: 305-446.

Coquerel, C., 1858. Note sur les larves appartenant à une espèce nouvelle de Diptère, (Lucilia hominivorax) developpées dans les sinus frontaux de l'homme à Cayenne. Annls Soc. ent. Fr. (3) 6: 171-176, pl. 4 (2).

Coquillett, D. W., 1910. The type-species of the North American genera of Diptera. Proc. U. S. natn. Mus. 37: 499-647.

Curran, C. H., 1934. The families and genera of North American Diptera. 512 pp., portr., figs. Curran, New York.

Cushing, E. C. \& Hall, D. G., 1937. Some morphological differences between the screwworm fly Cochliomyia americana C. \& P. and other closely alled or similar species in North America (Diptera: Calliphoridae). Proc. ent. Soc. Wash. 39: 195-200, pls. 16-17.

Cushing, E. C. \& Patton, W. S., 1933. Studies on the higher Diptera of medical and veterinary importance. Cochliomyia americana sp. nov., the screw-worm fly of the New World. Ann. trop. Med. Parasit. 27: 539-551, 7 figs.

Del Ponte, E., 1938. Las especies argentinas del género Cochliomyia T.T (Dipt. Musc.). Revta Ent., Rio de J. 8: 273-281, 2 figs. 
Deonier, C. C. \& Knipling, E. F., 1940. The biology of Compsomyiops wheeleri (Hough) and description of the larva. Ann. ent. Soc. Am. 33: 578-582, 6 figs.

Engel, O., 1931. Die Ausbeute der deutschen Chaco-Expedition 1925/26. Diptera. (Fortsetzung.) XXVI. Anthomyidae, XXVII. Muscidae und XXVIII. Sarcophagidae. Konowia 10: 133-154, pls. 1-6.

Fabricius, J. C., 1775. Systema entomologiae, sistens insectorvm classes, ordines, genera, species, adiectis synonymis, locis, descriptionibvs, observationibvs. $832[+32]$ pp. Flensbvrgi et Lipsiae.

Fabricius, J. C., 1805. Systema antliatorum secundum ordines, genera, species adiectis synonymis, locis, observationibus, descriptionibus. $372+30 \mathrm{pp}$.

Gagné, R. J., 1981. Chrysomya spp., Old World blow flies (Diptera: Calliphoridae), recently established in the Americas. Bull. ent. Soc. Am. 27: 21-22.

Gagné, R. J. \& Peterson, R. D., 1982. Physical changes in the genitalia of males of the screwworm, Cochliomyia hominovirax [sic] (Diptera: Calliphoridae), caused by mating. Ann. ent. Soc. Am. 75: 574-578, 8 figs.

Garcia, M., 1952. Consideraciones generales sobre el genero Cochliomyia Townsend, 1916 y descripcion de $C$. fontanai n.sp. (Diptera Calliphoridae). Publnes Inst. reg. Ent. sanit. 1-8 (1945-1950): 68-80, 7 figs.

Greenberg, B., 1971. Flies and disease. I. Ecology, classification and biotic associations. ix $+856 \mathrm{pp}$. many figs. Princeton Univ. Press.

Greenberg, B., 1973. Flies and disease. II. Biology and disease transmission. ix +447 pp., 54 figs. Princeton Univ. Press.

Gregor, F., 1975. Synanthropy of Anthomyiidae, Muscidae and Calliphoridae Diptera) in Cuba. Folia Parasit. 22: 57-71.

Guimarães, J. H., N. Papavero \& A. P. do Prado, 1983. As miíases na região neotropical (Identificação, biologia, bibliografia). Revta bras. Zool. 1(4): 239-416.

Hall, D. G., 1948. The blowflies of North America. Ent. Society of America, Thomas Say Foundation [vol. 4]: 477 pp., 9 figs. 46 pls., 5 col. pls.

Hall, D. G., 1965. Family Calliphoridae. Pp. 922-933, in Stone, A. et al. [editors]), A catalog of the Diptera of America North of Mexico. Agric. Handbk U. S. Dep. Agric. 276: iv + 1696 pp. Washington D.C.

Hough, G. de N., 1899. Synopsis of the Calliphorinae of the United States. Zool. Bull. 2: 283-290, 11 figs.

Hough, G. de N., 1900. South American Muscidae in the collection of S. W. Williston. Kans. Univ. Q. (A) 9: 203-232, pl. 44.

James, M. T., 1970. Family Calliphoridae, in Papavero, N. [editor], A catalogue of the Diptera of the Americas south of the United States 102: 28 pp. São Paulo.

Leake, E. W., Cushing, E. C. \& Parish, H. E., 1936. Biology of the primary screw worm fly, Cochliomyia americana, and a comparison of its stages with those of C. macellaria. Tech. Bull. U. S. Dep. Agric. 500: 24 pp., 14 figs., 1 pl.

Lahille, F., 1915. Nota sobre la ura y otras larvas dañinas de dipteros. Bol. Dir. Gen. Ganad. Min. Agric., Buenos Aires: 1-18, 7 figs., 2 pls.

Laurence, B. R., 1981. Geographical expansion of the range of Chrysomya blowflies. Trans. R. Soc. trop. Med. Hyg. 75: 130-131.

Lesbini, C., Weyenbergh, H. \& Conil, P. A., 1878. Études sur la myiasis. Actas Acad. nac. Sci., Buenos Aires 3: 41-98. [Published as three separate articles by these authors: the first describes the pathology, the second the early stages, and the third (Conil) the adult.]

Lynch Arribálzaga, E., 1880. Compsomyia macellaria (F.). Observaciones críticas sobre los caracteres, la sinonimia etc. de este Múscide. An. Soc. cient. argent. 10: 70-84.

Macquart, J., 1843. Diptères exotiques nouveaux ou peu connus. Tome deuxième. 3.e partie. Mém. Soc. Sci. Agric. Lille 1842: 162-460, 36 pls. [5-304]. 
Macquart, J., 1851. Diptères exotiques nouveaux ou peu connus. Suite du $4 .{ }^{e}$ supplément publié dans les mémoires de 1849. Mém. Soc. Sci. Agric. Lille 1850: 134-294, pls. i5-28 [161-336].

Mariluis, J. C., 1979. Notas sobre algunas sspecies del genero Hemilucilia Brauer 1895 (Diptera: Calliphoridae). Physis B. Aires 38 (C): 68, 86, 97.

Mariluis, J. C., 1980a. Contribucion al conocimiento del genero Hemilucilia Brauer, 1895 (Calliphoridae, Chrysomyiinae, Hemiluciliini). Revta Soc. ent. argent. 39: 83-87.

Mariluis, J. C., 1980b. Presencia del género Chrysomya Robineau-Desvoidy, 1830 en la región neotropical (Calliphoridae, Chrysomyiinae, Chrysomyiini). Revta Sac. ent. argent. 39: 126.

Mariluis, J. C., 1981. Nuevas Calliphoridae para la Argentina, Bolivia y Ecuador (Diptera). Revta Soc. ent. argent. 40: 103-105.

Mariluis, J. C., 1982. Contribución al conocimiento de las Calliphoridae de la Argentina. Op. lilloana 33: 59 pp., 181 figs., map.

McAlpine, J. F. et al. [coordinators], 1981. Manual of Nearctic Diptera. Volume 1. Res. Branch. Agric. Canada Monogr. 27: vi + 74 pp., figs.

Mello, J. A. S. N. de, 1959. Contribuição ao estudo do gênero "Hemilucilia" Brauer, 1895 (Calliphoridae, Diptera). Revta bras. Biol. 19: 429-439, 27 figs.

Mello, R. P. de, 1965. Contribuição ao estudo do gênero Callitrogopsis Townsend (Diptera, Calliphoridae). Studia ent. 8: 435-440, 25 figs.

Mello, R. P. de, 1968. Contribuição ao estudo do gênero "Paralucilia" Brauer \& Bergenstamm, 1891 (Diptera, Calliphoridae). Revta bras. Biol. 28: 177. 192, 56 figs.

Mello, R. P. de, 1972. Revisão das espécies do gênero Hemilucilia Brauer. 1895 (Diptera, Calliphoridae). Revta bras. Biol. 32: 539-554, 84 figs.

Melville, R. V., in press. Cochliomyia Townsend, 1915 (Diptera: Calliphoridae); proposed conservation by the suppression of Callitroga Brauer, 1883. Z.N.(S.) 707. Bull. zool. Nom.

Michelsen, V., 1979. Notes on the identity and type-material of the Anthomyiidae, Fanniidae and Muscidae (Diptera) described by J. C. Fabricius. Steenstrupia 5: 181-196.

Persson, P. I., 1972. "Eugenies Resa". Localities, dates and labels of the insects collected during the voyage around the world by the Swedish frigate "Eugenie" in the years 1851-1853. Ent. Tidskr. 92 [1971]: 164-172, 1 fig.

Philippi, R. A., 1861. Beschreibung einer neuen Fliege, deren Larven in der Nase und Stirnhöhle einer Frau gelebt haben. Z. ges. Naturw. Halle 17: 513-515.

Pont, A. C., 1983. Mya Rondani, 1850, and Somomya Bertoloni, 1861 (Insecta, Diptera): designation of type-species, and proposed suppression of Somomya under the plenary powers. Z.N.(S.) 2127. Bull. zool. Nom. 40: 106-110.

Prado, A. P. do \& Guimarães, J. H., 1982. Estado atual de dispersão e distribuição do gênero Chrysomya Robineau-Desvoidy na região neotropical (Diptera, Calliphoridae). Revta bras. ent. 26: 225-231.

Robineau-Desvoidy, A. J. B., 1830. Essai sur les Myodaires. Mém. prés. div. Sav. Acad. Sci. Inst. Fr. 2: 1-813.

Rondani, C., 1848. Esame di varie specie d'insetti ditteri brasiliani. Studi en . 1: $63-112$, pl. 3 b.

Rondani, C., 1980. Osservazioni sopra alquante specie di esapodi ditteri del Museo Torinese. Nuovi Ann. Sci. nat. Bologna (3) 2: 165-197, pl. 4.

Sabrosky, C. W., 1953. The scientific name of the screw-worm, with a note on Paralucilia fulvicrura (Diptera, Calliphoridae). Proc. ent. Soc. Wash. 55: 36-38.

Séguy, E., 1925. Étude sur quelques Calliphorinés testacés rares ou peu connus. Bull. Mus. natn. Hist. nat., Paris 31: 439-441.

Senior-White, R., Aubertin, D. \& Smart, J., 1940. The Fauna of British India, including the remainder of the Oriental Region. Diptera. Volume 6. Family Calliphoridae. xiii +288 pp., 152 figs., 2 maps, Taylor \& Francis, London. 
Shannon, R. C., 1926. Synopsis of the American Calliphoridae (Diptera). Proc. ent. Soc. Wash. 28: 115-139.

Smart, J., 1937. Calliphoridae, Calliphorinae. Dipt. Pat. S. Chile 7 (3): 376-384, figs. 72-74. British Museum (Natural History), London.

Snow, J. W., Sibenaler, A. J. \& Newell, F. G., 1981. Annotated bibliography of the screwworm, Cochliomyia hominivorax (Coquerel). USDA, Sci. Ed. Admin., Agric. Rev. Man., Sthn Ser. 14: iii + 32 pp.

Thomson, C. G., 1869. Diptera. Species novas descripsit C. G. Thomson. Pp. 443-614, pl. 9, in Kongliga svenska fregatten Eugenies resa omkring jorden under befäl af C. A. Virgin, aren 1851-1853. 2 (Zoologi), 1, Insecta. 617 pp. Stockholm, "1868".

Townsend, C. H. T., 1915. A new generic name for the screw-worm fly. J. Wash. Acad. Sci. 5: 644-646.

Townsend, C. H. T., 1916. Designations of muscoid genotypes, with new genera and species. Insecutor Inscit. menstr. 4: 4-12.

Townsend, C. H. T., 1918. New muscoid genera, species and synonymy (Diptera). Insecutor Inscit. menstr. 6: 151-156.

Townsend, C. H. T., 1935. New muscoid genera, mainly from the Neotropical region. Revta Ent. 5: 68-74.

Townsend, C. H. T., 1937. Manual of Myiology in twelve parts. Part. 5. Muscoid generic diagnoses and data. Glossinini to Agriini. 234 pp. São Paulo, Itaquaquecetuba.

Verhuell, Q. M. R., 1850. Mededeeling der metamorphose van eene in Guyana voorkomende vliegensoort. Tijdschr. wis- en natuurk. Wet. 3: 273-275, fig.

Walker, F., 1849. List of the specimens of dipterous insects in the collection of the British Museum, 4: 689-1172. British Museum, London.

Walker, F., 1853. Insecta saundersiana: or characters of undescribed insects in the collection of William Wilson Saunders, Esq., F.R.S., F.L.S., \&c. Volume 1, Diptera, [part 4]: 253-414. Van Voorst, London.

Walker, F., 1861. Characters of undescribed Diptera in the collection of W. W. Saunders, Esq., F.R.S., \&c. [Part.] Trans, ent. Soc. Lond. (2) 5: 297-334.

Wiedemann, C. R. W., 1830. Aussereupopäische zweiflügelige Insekten. Part 2. xii +684 pp., 5 pls. Hamm.

Wulp, F. M. van der, 1896. Diptera. Volume 2 [part]. In Godman, F. D. \& Salvin, O. [editors], Biologia Centrali-Americana 129: 289-304. London.

Zumpt, F., 1956a. Calliphoridae (Diptera Cyclorrhapha). Part 1: Calliphorini and Chrysomyiini. Explor. Parc natn. Albert Miss. G. F. de Witte 87: 1-200, 113 figs.

Zumpt, F., 1956b. Calliphorinae. In Lindner, E. [editor], Fliegen palaearkt. Reg. 64i: 140 pp., 47 figs., 10 pls. Schweizerbart, Stuttgart.

Zumpt, F., 1965. Myiasis in man and animals in the Old World. A textbook for physicians, veterinarians and zoologists. $\mathrm{xv}+267$ pp., 346 figs. Butterworths, London. 


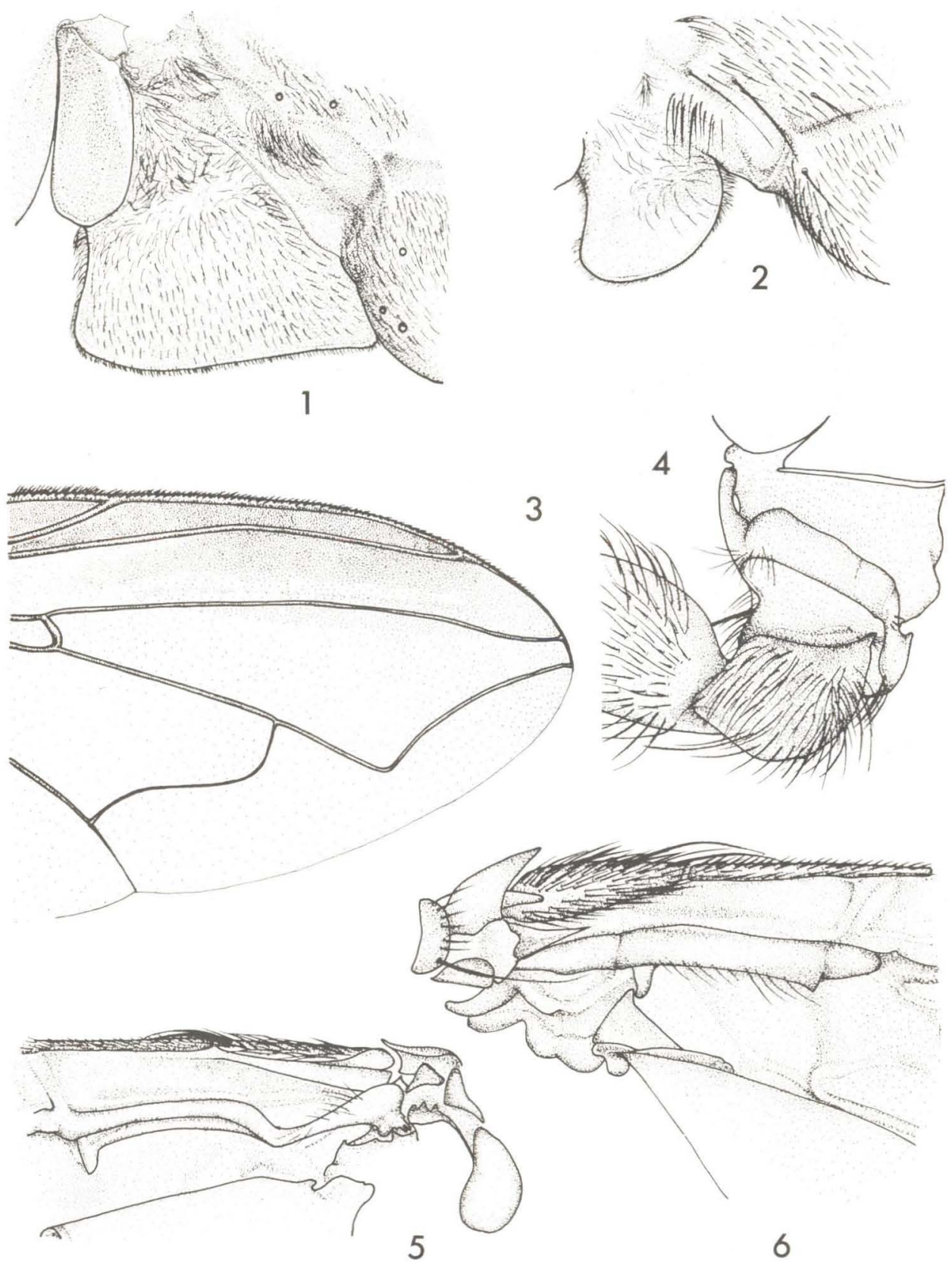

Fig. 1 - Dorsal view of lower calypter of Chrysomya megacephala; Fig. 2 The same of $q$ Paralucilia adespota. Chloroprocta idioidea: Fig. $3-$ tip of wing; Fig. $4-$ posterior view of hind coxa; Fig. $5-$ ventral view of wingbase; Fig. 6 - Dorsal view of wing-base. 

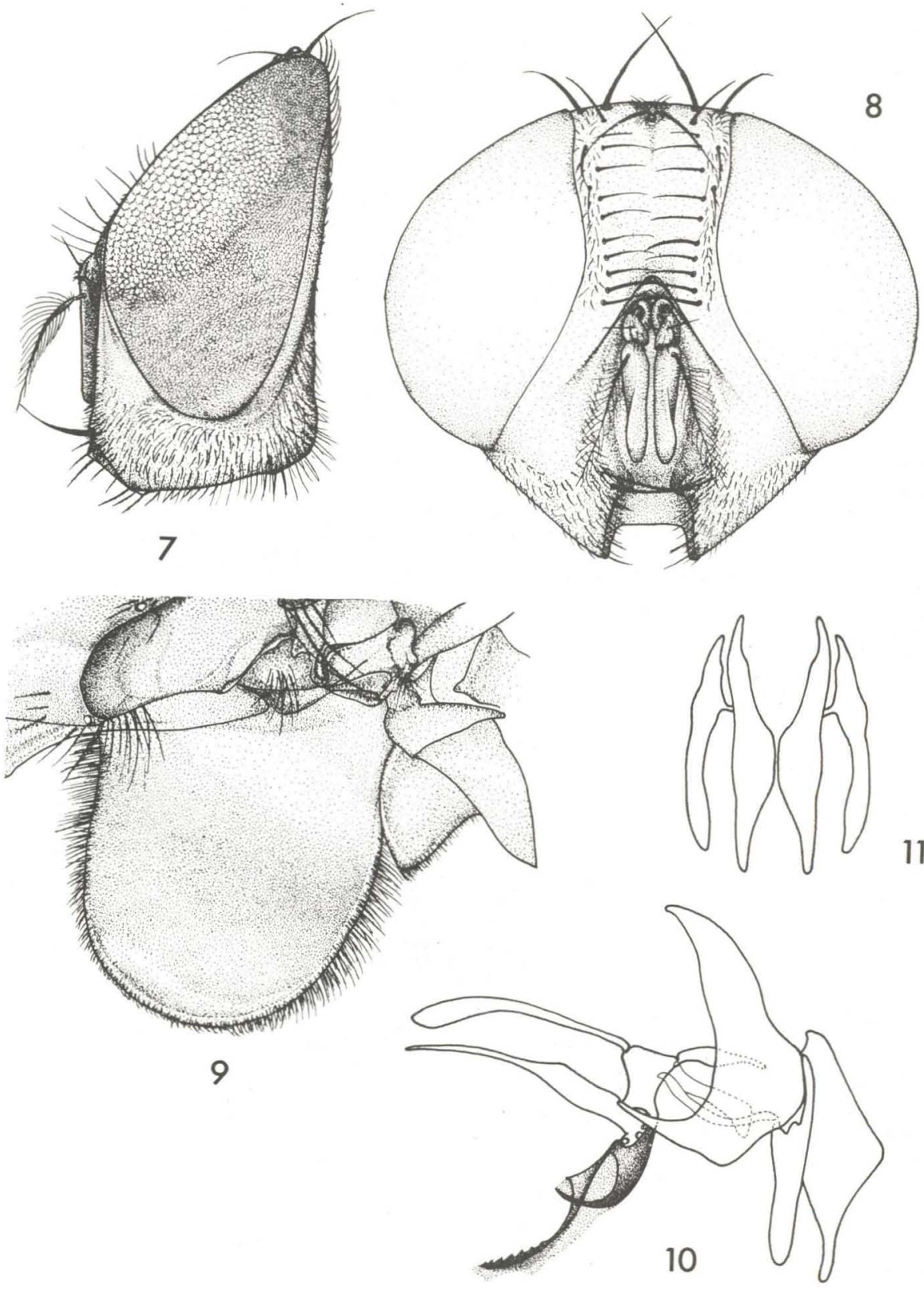

Chloroprocta idioidea: Fig. 7 - Lateral view of $\hat{o}$ head; Fig. 8 - Frontal view of + head; Fig. $9-$ Dorsal view of lower calypter; Fig. $10-$ Lateral view of $\hat{\delta}$ terminalia; Fig. $11-$ Dorsal view of $\hat{\delta}$ cercus. 

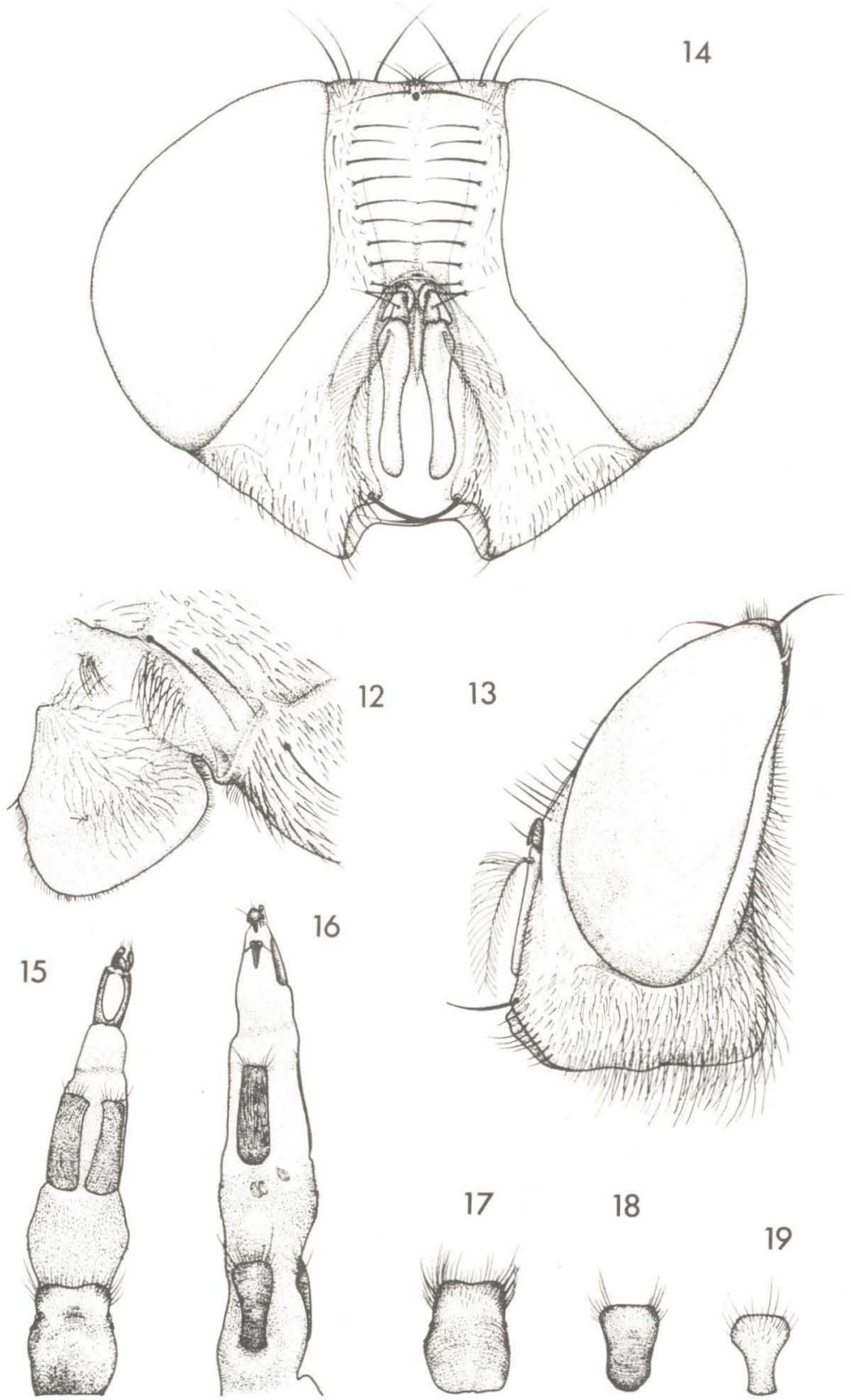

17

18

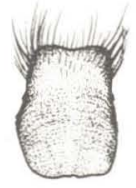

19

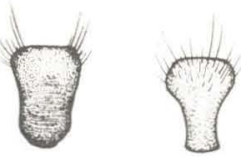

Fig. 12 - Dorsal view of lower calypter of ô Paralucilia adespota; Fig. 13 Lateral view of $\delta$ head of $P$. fulvinota; Fig. $14-$ Frontal view of $q$ head of P. fulvinota; Figs. 15-16 - Dorsal (15) and ventral (16) views of $\rho$ ovipositor of $P$. fulvinota; Figs. 17-18 - Tergite 6 (17) and sternite 6 (18) of o ovipositor of $P$. xanthogeneiates; Fig. 19 - Sternite 6 of $q$ ovipositor of $P$. adespota. 

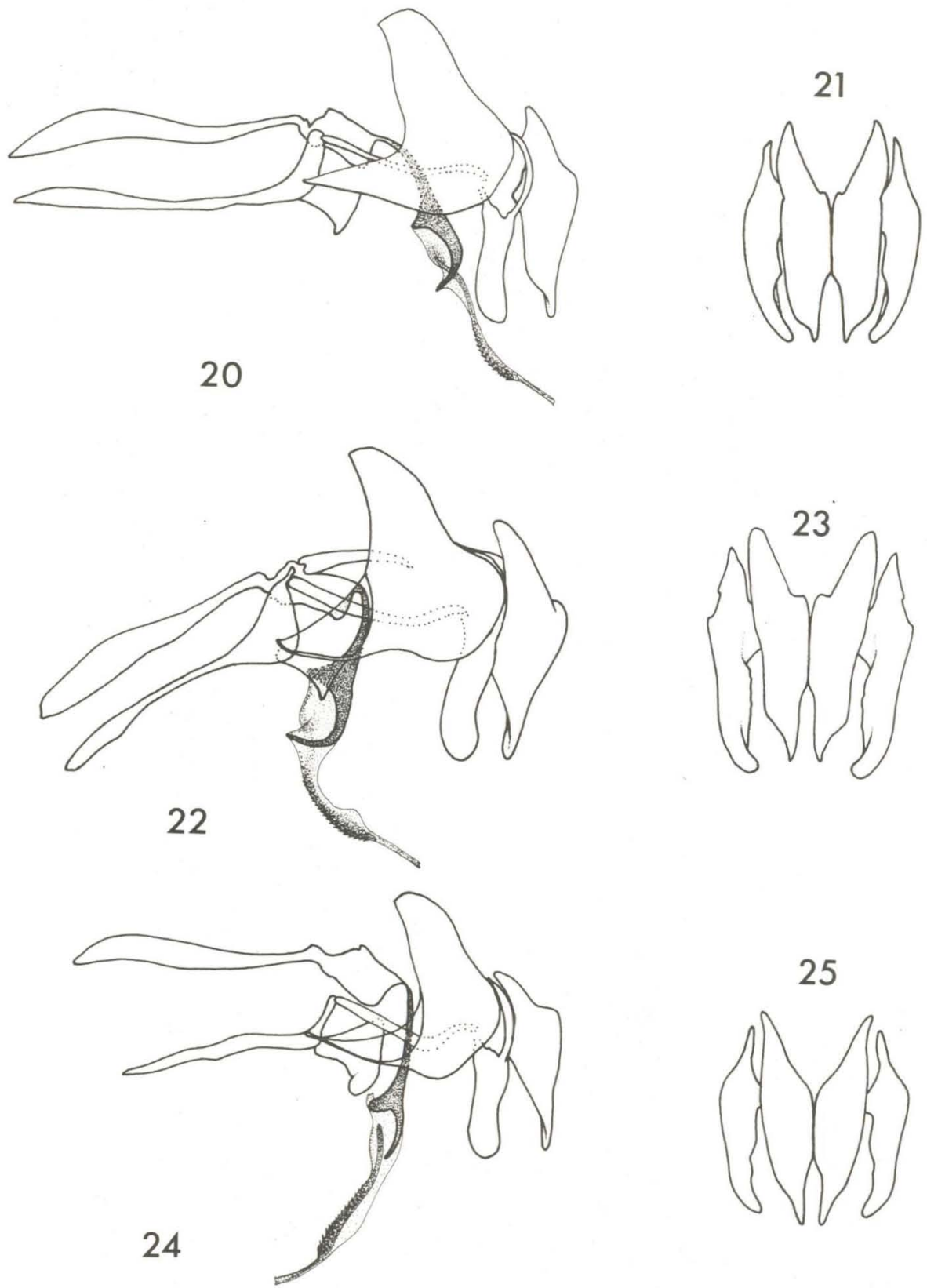

o terminalia of Paralucilia: Figs. 20-21 - Lateral view of terminalia (20) and dorsal view of cercus (21) of fulvinota; Figs. 22-23 - Lateral view of terminalia (22) and dorsal view of cercus (23) of xanthogeneiates; Figs. 24-25 Lateral view of terminalia (24) and dorsal view of cercus (25) of adespota. 

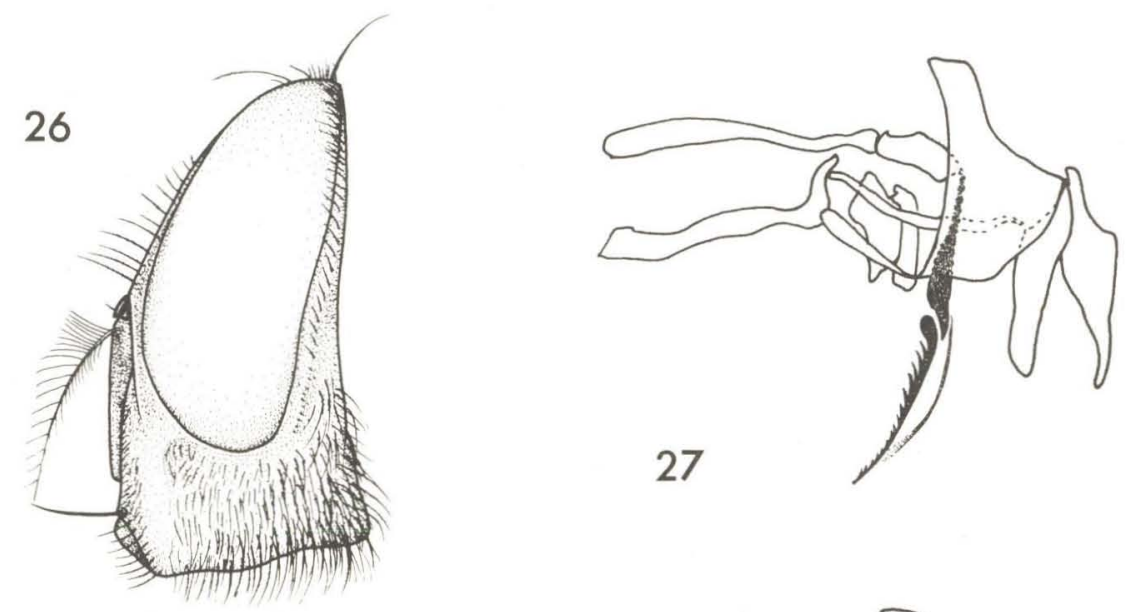

28

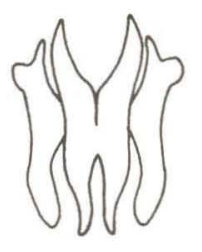

30

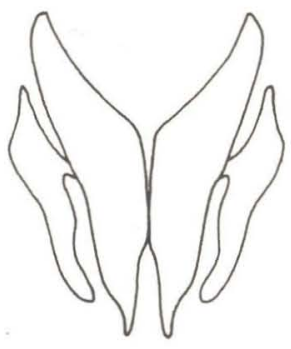

29

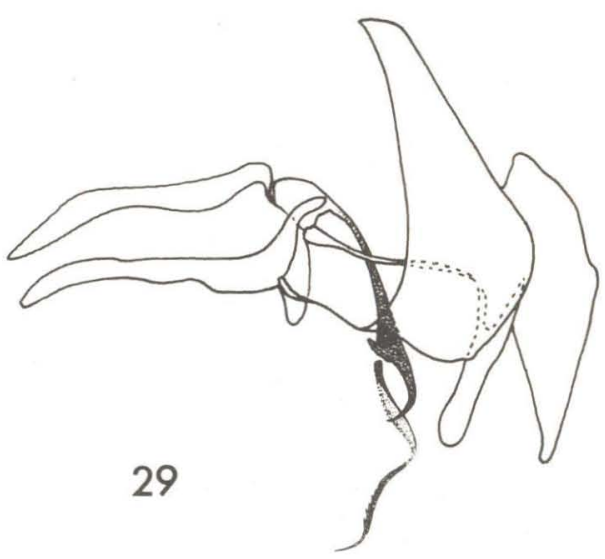

32
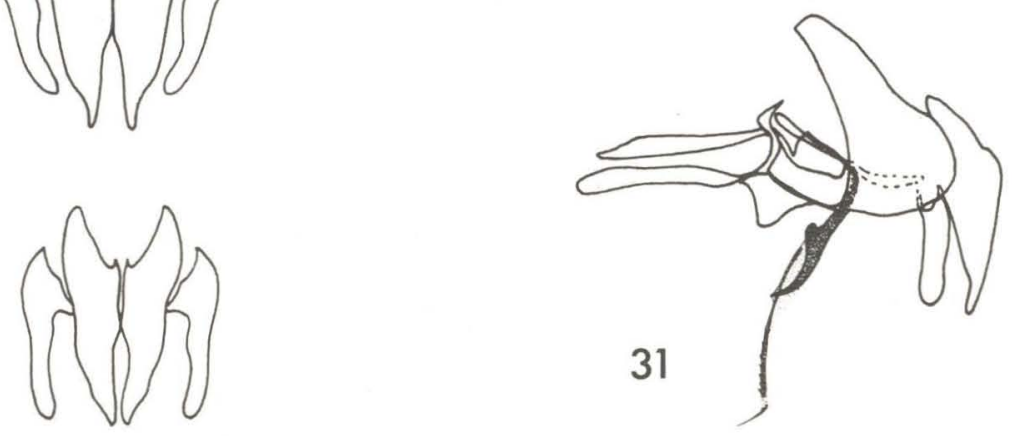

Fig. 26 - Lateral view of $\hat{o}$ head of Hemilucilia semidiaphana. $\hat{\sigma}$ terminalia of Hemilucilia: Figs. 27-28 - Lateral view of terminalia (27) and dorsal view of cercus (28) of benoisti; Figs. 29-30 - Lateral view of terminalia (29) and dorsal view of cercus (30) of segmentaria; Figs. 31-32 - Lateral view of terminalia (31) and dorsal view of cercus (32) of semidiaphana. 

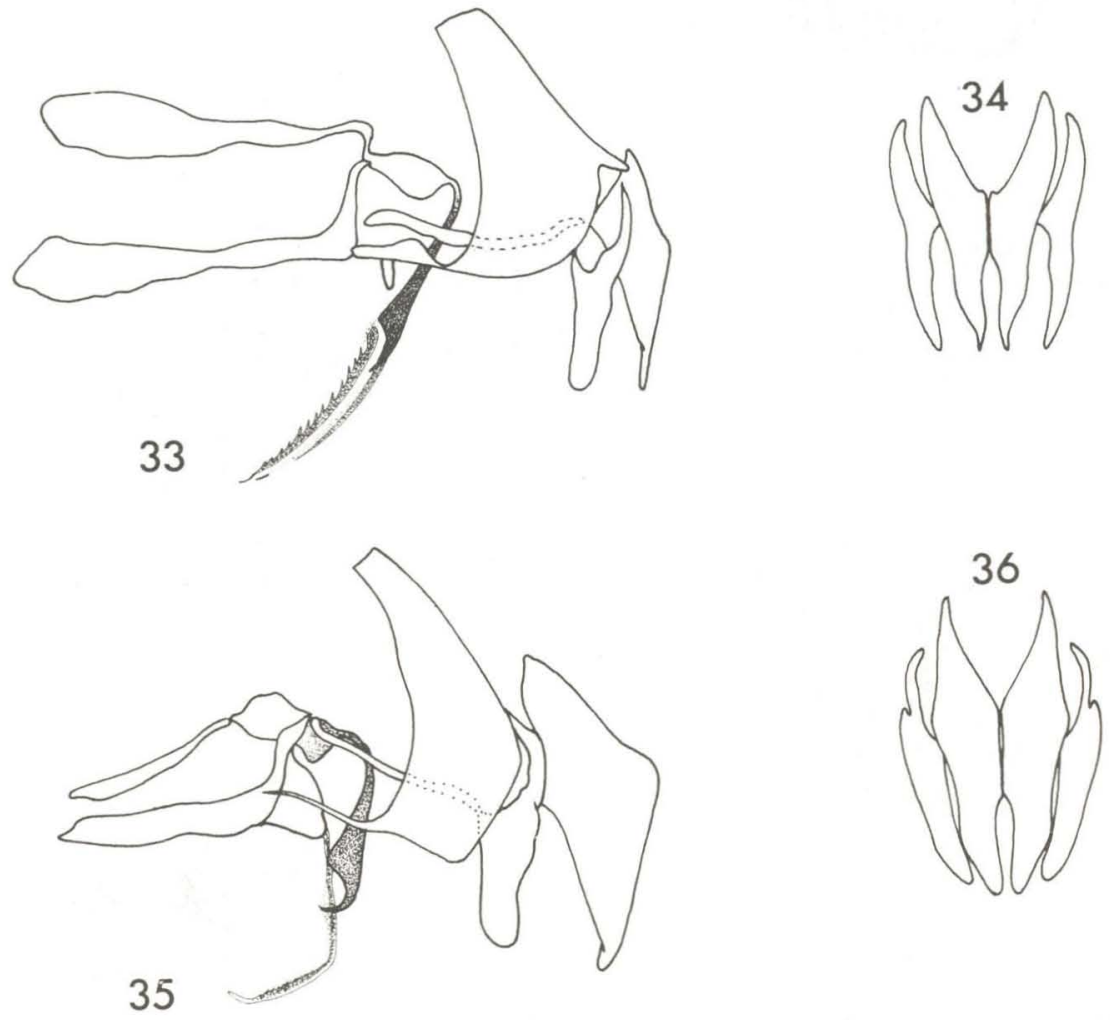

ô terminalia of Hemilucilia: Figs. 33-34 - Lateral view of terminalia (33) and dorsal view of cercus (34) of souzalopesi; Fig. 35-36 - Lateral view of terminalia (35) and dorsal view of cercus (36) of melusina. 

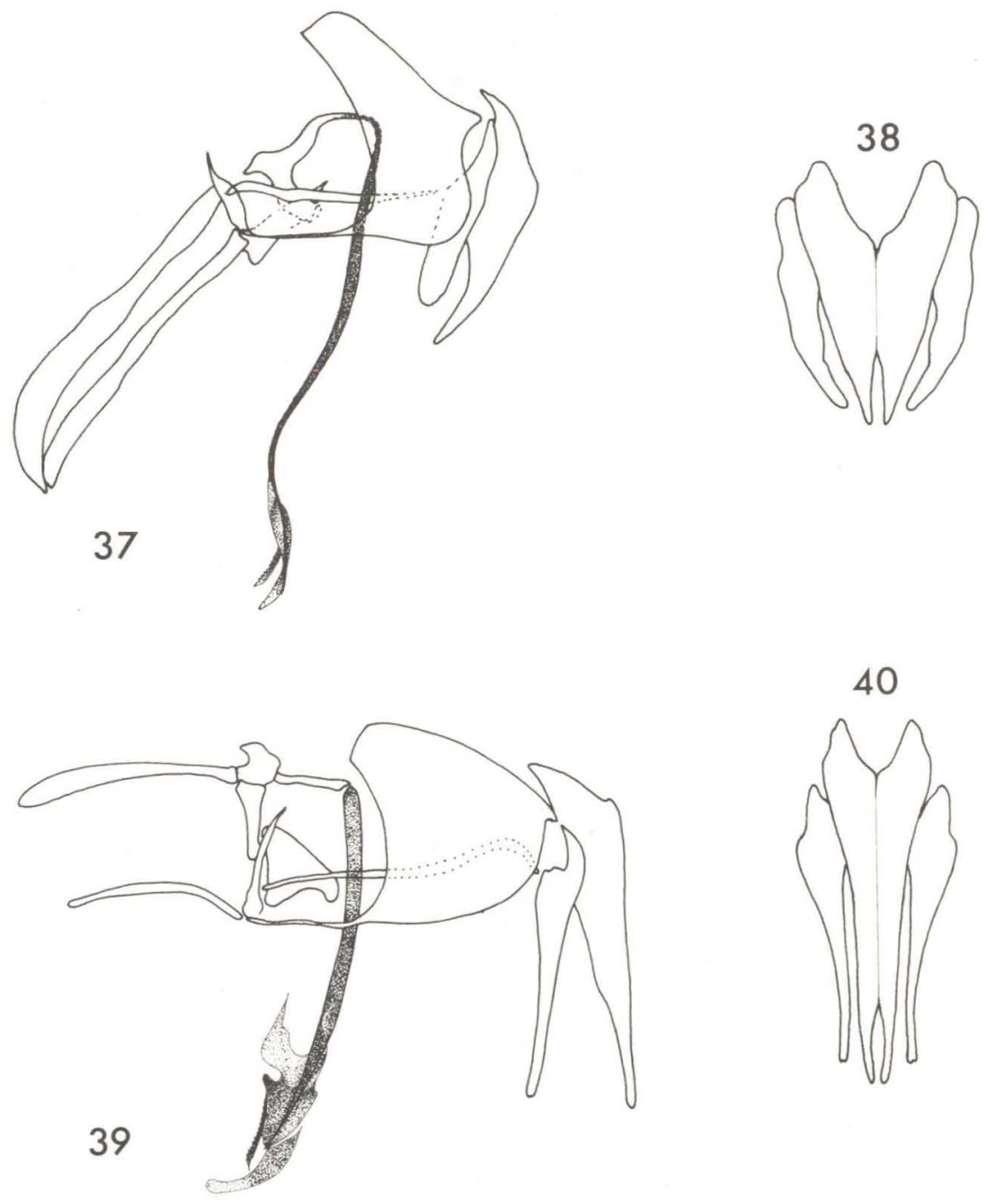

o terminalia of Cochliomyia: Figs. 37-38 - Lateral view of terminalia (37) and dorsal view of cercus (38) of minima; Figs. 39-40 - Lateral view of terminalia (39) and dorsal view of cercus (40) of aldrichi. 

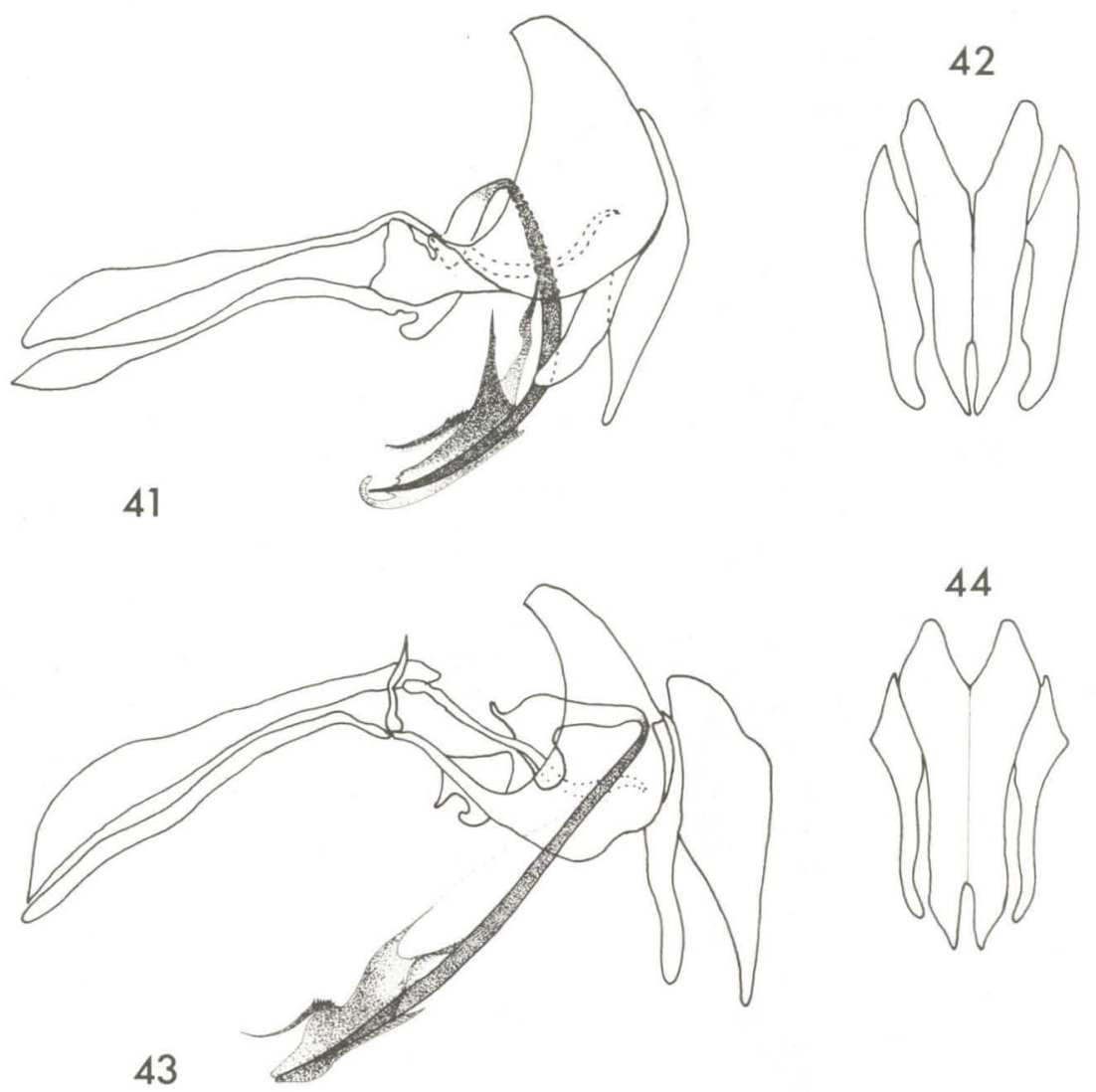

ô terminalia of Cochliomyia: Figs. 41-42 - Lateral view of terminalia (41) and dorsal view of cercus (42) of hominivorax; Figs. 43-44 - Lateral view of terminalia (43) and dorsal view of cercus (44) of macellaria. 

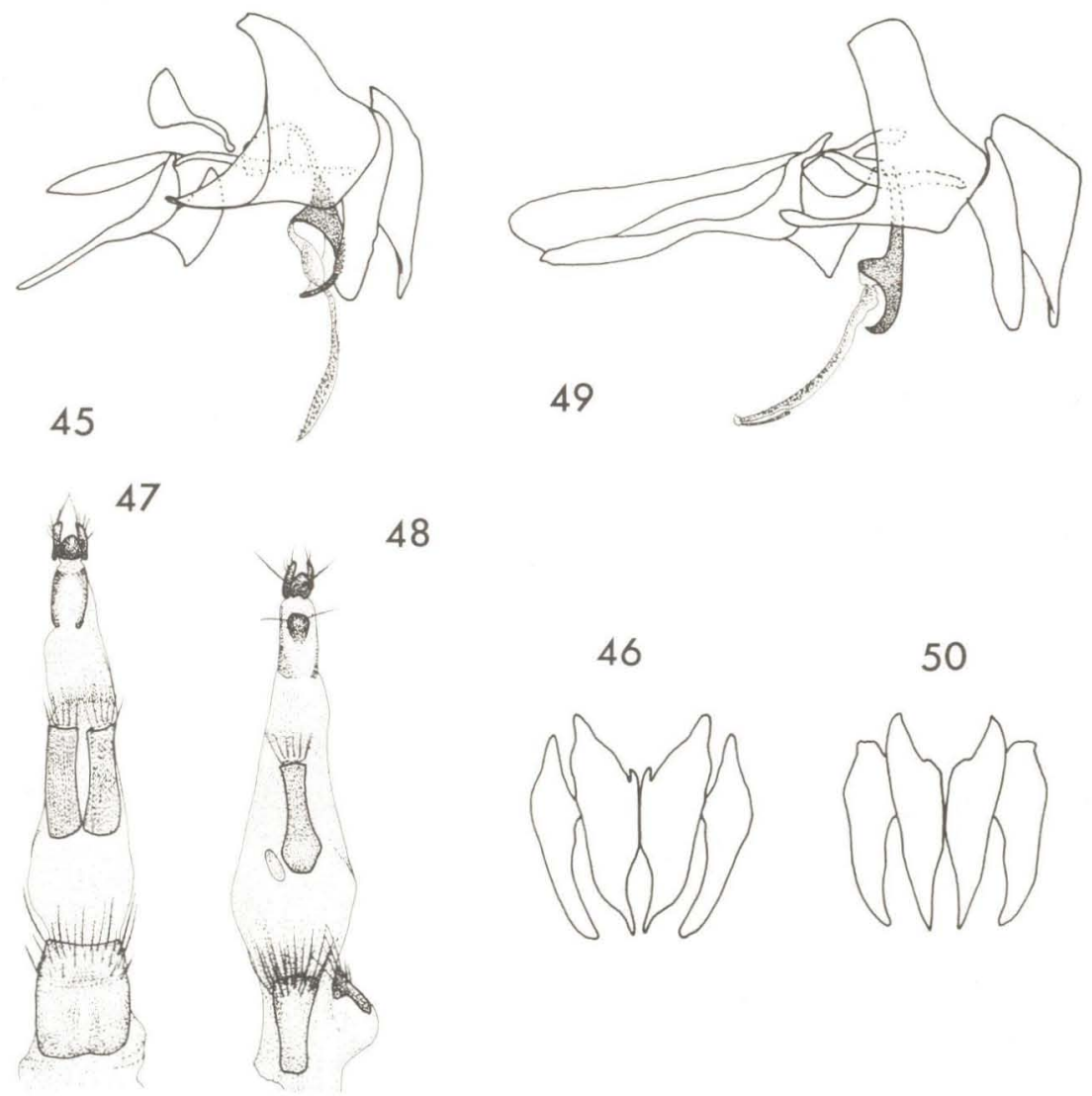

48

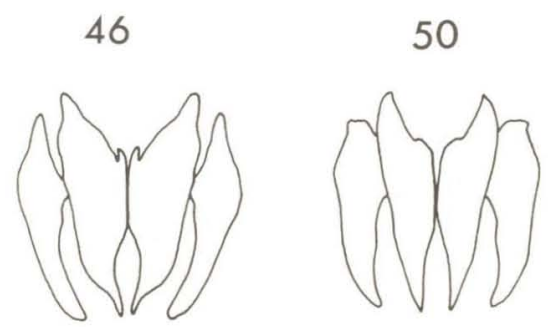

Compsomyiops fulvicrura: Fig. 45 - Lateral view of $\delta$ terminalia; Fig. 46 dorsal view of $\hat{\sigma}$ cercus; Figs. $47-48$ - Dorsal (47) and ventral (48) views of $q$ ovipositor. C. callipes: Fig. 49 - Lateral view of $\hat{\sigma}$ terminalia; Fig. 50 - Dorsal view of $\delta$ cercus. 